\title{
THE EFFECT OF HYDROTHERMAL PRETREATMENT ON THE ANAEROBIC DIGESTION OF THICKENED WASTE ACTIVATED SLUDGE AND SOURCE SEPARATED ORGANICS
}

\author{
by
}

S Ahmad Shabir Razavi,

B.Sc, Chemical Engineering, Balkh University, 2011

\author{
A thesis \\ presented to Ryerson University \\ in partial fulfillment of the \\ requirements for the degree of \\ Master of Applied Science \\ in the program of \\ Civil Engineering
}

Toronto, Ontario, Canada, 2019

(C) Ahmad Shabir Razavi, 2019 


\section{Author's Declaration for Electronic Submission of a Thesis}

I hereby declare that I am the sole author of this thesis. This is a true copy of the thesis, including any required final revisions, as accepted by my examiners.

I authorize Ryerson University to lend this thesis to other institutions or individuals for the purpose of scholarly research.

I further authorize Ryerson University to reproduce this thesis by photocopying or by other means, in total or in part, at the request of other institutions or individuals for the purpose of scholarly research. I understand that my thesis may be made electronically available to the public. 
The Effect of Hydrothermal Pretreatment on the Anaerobic Digestion of Thickened Activated Sludge and Source Separated Organics

Master of Applied Science, 2019

S Ahmad Shabir Razavi, Civil Engineering, Ryerson University.

\begin{abstract}
The objective of this study was to evaluate the impact of hydrothermal pretreatment of source separated organics (SSO) and thickened waste activated sludge (TWAS) on the solubilization and biomethane production. The feedstocks went through 15 different conditions in a wide range of temperature $\left(150-240^{\circ} \mathrm{C}\right)$, retention time (5-30) min and severity indexes (3-5).

The result of the study revealed that the effect of hydrothermal pretreatment can vary based on the feedstock primary properties and the optimum pretreatment condition. In this study, the optimum pretreatment conditions for highest solubilization and solid reduction of the SSO were $220^{\circ} \mathrm{C}$ and 10 minutes retention time, however, for highest methane production, it was $190^{\circ} \mathrm{C}$ for 20 minutes. In case of TWAS, the result revealed that the maximum biomethane production was achieved at pretreatment conditions of $160^{\circ} \mathrm{C}$ and $20 \mathrm{~min}$, while, the highest solubilization and solid reduction was observed in $220^{\circ} \mathrm{C}$ and 10 minutes retention time.
\end{abstract}




\section{Acknowledgements}

I would like to express my deepest gratitude to my dear supervisor Dr. Elsayed Elbeshbishy for his never-ending patience, guidance, support and consideration. I am forever in debt of his kind support that showed me the right path and I would not have been able to complete my research and studies without his insight and motivation. I would specially like to thank my co-supervisor Dr. Hisham Hafez for his guidance and support.

I would also like to offer my regards and blessings to my research partner and good friend Farokhlaqa Kakar for her support and help in all aspect of my studies and research. Without her contribution this research would not be completed, her help and support will always be remembered.

I am deeply in debt to all who supported and guided me through my study program; especially my research group mates Anahita Rabii, Frances Okyoea, Sharmeen Hyder and Michele Ponzelli. I specially thank Dr. Amir Abas Bazyar, Dr. Ehssan Hosseini Koupaie, Dr. Armineh Azizi and Robin Luong for their instructions and help during my experiments in the lab.

Lastly, I would like to express my sincere thanks to the love of my life Masouda and to my family for their support, encouragement and unconditional love. I am greatly indebted to them for their sacrifice and the energy they gave me to complete my research. 


\section{Table of Contents}

Author's Declaration for Electronic Submission of a Thesis ..................................................... ii

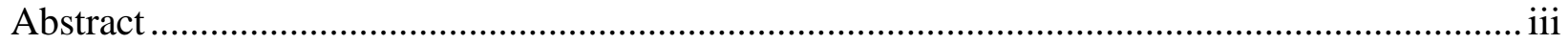

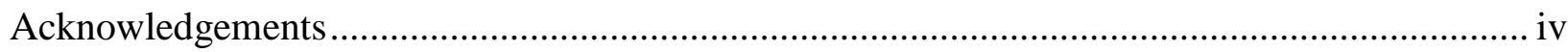

List of Figures ................................................................................................................ vii

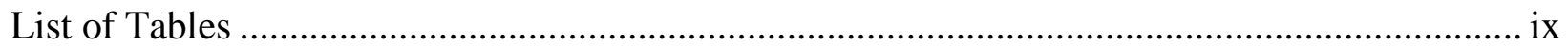

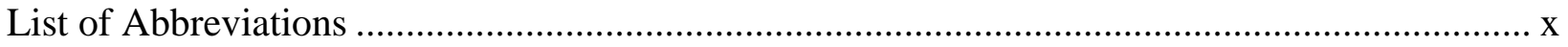

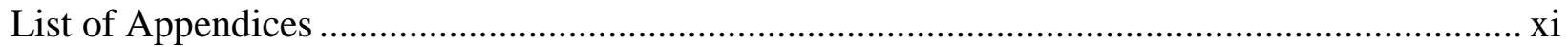

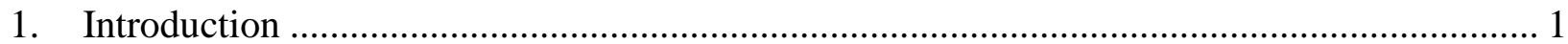

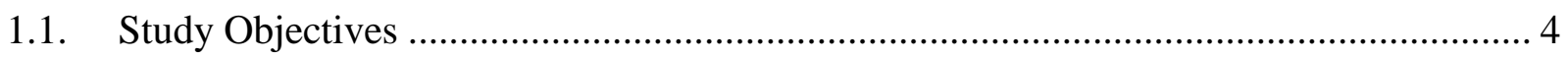

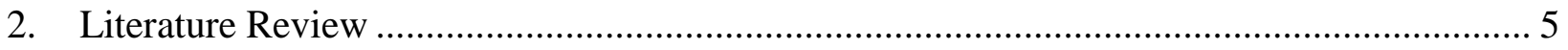

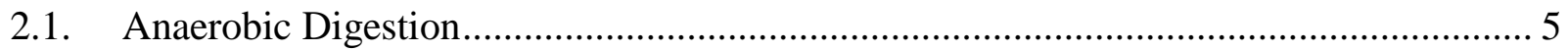

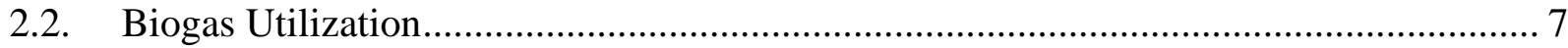

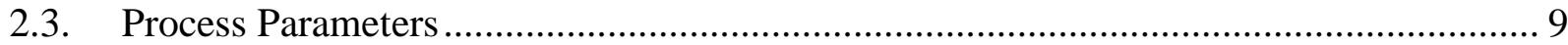

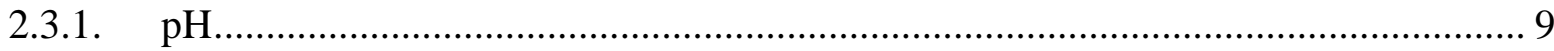

2.3.2. Carbon to Nitrogen Ratio (C/N ratio) ................................................................ 10

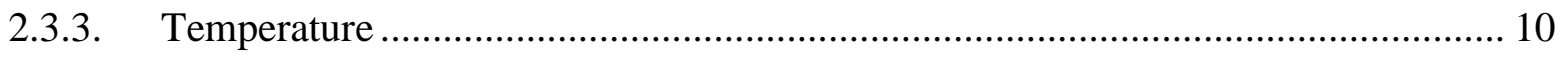

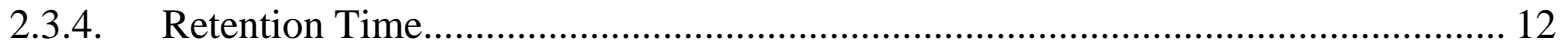

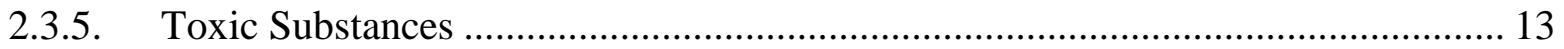

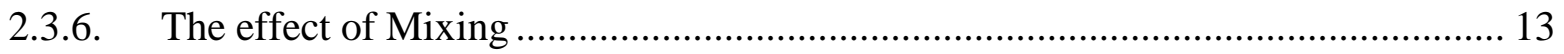

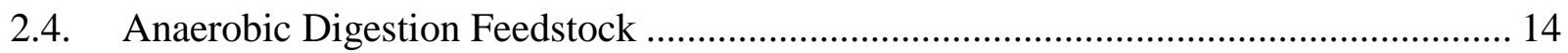

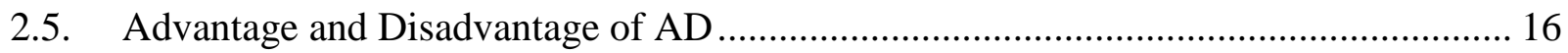

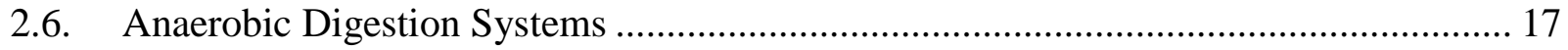

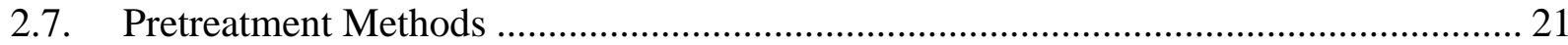

2.7.1. Mechanical pretreatment.......................................................................... 22

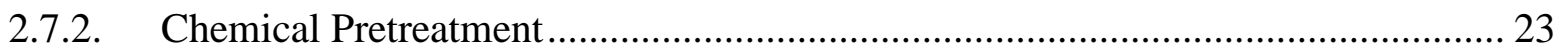

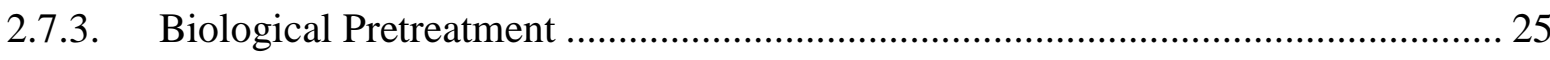

2.7.4. Hydrothermal Pretreatment..................................................................... 26

2.8. Effect of Hydrothermal Pretreatment on Anaerobic Biodegradability of Waste ........... 31

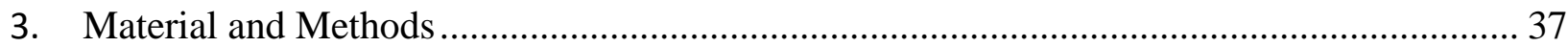

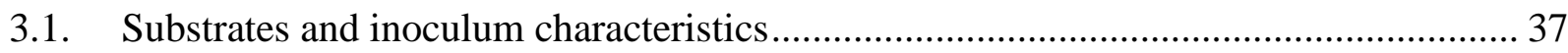

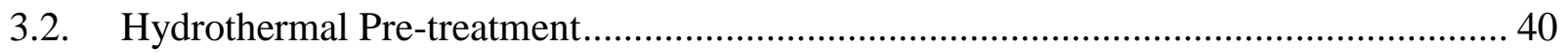




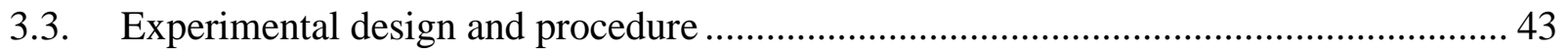

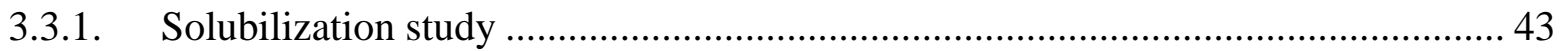

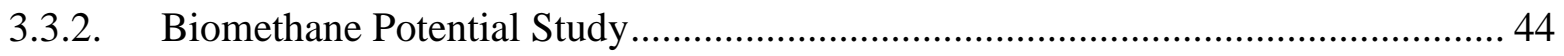

3.3.3. Analytical Methods ....................................................................................... 45

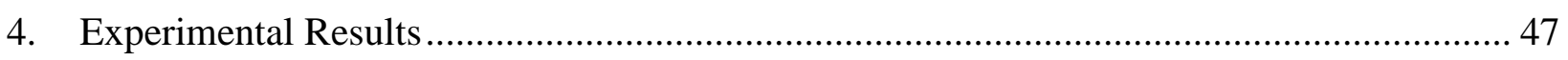

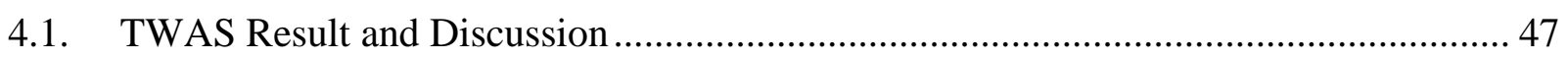

4.1.1. Effects of Hydrothermal Pretreatment on COD Solubilization of TWAS ............. 47

4.1.2. Suspended Solid Reduction of TWAS ............................................................... 51

4.1.3. Impact of hydrothermal pretreatment on anaerobic digestion of TWAS ...............5 53

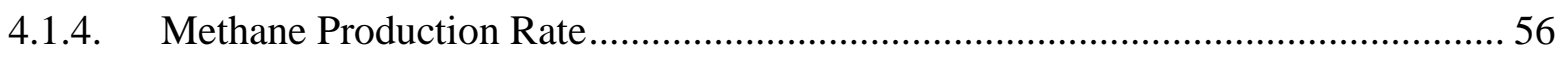

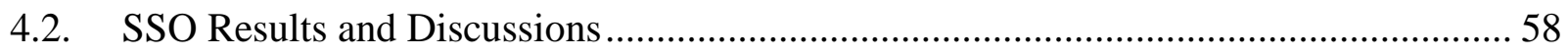

4.2.1. Effects of hydrothermal pretreatment on SSO disintegration ................................. 58

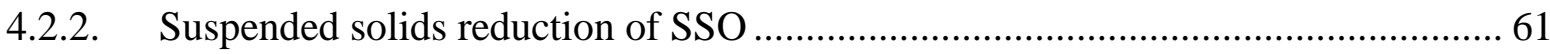

4.2.3. Effect of hydrothermal pretreatment on anaerobic digestion of SSO ..................... 63

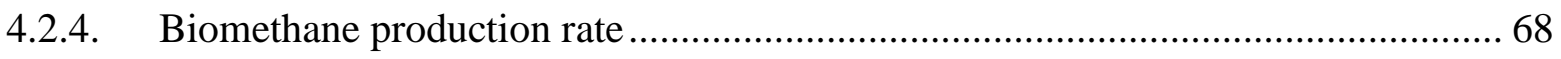

5. Impact of Hydrothermal Pretreatment on TWAS and SSO ……...................................... 71

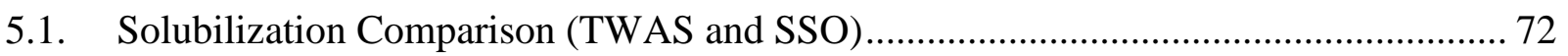

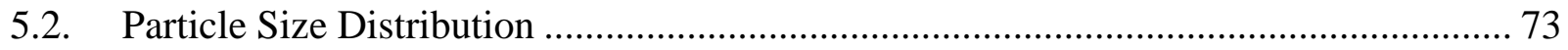

5.3. Comparison of TWAS and SSO Anaerobic Biodegradability ..................................... 75

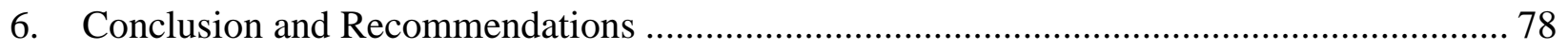

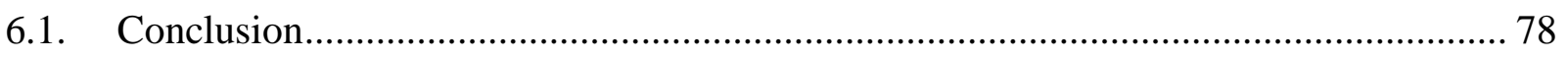

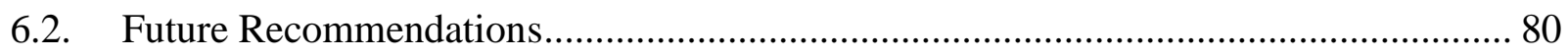

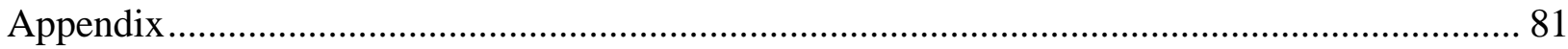

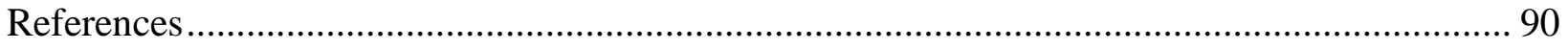




\section{List of Figures}

Figure 2.1. Schematic representation of anaerobic digestion process 6

Figure 2.2. Various aspects of anaerobic digestion influenced by feedstock composition 15

$\begin{array}{lr}\text { Figure 2.3. Digestion systems for waste with different total solid contents } & 18\end{array}$

Figure 2.4. Digestion systems for waste with different total solid contents 20

$\begin{array}{lr}\text { Figure 2.5. Process flow diagram (Cambi Process) } & 29\end{array}$

Figure 2.6. Process flow diagram (BIOTHELYS Process) 29

Figure 3.1. SSO process in Disco Road Organic facility 38

Figure 3.2. Process description of TWAS in a wastewater treatment plant 40

Figure 3.3. Parr4848 Hydrothermal Reactor 41

Figure 3.4. Parr 4848 Hydrothermal Reactor Real time plotting by SpecView Software $\quad 42$

Figure 4.1. Effect of Hydrothermal Pretreatment on Concentration of Soluble COD 47

Figure 4.2. Effect of Hydrothermal Pretreatment on Soluble COD improvement comparing to $\begin{array}{lr}\text { non-pretreated } & 48\end{array}$

Figure 4.3. The Concentration of Soluble Protein and Carbohydrate 50

Figure 4.4 The effect of hydrothermal pretreatment on Suspended Solids Concentration 51

Figure 4.5 The effect of hydrothermal pretreatment on Suspended Solids Reduction 52

Figure 4.6. The cumulative methane production of the BMP digesters 53

Figure 4.7. Methane Yield Improvement Comparing with Non-Pretreated 54

Figure 4.8. Effect of Hydrothermal Pretreatment on Methane Production Rate 57

Figure 4.9. Effect of Hydrothermal Pretreatment on Highest Methane 57

Figure 4.10. The effect of hydrothermal pretreatment on SSO Solubilization-SCOD concentration 
Figure 4.11. The effect of hydrothermal pretreatment on SSO solubilization improvement (relative to control)

Figure 4.12. Soluble Carbohydrate and Protein Concentration Comparing to the Non-Pretreated Sample

Figure 4.13. The effect of hydrothermal pretreatment on suspended solids; suspended solids concentration

Figure 4.14. The effect of hydrothermal pretreatment on suspended solids; suspended solids reduction efficiency

Figure 4.15. The cumulative methane production of the BMP digesters (@ the STP)

Figure 4.16. The effect of hydrothermal pretreatment on methane yield improvement (@ the STP)

Figure 4.17. Effect of hydrothermal pretreatment on ultimate methane yield (@ the STP) 65

Figure 4.18. The effect of hydrothermal pretreatment on daily methane production rate 69

Figure 4.19. The effect of hydrothermal pretreatment on maximum methane production rate 69

Figure 5.1. The effect of hydrothermal pretreatment on COD solubilization of TWAS and SSO comparison

Figure 5.2. The effect of hydrothermal pretreatment on Particle Size of (a) SSO (b) TWAS (D90)

Figure 5.3. The main-effect plot of methane yield improvement vs pretreatment temperature, retention time, and severity index (a) TWAS (b) SSO 


\section{List of Tables}

Table 2.1. Sources of feedstock for bioenergy production in anaerobic digestion

Table 2.2. Advantage and disadvantage of anaerobic digestion comparing to other biological treatments

Table 3.1. Characteristics of Feedstock and Inoculums

Table 3.2. Hydrothermal Pre-treatment conditions (Temperature, Severity Index and Retention Time) 


\begin{tabular}{ll} 
List of Abbreviations & \\
COD & Chemical Oxygen Demand \\
CSTR & Continues Steered Tank Reactor \\
F/M & Food to Microorganism Ratio \\
GC & Gas Chromatograph \\
HRT & Hydraulic Retention Time \\
OFMSW & Organic Fraction of Municipal Solid Waste \\
PID & Proportional Integral Derivative \\
PS & Primary Sludge \\
RNA & Ribonucleic Acid \\
S Carbohydrate & Soluble Carbohydrate \\
S Protein & Soluble Protein \\
SCOD & Soluble Chemical Oxygen Demand \\
SI & Severity Index \\
SRT & Solid Retention Time \\
SSO & Source Separated Organics \\
T Carbohydrate & Total Carbohydrate \\
T Protein & Total Protein \\
TCOD & Total Chemical Oxygen Demand \\
TS & Total Solid \\
TSS & Total Suspended Solid \\
TWAS & Thickened Waste Activated Sludge \\
UASB & Up-flow Anaerobic Sludge Bed \\
VFA & Volatile Fatty Acid \\
VS & Volatile Solid \\
VSS & Volatile Suspended Solid \\
WWTP & Wastewater Treatment Plant \\
\hline
\end{tabular}




\section{List of Appendices}

Figure A.1. The Effect of Hydrothermal Pretreatment on Concentration of Ammonia in SSO

Figure A.2. The Effect of Hydrothermal Pretreatment on Concentration of Alkalinity in SSO

Figure A.3. The Effect of Hydrothermal Pretreatment on Concentration of Carbohydrates in SSO

Figure A.4. The Effect of Hydrothermal Pretreatment on Biogas Production in SSO

Figure B.1. The Effect of Hydrothermal Pretreatment on Concentration of Alkalinity in TWAS

Figure B.2. The Effect of Hydrothermal Pretreatment on Concentration of Ammonia in TWAS

Figure B.3. The Effect of Hydrothermal Pretreatment on Concentration of Carbohydrates in TWAS

Figure B.4. The Effect of Hydrothermal Pretreatment on Biogas Production in TWAS 


\section{Introduction}

Population growth along with high living standard has resulted in excessive production of waste which brought a noticeable challenge on solid waste management. Disposing the produced sludge during wastewater treatment or organic fraction of municipal solid waste which is mostly food waste and yard waste in an environmentally friendly way has become a worldwide problem. It is estimated that produced wastewater sludge globally exceeds ten thousand tons per day and a typical wastewater treatment plant produce one hundred thousand tons of sludge per year (Tarique et al., 2017). Every year, $1.3 \times 10^{9}$ tonnes of food waste goes to landfills globally that produce $3.3 \times 10^{9}$ tonnes of $\mathrm{CO}_{2}$. In Canada, more than 27 million tonnes of food waste are disposed yearly. Disposing this huge amount of waste in a proper way with a small footprint on environment has brought many efforts and ending up to different methods for waste management. For example the produced organic waste can cause severe health and environmental issues if managed incompetently, sending organic waste to landfill is a conventional way of waste management but can cause soil and groundwater contamination and also contribute significantly to greenhouse gas emission (Tarique et al., 2017).

Municipalities have taken different management actions to improve the management of sludge and organic fraction of municipal solid wastes (OFMSW). For OFMSW source separated collection has been an effective way to prevent mixing of organic and non-organic waste and divert organic waste from landfill. For example, the total organic waste that was diverted away from landfill disposal in the United States increased from 9.6\% in 1980 to $34.5 \%$ in $2012(\mathrm{H}$. Han \& Z. Zhang, 2017). Source separated organics (SSO) is a term used to address the mixture of various organic components in municipal solid waste generated at residential, commercial, and institutional sectors. In addition to the food waste as the major component, SSO contains other organic materials including trimming plant wastes (grass, leaves, etc.), paper fibres (napkins, paper towels, tea bags, etc.), and wood waste (Canada Ministry of Environment, 2013).

The application of biological processes for the treatment and/or conversion of organic waste to value-added products has aroused significant attention as it has financial advantages and also causes less environmental impacts compared to the existing waste handling/disposal methods (i.e., landfilling, incineration, gasification, etc.) (Razavi et al., 2019; Naroznova et al., 2016). The bioconversion of organic has been even more striking in recent years as a result of new 
regulations which ban the disposal of food waste and SSO through landfilling or incineration (Mahmoodi et al., 2018). Among various biological processes (i.e., aerobic treatment, composting, etc.), the implementation of anaerobic digestion (AD) process for the conversion of organic waste to bioenergy has known to be an energy-efficient process with less environmental footprint ( Elbeshbishy et al., 2017). This approach has been developed since the energy crises in 1970s and recent concern about global warming has led to improvement of AD process for higher biogas production (Carlsson et al., 2012). It is a sustainable method to treat organic waste and convert to value added products as this biological treatment not only degrade organic matter to produce biogas but also it reduces the production of sludge and comparing to other sludge management methods like incineration and landfilling it has outstanding financial advantage and causeless environmental impacts (Han et al., 2017). In comparison, composting requires large land and can release uncontrolled odorous volatile organic compounds and pathogens (Lin et al., 2018). Aerobic treatment processes are also associated with several drawbacks including high energy demand, high rate of waste sludge production and low process efficiency under high organic loads (Shao et al., 2013). In addition to the bioenergy production in the form of methane, the AD process has the advantage of producing stabilized fertilizer while achieving significant waste volume reduction which is vary appealing when dealing with high solids content organic waste such as food waste or SSO (Parthiba et al., 2017).

$\mathrm{AD}$ is a vital process prior to disposal for stabilization of waste and it has been used worldwide in modern wastewater treatment plants and considered to be environmental friendly and an economical approach used for biosolids management (Vlyssides \& Karlis, 2004; Jain et al., 2015). AD process is a biochemical process occurs in absence of oxygen in four distinguished stages. The first stage is hydrolysis that disintegrates particulate matter and converts organic polymers to simple monomers and it follows by three other stages; acidogenesis, acetogenesis, and methanogenesis. The hydrolysis in which the bacteria use their enzymes to break down the high molecular weight or particulate matters into soluble compounds or monomers is known as the rate-limiting stage (Carrère et al., 2010; Elbeshbishy et al., 2011). By improving this step organic matters become more available to bacteria which ends up to higher biomethane production and reduction of sludge volume for disposal (Donoso-Bravo et al., 2011). In order to improve the decomposition and solubilization during hydrolysis stage, pre-treatment process has been explored. Different pre-treatment methods such as thermal, mechanical, and chemical have 
been investigated and most pre-treatments showed improvement in solubilization of organics on different substrates by decomposition of cell walls and releasing the intracellular organic that make it available for microorganisms during anaerobic digestion (Wilson \& Novak, 2009). Among various methods of pre-treatment, the application of hydrothermal pre-treatment has shown to be more promising in converting the particulate fraction of organic matter into the soluble phase (Cesaro \& Belgiorno, 2014). Several full scale wastewater treatment facilities are operating with hydrothermal pre-treatment and it has been more interested to wastewater industrial as a method to accelerate biogas production and improve the dewaterability of sludge (Donoso-Bravo et al., 2011). Hydrothermal pre-treatment is an effective method to achieve organic matter degradation by combining high temperature and pressure in order to achieve solubilization and cell destruction of sludge and it does not need chemical catalyst which makes it cost effective and environmental friendly (Kim, Lee, \& Park, 2015a). In hydrothermal pretreatment temperature is the dominant parameter that enhances the hydrolysis of dissolved macromolecular matters such as insoluble proteins and large-molecular-weight carbohydrates. Temperature raise during the pre-treatment breaks down the insoluble organic material into soluble component and rupturing the cell membranes that releases organic matters (Guilford et al., 2017). A wide range of studies have investigated the effect of hydrothermal pre-treatment on food waste and wastewater sludge and the results reveal the effectiveness of hydrothermal pretreatment on increasing the solubilization and biodegradability rate (Pérez-Elvira et al., 2014; Pilli et al., 2015; Barber et al., 2016; Fdz-Polanco et al., 2008). Despite many research on hydrothermal pre-treatment still there is not a general agreement on the optimal condition, different pretreated temperatures were suggested for hydrothermal pre-treatment of food waste and sludge, (Appels et al., 2008) shows the best condition to be $80^{\circ} \mathrm{C}$ while (Barber et al., 2016) and (Fdz-Polanco et al., 2008) reported $140^{\circ} \mathrm{C}$ and $170^{\circ} \mathrm{C}$ respectively as the best temperature for hydrothermal pre-treatment in biomethane production. These studies reveal that substrates exposed to hydrothermal pre-treatment ends up to different results as the characteristics and composition of the substrate is very important and this variability is the main barrier over finding the suitable pre-treatment condition prior to AD.

Although the hydrothermal pre-treatment is now industrialized and practiced in 39 full scale

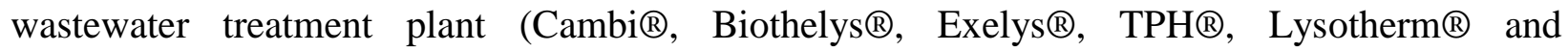
Turbotec $($ ) but there is no general agreement on optimum condition. According to the research 
the accepted operation condition has a wide range of heating temperature from 120 to $230{ }^{\circ} \mathrm{C}$ and retention time ranges from 20 to $60 \mathrm{~min}$ (Sapkaite et al., 2017).

\subsection{Study Objectives}

The objective of this study was to investigate the effect of temperature and holding time on SSO and TWAS in a wide range of temperature and retention time within different severity indexes (SIs) and have a comparison on the effect of hydrothermal pre-treatment on wastes with different characteristics. Although there are many research investigate the hydrothermal pre-treatment on sludge and food waste but to the best knowledge of author there is no comprehensive study about hydrothermal pre-treatment considering SI and a wide range of temperature and retention time. The aim of this research is to fill the gap and find the optimum hydrothermal pre-treatment condition of TWAS and SSO between five different SIs and also within each SI. 


\section{Literature Review}

\subsection{Anaerobic Digestion}

Anaerobic Digestion (AD) is an imitation of natural biochemical process that microorganisms decompose organic matter in absence of oxygen to biogas $\left(\mathrm{CH}_{4}\right.$ and $\left.\mathrm{CO}_{2}\right)$. $\mathrm{AD}$ also happens naturally in landfills which reduce organic matters and produce biogas while stabling the organic waste. Volta is the first person who discovered the anaerobic process in 1776 demonstrating a combustible air from sediments of a pond and Moigno applied the first anaerobic treatment of domestic wastewater using a septic tank in 1881. In 1890 the first hybrid anaerobic system was introduced by Scott Moncrief and by 1930 the technology of AD was well established that applied in full scale. After world war two water treatment process using aerobic condition in the biological treatment and tertiary treatment become common but after the energy crisis in 1970 the application of $\mathrm{AD}$ draw worldwide attention.

The microbial activity of AD process is complicated involving different prokaryotic kingdoms like Bacteria and Archaea that interact between each other during the course of bioenergy production. The produced bioenergy is a mixture of approximately $65 \%$ methane and $35 \%$ carbon dioxide. Beside biomethane production $\mathrm{AD}$ has many other benefits to waste management and the environment that includes; mass reduction, odor removal and pathogen reduction (Nandiyanto et al., 2018). The metabolic reaction that happens between different groups of microbial clusters under anaerobic condition with an oxidation reduction potential<$200 \mathrm{mV}$ leads the process (Sapkaite et al., 2017). During anaerobic fermentation process since it happens in absence of oxygen and there is not electron acceptor the products of the process accepts electron from organic breakdown and organic matter forms as electron donor and acceptor (Raman et al., 2013).

In this complex process four different clusters of bacteria are involved in different steps of the process illustrated in Figure 2.1, which are hydrolysis, acidogenesis, acetogenesis, and methanogenesis. The first stage of $\mathrm{AD}$ is hydrolysis. In this stage microorganisms break down insoluble organics and macromolecular organics like polysaccharide, proteins and nucleic acid and lipids to soluble monomers such as glucose, amino acids and fatty acids so they can be available for acidogenesis bacteria in the second stage of $\mathrm{AD}$. This conversion happens by microorganism secreting enzymes like lipases, proteases, amylases and cellulases to hydrolyze 
complex polymers into monomers. The products of hydrolysis steps which are fatty acids, monosaccharide, amino acids, purines and pyrimidines comes from conversion of lipids, polysaccharide, protein and nucleic acids respectively. The intermediate product formed during hydrolysis stage is a suitable substrate for the acidogenesis bacteria, the soluble organic further degrades and convert to volatile fatty acids (acetic acid, proponoic acids and butric acids), $\mathrm{CO}_{2}$, $\mathrm{H}_{2} \mathrm{~S}$ and ammonia by fermentative bacteria.

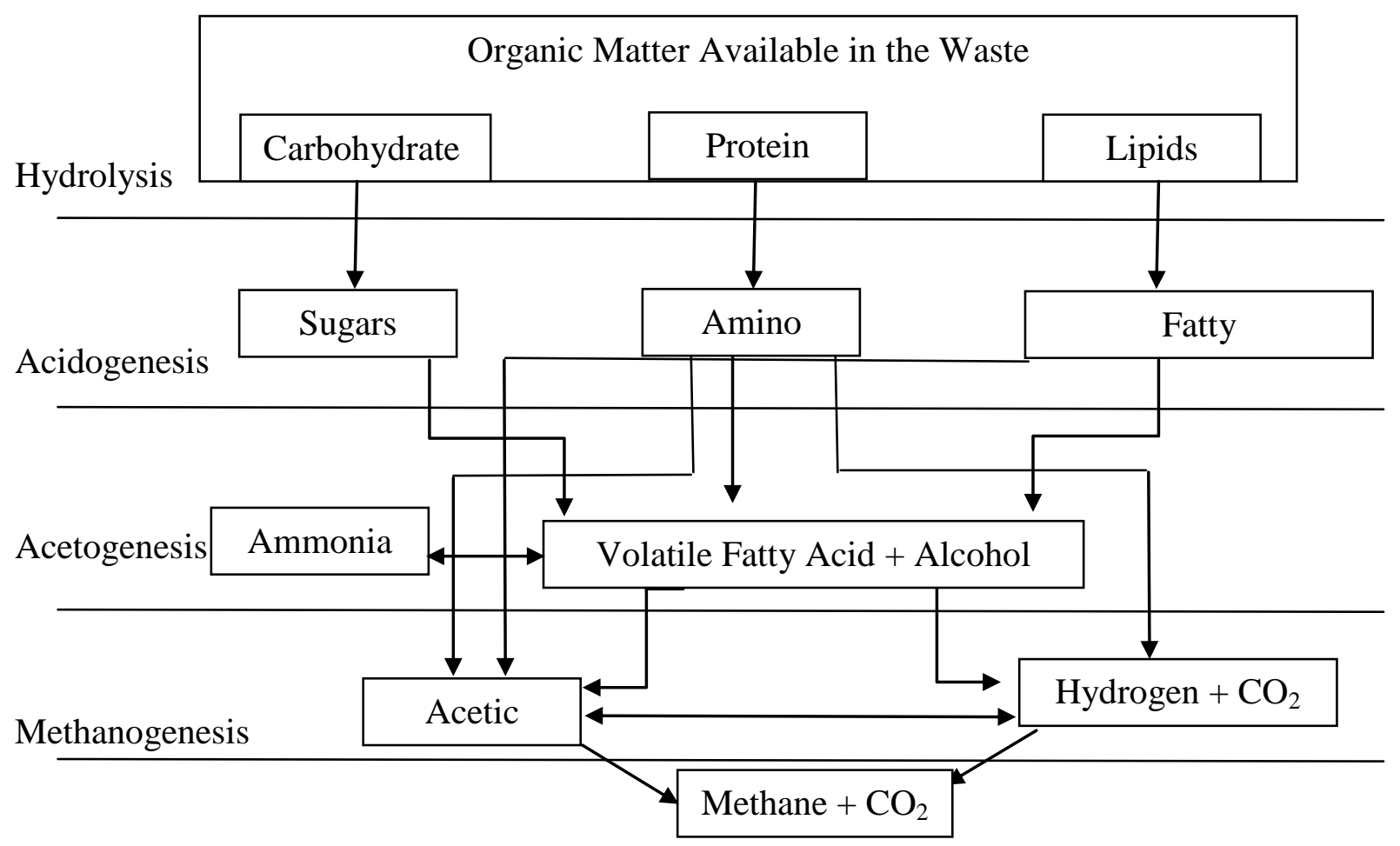

Figure 2.1. Schematic representation of anaerobic digestion process

The third stage of AD is Acetogenesis that convert higher organic acids (volatile fatty acids) and alcohols to acetic acid, hydrogen and $\mathrm{CO}_{2}$. In this conversion, the partial pressure of $\mathrm{H}_{2}$ controls the process. In last stage, the final product methane and $\mathrm{CO}_{2}$ is produced by two different methanogenesis bacteria. Aceticlastic methanogenesis produce methane by splitting acetate to methane and $\mathrm{CO}_{2}$ and the second group hydrogenotrophic methanogenesis produce methane from hydrogen as electron donor and $\mathrm{CO}_{2}$ as electron acceptor (Raman et al., 2013). Most of methane (approximately 70\%) produced during AD converts by aceticlastic methanogenesis splitting acetic acid to methane and carbon dioxide. 
The remaining is produced by hydrogenotrophics producing methane by $\mathrm{CO}_{2}$ and $\mathrm{H}_{2}$.

$4 \mathrm{H}_{2}+\mathrm{CO}_{2} \rightarrow \mathrm{CH}_{4}+2 \mathrm{H}_{2} \mathrm{O}$

$\mathrm{AD}$ is a series of complicated process which is rate controlled by different anaerobic bacterial groups. For example, the first step, hydrolysis is the rate limiting step for feedstock with high suspended solids content like organic solid waste and the last stage methanogenesis is the ratedetermining step as if the concentration of volatile fatty acids increases during the process and methanogenesis bacteria cannot consume it to produce methane and the balance of the process can be inhabited. In AD to keep the process in balance the rate of all stages should be equal. For example, in an $\mathrm{AD}$ process if the first stage that degrades the organics happens in a faster rate and it decreases the $\mathrm{pH}$ value by accumulation of acid and if the second stage is faster than it is inhabited by the first stage. In an $\mathrm{AD}$ reactor, all four stages are occurring at the same time and require ideal condition for all clusters of bacteria involved in the process. Thus, in an AD process in the design different factors like substrate properties should be also considered in order to have a successful process (Weiland, 2010).

\subsection{Biogas Utilization}

In an anaerobic digestion process, the biogas can be produced by a wide range of waste feedstock coming from agriculture sector or any other organic waste streams. The biogas produced during the $\mathrm{AD}$ is mostly composed of methane and carbon dioxide with a small percentage of hydrogen sulfide, vapors of water, ammonia and siloxane. Biogas can be used as a raw after $\mathrm{AD}$ or upgraded to increase its energy content and inject it to the natural gas grid. It can be used in a variety of ways as a source of energy for example it can be used to generate heat and steam, combined heat and electricity, upgrading and using as vehicle fuels, upgrading and injecting biogas to natural gas grid or even production of chemicals and proteins. A good example of using biogas as vehicle fuel is in Sweden. In last decade the market for using biogas as vehicle fuel grow rapidly and today seventy thousand vehicles burn upgraded biogas as a source of energy from 500 filling stations (Holm-Nielsen et al., 2009). Upgrading the biogas to the natural gas quality and injecting it to the natural gas grid is an effective method of integrating it to the energy sector. The purification level of biogas 
in some countries like Sweden, Germany and Switzerland before injecting to the main gas network is to remove all contaminants and carbon dioxide and upgrade biogas to $95 \%$ biomethane (Weiland, 2010). The produced biogas might not be consumed on the site for example in a farming area and injecting it as biomethane in the natural gas network enables to transport it and use it in large energy consumption area.

Before using the biogas as source of renewable energy it has to be purified from its harmful content to an extent suitable for consumption. There are many studies focusing mainly on removal of carbon dioxide, hydrogen sulfide, ammonia and siloxane from biogas. There are different methods to purify the biogas and it is divided into two main approaches. The method that used reactive and non-reactive adsorbents and absorbents are called physiochemical method and using microorganisms to consume the impurities are called biological process. Carbon dioxide with a high concentration in biogas is one of the main impurity that can be removed by pressure swing adsorption on zeolite and selective membrane separation. The most common approaches of biogas purification from carbon dioxide are scrubbing with water or organic solvents like polyethylene glycol. The other method that is less used comparing to previous methods mentioned are removing it by alkanol amines like monoethanolamine. The polymeric membrane technology is one of the effective method for biogas improvement to enhance the methane concentration to a level suitable for injection in to the national gas distribution network. By this method beside carbon dioxide, hydrogen sulfide can also be removed and if the concentration of components of biogas that degrade the membrane like ammonia is low, it can be more economical approach comparing to conventional methods of removing impurities from biogas (Molino et al., 2013). Removing carbon dioxide from the biogas results in losing a portion of biomethane and as it is a strong greenhouse gas releasing it to the atmosphere is harmful for environment.

Hydrogen sulfide is a harmful content that is an obstacle on the energy conversion. To use biogas as a source of energy for combined heat and power generation the concentration of $\mathrm{H}_{2} \mathrm{~S}$ should be lower than $250 \mathrm{ppm}$ as higher concentrations can deteriorate the oil used for lubrication and cause corrosion (Weiland, 2010). Nowadays, the hydrogen sulfide from biogas is mostly removed by biological desulfurization method that oxidize hydrogen sulfide 
by injecting a specific amount of air (2-5\%) into biogas inside the headspace. Sulfobacter oxydans bacteria must be present as it is responsible for removing hydrogen sulfide from biogas in a mesophilic temperature. Hydrogen sulfide can also be removed by chemical absorption in aqueous solution. The bases of this process is because hydrogen sulfide as a tendency to metallic cation. It is reported that $\mathrm{Fe}$ with $\mathrm{H}_{2} \mathrm{~S}$ reacts according to the following equations (Sikkema, Junginger, Pichler, Hayes, \& Faaij, 2010):

$$
\begin{aligned}
& 2 \mathrm{Fe}^{3+}+\mathrm{H}_{2} \mathrm{~S}=2 \mathrm{Fe}^{2+}+\mathrm{S}+2 \mathrm{H}^{+} \\
& 2 \mathrm{Fe}^{2+}+0.5 \mathrm{O}_{2}+\mathrm{H}_{2} \mathrm{O}=2 \mathrm{Fe}^{3+}+2(\mathrm{OH})^{-}
\end{aligned}
$$

\subsection{Process Parameters}

The environmental factor for a process based on activity of microorganism is the determining parameter for its successful operation. $\mathrm{As} \mathrm{AD}$ is a process lead by bacterial activity, environmental factors like $\mathrm{pH}$, temperature, carbon to nitrogen ratio ( $\mathrm{C} / \mathrm{N}$ ratio), mixing, nutrients and toxicity are the defining variables for optimizing and increasing the degradation efficiency.

\subsection{1. $p H$}

In $\mathrm{AD}$ process, different bacterial groups are involved and the optimum $\mathrm{pH}$ range is different for each stage of the process, so it is a vital factor in AD. Methanogenesis bacteria is very sensitive to $\mathrm{pH}$ variation comparing to other clusters of bacteria in the process and also methanogenesis are responsible for the end product and it is important to set the $\mathrm{pH}$ for the methanogenesis bacteria. The suitable $\mathrm{pH}$ for $\mathrm{AD}$ ranges from 6.8 to 7.2 and acidity environment inhabit the methane production (Khalid et al., 2011). During the AD process the initial $\mathrm{pH}$ increases due to the production of Volatile Fatty Acids (VFAs) and to stabilize the $\mathrm{pH}$ adequate alkalinity is needed to be added as a buffer to control the rapid increase in $\mathrm{pH}$. The $\mathrm{pH}$ can be stabilized also during the process by methanogenesis bacteria consuming VFA and alkalinity production in the form of ammonium bicarbonate and $\mathrm{CO}_{2}$. The $\mathrm{pH}$ in the gas phase is controlled by $\mathrm{CO}_{2}$ and in liquid phase by ammonium bicarbonate (Appels et al., 2008). In order to ensure the proper

operation of $\mathrm{AD}$ the VFAs to alkalinity ratio should be around five and optimum alkalinity concentration should be in range of $2000-5000 \mathrm{mg} / \mathrm{L}$ as $\mathrm{CaCO}_{3}$ (Duan et al., 2009) 


\subsubsection{Carbon to Nitrogen Ratio (C/N ratio)}

The Feedstock for AD to produce biogas can be in different physical state (Solid, Slurries and diluted or concentrated liquid). In some plants sludge from wastewater treatment plant is used as feedstock while for others it can vary from food waste to agriculture waste and manure. Beside other determining factors, $\mathrm{C} / \mathrm{N}$ ratio is a key factor in the $\mathrm{AD}$ process as the ratio higher or lower than the suitable condition causes problem for the process. The optimal $\mathrm{C} / \mathrm{N}$ ratio is $20-30$ for methane production and if the ratio is beyond 30 it results in lower biogas production. $\mathrm{C} / \mathrm{N}$ ratio less than 20 is toxic and can inhabit the process by ammonia accumulation and $\mathrm{pH}$ increase (Karim et al., 2005). Methanogenesis bacteria are sensitive to $\mathrm{pH}$ variation and $\mathrm{C} / \mathrm{N}$ ratio controls the $\mathrm{pH}$ value. Higher carbon concentration during the $\mathrm{AD}$ process stimulate the formation carbon dioxide concentration which drops the $\mathrm{pH}$ and higher concentration of nitrogen causes the accumulation of ammonia that rise $\mathrm{pH}$ value (Dioha et al., 2013).

In order to reach to the optimum ratio of carbon to nitrogen co-digestion of different waste is a good option like sewage with animal manure (Raman et al., 2013). Co-digestion is a treatment method that two or more feedstocks combine to provide a better organic source to improve the anaerobic digestion process. Co-digestion has many benefits for $\mathrm{AD}$ as an example it dilutes the toxic component in the feedstock, improve the biodegradability of organics and enhance the balance of nutrients. It was observed that co-digestion increase the $\mathrm{C} / \mathrm{N}$ ratio and stabilize the AD process and also decrease the concentration of nitrogen (Khalid et al., 2011).

In a study that used ten different waste feedstocks for $\mathrm{AD}$ with different $\mathrm{C} / \mathrm{N}$ ratio ranging from 10:1 to 82:1 shows that the highest biogas production occurred in cow dung and followed by poultry droppings. The lowest biogas produced happened in neem leaves and sugar can bagasse. The $\mathrm{C} / \mathrm{N}$ ratio of cow dung, poultry droppings, neem leaves and sugar can bagasse are 13:1, 15:1, 82:1 and 53:1 respectively. Findings from this study concluded that TS, VS and concentration of minerals are also a defining factor in $\mathrm{AD}$ and biogas production (Dioha et al., 2013).

\subsubsection{Temperature}

Temperature has a vigorous effect on $\mathrm{AD}$ process influencing the growth rate and metabolism of microorganisms. $\mathrm{AD}$ can operate in a wide range of temperature dividing in three different temperature conditions acetotrophic, mesophilic and thermophilic with a temperature range from 20 to $60^{\circ} \mathrm{C}$. The pressure of $\mathrm{H}_{2}$ can be influenced by temperature, so temperature can impact the 
kinetics of synthropic metabolism. Thermodynamics shows that endergonic reactions like degradation of propionate to acetate, $\mathrm{CO}_{2}, \mathrm{H}_{2}$ favors higher temperature while exergonic reactions like hydrogenotrophic methanogenesis favors less temperature (Appels et al., 2008).

The maximum methane production happens in mesophilic $\left(30-35{ }^{\circ} \mathrm{C}\right)$ and thermophilic $(50-60$ ${ }^{\circ} \mathrm{C}$ ) conditions considering the feasibility and economics while the AD can also happen in lower temperature like $20{ }^{\circ} \mathrm{C}$ (psychrophilic condition). Mesophilic digesters are conventional ways of biogas production while in the last 15 years thermophilic digesters are also become available in full scale plants. In Denmark nowadays most of the biogas plants are operating in thermophilic condition and proves that the stability of the process is no longer a problem (Hartmann \& Ahring, 2006). In AD, the temperature is an important parameter in regard to the metabolism rate of microorganism and also to the physical and chemical characteristics of substrate. For example, in thermophilic $\mathrm{AD}$ the digestion rate is four times higher comparing to mesophilic condition and it enhances the solid reduction and pathogenic destruction. The hygiene of the end product produced during $\mathrm{AD}$ is now an important factor as it is a policy of EU for disposing waste originated form animal and human. Thermophilic condition for $\mathrm{AD}$ is encouraged in this regard as it eliminates the pathogen and produce class A biosolids (Gavala et al., 2003). Preserving the optimal condition is critical as active bacteria in thermophilic condition is sensitive to temperature fluctuation and it also requires higher energy. Many studies have been carried out to evaluate the performance of mesophilic and thermophilic AD. In a full scale anaerobic digester, the adaptation of digester form mesophilic $38{ }^{\circ} \mathrm{C}$ to $55^{\circ} \mathrm{C}$ was observed in Central Wastewater Treatment in Prague. This study concluded that higher temperature in AD process result in higher biodegradation of the sludge. The maximum methane production rate and yield was observed in thermophilic condition and increasing the substrate load did not unstable the degradation process and it avoid digesters over loading (Zábranská et al., 2000). In a study by Technical University of Denmark that investigate the effect of thermophilic and mesophilic AD it was concluded that in thermophilic digester the destruction rate of organic waste is higher and results in higher methane yield comparing to mesophilic digestion and it also shows that the effectiveness of thermophilic condition is more clear in shorter retention time(Gavala et al., 2003). The biogas production from OFMSW was also been studied and it was observed that with a short HRT of 12 days, the biogas production in a thermophilic digester is almost double to a mesophilic digester (Hartmann \& Ahring, 2006). 
Although the pathogen destruction is higher in the thermophilic digesters and retention time is lower, their applications are limited due to high energy demand and low stability in the process comparing to mesophilic digesters. As an example; thermophilic digester can be easily imbalanced by highly biodegradable waste as the acidogenesis over produce acids and inhabit the biogas production (Alqaralleh, 2012).

\subsubsection{Retention Time}

There are two types of retention time in AD process are solid retention time (SRT) and hydraulic retention time (HRT). The ratio between the solid content in the reactor by the solid flow rate demonstrates the average SRT. HRT represent the average time of waste and wastewater being exposed to microorganisms. SRT is one of the important parameters in AD process that control the waste to biogas conversion (Cesaro \& Belgiorno, 2014). In a convention mixed reactor, the SRT and HRT are equal while in a retained biomass reactor the SRT is not equal to HRT, typically, it is higher than HRT. Higher SRT can be achieved by increasing the digester volume, increasing the solid content or using a retained biomass reactor. At short SRT the time for microorganisms is insufficient to grow and replace the removed bacteria and if SRT is shorter than $48 \mathrm{hrs}$, the rate of microorganism loss surpasses the production rate and methane producing bacteria can be washed out of the reactor (Duan et al., 2009). Higher SRT improves the stability of digested but increase the digester volume and capital cost. The SRT and HRT also relates to the properties of the feedstock for example for readily biodegradable waste shorter HRT is required. The biogas composition can also be related to the retention time of the feedstock in the digester (Weiland, 2010).

Equation (2.3) represent the calculation for HRT and equation (2.4) presents the calculation of SRT for continues stirred tank reactor (CSTR).

$H R T=\frac{\text { Volume of the Reactor }(V)}{\text { Influent Flow Rate }(Q)}=\frac{L}{L / d}=d$

$S R T=\frac{\text { Mass of the biomass in reactor }}{\text { Mass rate of the biomass leaving }}=\frac{V * V S S}{Q_{\text {out }} * V S S}=\frac{V}{Q_{\text {out }}}=H R T d$

In a research that studied the effect of SRT on carbohydrate, lipids and protein hydrolysis and acidification it was shown that particulate protein hydrolysis in methanogenesis stage that 
happens in a SRT $>8$ days. It was also reported that almost $60 \%$ of the particulate organic matter are hydrolyzed during the methanogenic and SRT $<8$ will end up in less biogas production (Miron et al., 2000).

\subsubsection{Toxic Substances}

Some substances with a certain concentration can inhabit the anaerobic digestion process as it can be harmful for methanogenesis bacteria. The problem raised by toxic substances present in the process is not simple as it is related to many other parameters. Although high concentration of some substances can inhabit the process but a certain concentration of the same substance can be a stimulation for the process. The inhibition of anaerobic digestion not only related to concentration toxic substances but also to some other parameters like environmental conditions such as $\mathrm{pH}$ and temperature.

There are different organic and non-organic matters like VFA, ammonia, sulfide, salts and heavy metals that their concentration beyond a certain threshold inhabits the process (Pavlostathis \& Gossett, 1989). VFA is an intermediate product of the AD and its high concentration affect the

$\mathrm{pH}$ and alkalinity so the threshold level relates on these variables. Ammonia which is a necessary nutrient for the process at concentration in range of $1500-3000 \mathrm{mg} / \mathrm{L}$ can be an inhibitory in higher pH>7.2 (Hartmann \& Ahring, 2006), temperature also has a great effect on toxicity of ammonia. Hydrogen sulfide concentration shows the same trend as ammonia and its toxicity relates also mostly to $\mathrm{pH}$ and alkalinity, the threshold value reported by literature review ranges from 200 to $1500 \mathrm{mg} / \mathrm{L}$. Presence of heavy metals can also be an inhibition or stimulation for example for heavy metals concentration beyond $1 \mathrm{mg} / \mathrm{L}$ although trace metals like $\mathrm{Fe}, \mathrm{Ni}, \mathrm{Mg}$ and $\mathrm{Ca}$ are vital for metabolic activity of microbial cell.

\subsubsection{The effect of Mixing}

$\mathrm{AD}$ process can be influenced by many parameters but it is mainly effected by the retention time and the contact of organics with microorganism. In order to ensure the sufficient contact of the substrate with bacteria hydraulic mixing in the digester should be provided. Many studies have proved that mixing is an important factor for organic conversion to biogas but the optimum mixing ratio is debatable (Karim et al., 2005). As substrate mixing in the digester ensure a uniform distribution of it bacteria and heat through out the process. Beside this mixing helps to 
reduce the particle size and also release the gas from the mixture. Many studies evaluate the mixing time and its severity in the process of $\mathrm{AD}$ and their results are inconsistent. In some of research adequate mixing were suggested for a higher efficiency of the process while in others no mixing was reported as a suitable condition. It was reported that insufficient mixing for low solid substrate causes a floating layer of solid in the digester (Chen et al., 1990). In another study, the intermittent mixing of 2 minutes after each hour was reported to result in higher methane yield than continues mixing for municipal solid waste. In another study, the effect of mixing on manure slurry concluded that the solid concentration is related. It evaluate the effect of digester mixing on 5\% manure slurry that shows mixing has no impact on the biogas production while for 10 and $15 \%$ concentration the digester equipped with mixer shows higher methane yield comparing to non-mixed digester (Karim et al., 2005).

\subsection{Anaerobic Digestion Feedstock}

In bioenergy production, any substrates that can be converted to a renewable source of bioenergy is called feedstock and it can vary from readily degradable organics like wastewater to wastes with high solid contents. By anaerobic digestion technology even toxic wastes can also be converted to bioenergy and they can be considered as a feedstock. Historically for anaerobic digestion process manure and sludge from wastewater treatment plants were used as feedstock for biomethane production. By the energy crises in 1970 and challenges of waste management the application of anaerobic digestion broadened and new feedstock like municipal and industrial wastes were introduced to anaerobic digestion as an interdisciplinary approach to substitute fossil fuels with a new source of renewable energy and decrease the volume of disposed waste.

By recent concerns about environmental problems and landfilling that stimulate new developments in anaerobic digestion technology occurred that divert wastes like organic fraction of municipal solid waste from landfill and use it as feedstock for anaerobic digestion. Furthermore, sophisticated control devices and reactors enabled anaerobic digestion to treat industrial wastes with low concentration of organics. Now the waste used as feedstock for anaerobic digestion comes from various sources presented in the table 2.1 (Steffen et al., 1998). 
Table 2.1. Sources of feedstock for bioenergy production in anaerobic digestion

\begin{tabular}{|l|l|l|}
\hline \multicolumn{1}{|c|}{ Agriculture } & \multicolumn{1}{c|}{ Communities } & \multicolumn{1}{c|}{ Industry } \\
\hline $\begin{array}{l}\text { Manure (Cattle, pig, } \\
\text { poultry) }\end{array}$ & $\begin{array}{l}\text { Organic Fraction of Municipal Solid } \\
\text { Waste }\end{array}$ & Food/beverage processing \\
\hline Energy crops & Sewage Sludge & Dairy \\
\hline Algal biomass & Grass clippings and garden waste & Starch and sugar industry \\
\hline Harvest remains & Food waste & $\begin{array}{l}\text { Biochemical/pulp and paper } \\
\text { industry }\end{array}$ \\
\hline
\end{tabular}

Nature of feedstock has interdependence connection with various aspects of anaerobic digestion like design of reactor, quality of products, bacterial physiology and economic consideration, Figure.2.2 shows all impacted aspects of anaerobic digestion by the composition of feedstock. Anaerobic digestion is a metabolic process of microorganisms and it is obvious that wastes with high concentration of polymeric components needs a different reactor design comparing to a readily biodegradable waste with high concentration of volatile fatty acids. In anaerobic digestion, the time for digestion process for different components of waste varies.

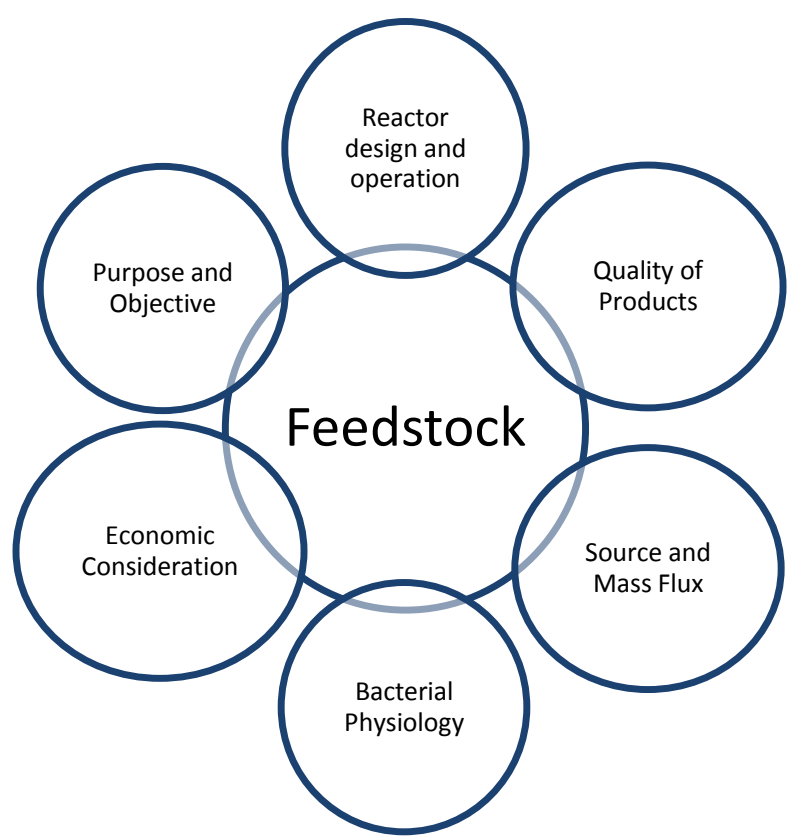

Figure 2.2. Various aspects of anaerobic digestion influenced by feedstock composition (Steffen et al., 1998) 
For example, carbohydrates like low molecule sugar, alcohols and volatile fatty acids digests in much higher rate taking few hours while hemicelluloses, fats and proteins degradation takes few days but for lignin component or cellulosic material it might take weeks or even the digestion might be negligible.

The quality of anaerobic digestion products also relates to the feedstock source and composition, as the final products of the process are bioenergy (methane) and soil conditioner (digestate) the composition and quality of feedstock needs a comprehensive assessment.

In anaerobic digestion, the economic feasibility should be also considered. For example, if treatment of a waste needs sophisticated expensive equipment, its financial and environmental benefits should be compared with its cost. For example the anaerobic digestion in order to be cost effective the concentration of organic matter (COD) must be at least 1500-2000 mg/L (Elbeshbishy, 2011). The objective of anaerobic digestion is not mainly bioenergy and soil conditioner production, for example the aim of treating wastewater from industry is to decrease the COD concentration in the effluent while for organic fraction of solid waste the objective of anaerobic digestion is to divert waste from landfill and convert the waste to value-added products (Steffen et al., 1998).

\subsection{Advantage and Disadvantage of AD}

Biological treatment of waste to value-added products have been one of the leading approaches for waste management as it has negligible impacts on environment comparing to other waste management methods like incineration and landfilling (Naroznova et al., 2016). In biological treatment, the implementation of $\mathrm{AD}$ is an energy efficient process as it converts organic wastes to bioenergy and the environmental impacts are much less comparing to other biological treatments such as composting. Composting requires large area and release odor that comes from volatile organics and might cause severe health problems.

Table 2.2. Advantage and disadvantage of anaerobic digestion comparing to other biological treatments

\begin{tabular}{|l|l|}
\hline Advantages & Disadvantages \\
\hline Lower energy needed & Longer startup time \\
& \\
\hline Lower sludge production & Might require alkali addition \\
\hline
\end{tabular}




\begin{tabular}{|l|l|}
\hline Smaller amount of nutrients needed & Further treatment needed prior to disposal \\
\hline $\begin{array}{l}\text { Biomethane produced as a renewable energy } \\
\text { source }\end{array}$ & $\begin{array}{l}\text { Biological phosphorus and nitrogen removal } \\
\text { is not possible }\end{array}$ \\
\hline Smaller reactor volume & $\begin{array}{l}\text { Sensitive to the environmental factors like } \\
\text { temperature effect on reaction rates }\end{array}$ \\
\hline Smaller carbon footprint & Potential of odor production \\
\hline Effective pre-treatment process & High retention time \\
\hline
\end{tabular}

Anaerobic digestion comparing to other waste management has many advantages that surpass its disadvantages. The main advantages associated with anaerobic digestion are reducing greenhouse gas emissions by providing a renewable source of energy biomethane production, reduce the risk of soil and water pollution that come from other methods of waste management, reduced sludge volume, converting waste to value added products, reducing odor up to $80 \%$ that is common with other management methods, destroy pathogen, weed and seeds in the final product and having a small foot print in environment. The major drawbacks associated with anaerobic treatment of wastes are mainly slow process which requires longer processing time, high capital and operation costs and longer start up time due to low growth rate.

The AD beside all its benefits, accompanied by some risks and disadvantages. AD plants come with a huge capital, operation and maintenance cost. It can have some risk and negative environmental impact like odor production which is a nuisance for neighbors. Its location should be selected considering the travel distance to decrease the emissions from transporting cars and also cost of the operation. Also as AD deals with organic waste as feedstock and biogas as a production during the process it can be cause health problems from pathogens or it might cause explosion and fire if designed or managed improperly.

\subsection{Anaerobic Digestion Systems}

According to the process design anaerobic digestion system is divided in two main components, low rate systems and high rate systems. Low rate systems that means long retention time is used for wastes like slurries and solid waste which needs more time for the digestion process and high rate systems which has shorter hydraulic retention time is mainly used for wastewater. In low rate systems, the HRT and SRT are similar but for high rate system the SRT should be much 
longer than HRT. This means that in high rate the system is designed to preserve the mass of bacterial sludge or separated it and relocate it back in the reactor. High rate systems are divided in to suspended bacterial mass and fixed bacterial films (Wijffels \& Barten, 2003). For low rate systems common reactors are batch, accumulation, plug flow and most commonly used reactor CSTR. In high rate system contact process, anaerobic filter, fluidized bed and up-flow anaerobic sludge bed (UASB) and expanded granular is commonly used.

Based on solid concentration in the substrate the systems classified into wet fermentation and dry fermentation. For substrates with solid concentration of $15-25 \%$ wet fermentation is used and for substrates with concentration of TS higher dry fermentation is used. Figure 2.3 depicts the schematic overview for solid and slurry waste.

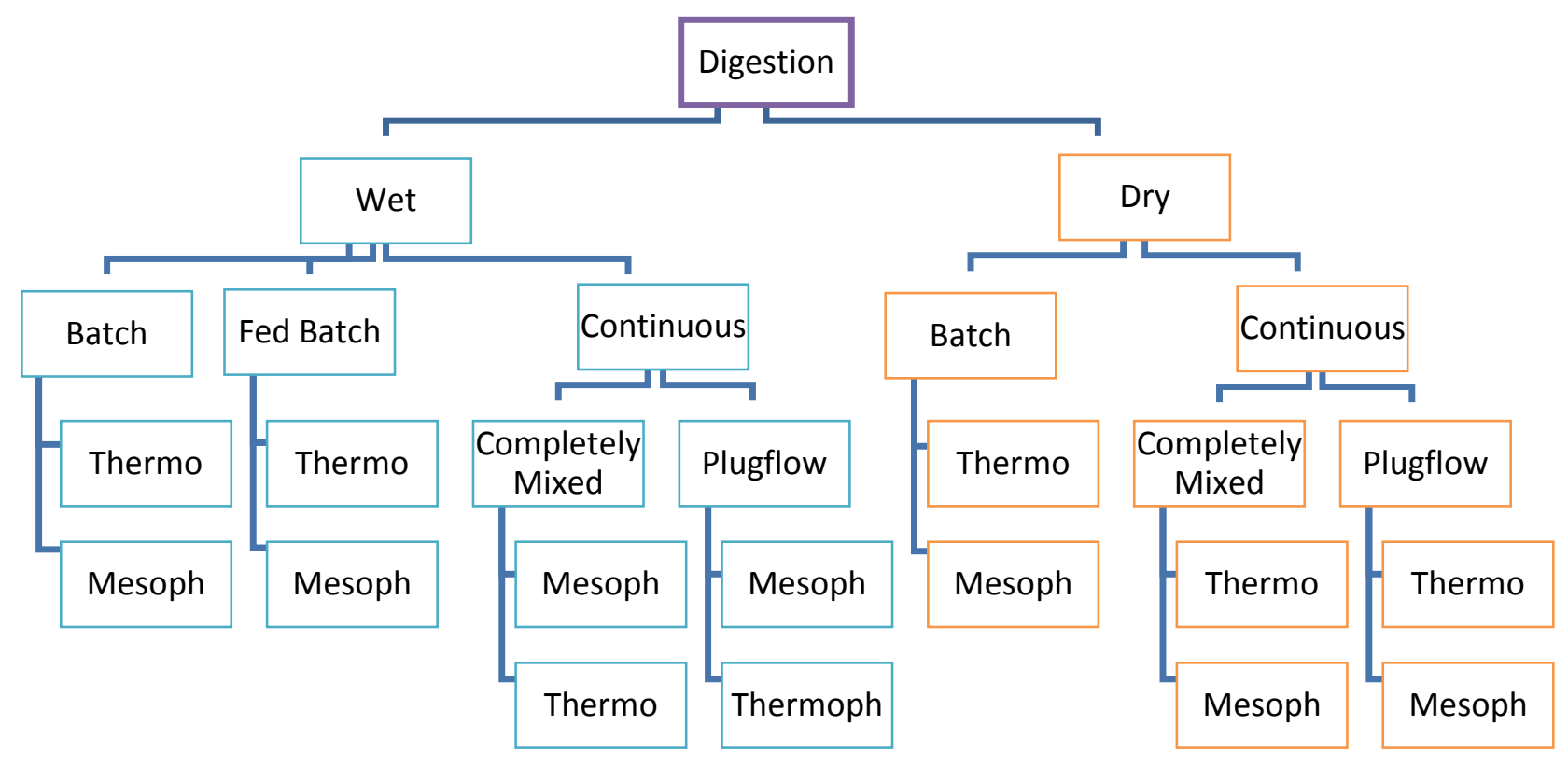

Figure 2.3. Digestion systems for waste with different total solid contents

CSTR reactors are one of the most common reactor for wet low rate digestion systems and they are used to treat feedstock with $2-10 \%$ total solid concentration. The substrate mixing likelihood and methane yield comparing to the energy needed are important parameters in select SCTR 
reactor. Mixing in the reactor ensures a homogenous substrate and equal availability of substrate to microorganism and prevents stratifications and use is different mixing methods like mechanical mixing or effluent gas mixing as it is represented in Figure 2.4. This reactor is usually used to treat waste from wastewater treatment plants, animal manure, and food waste and use them for co-digestion. 


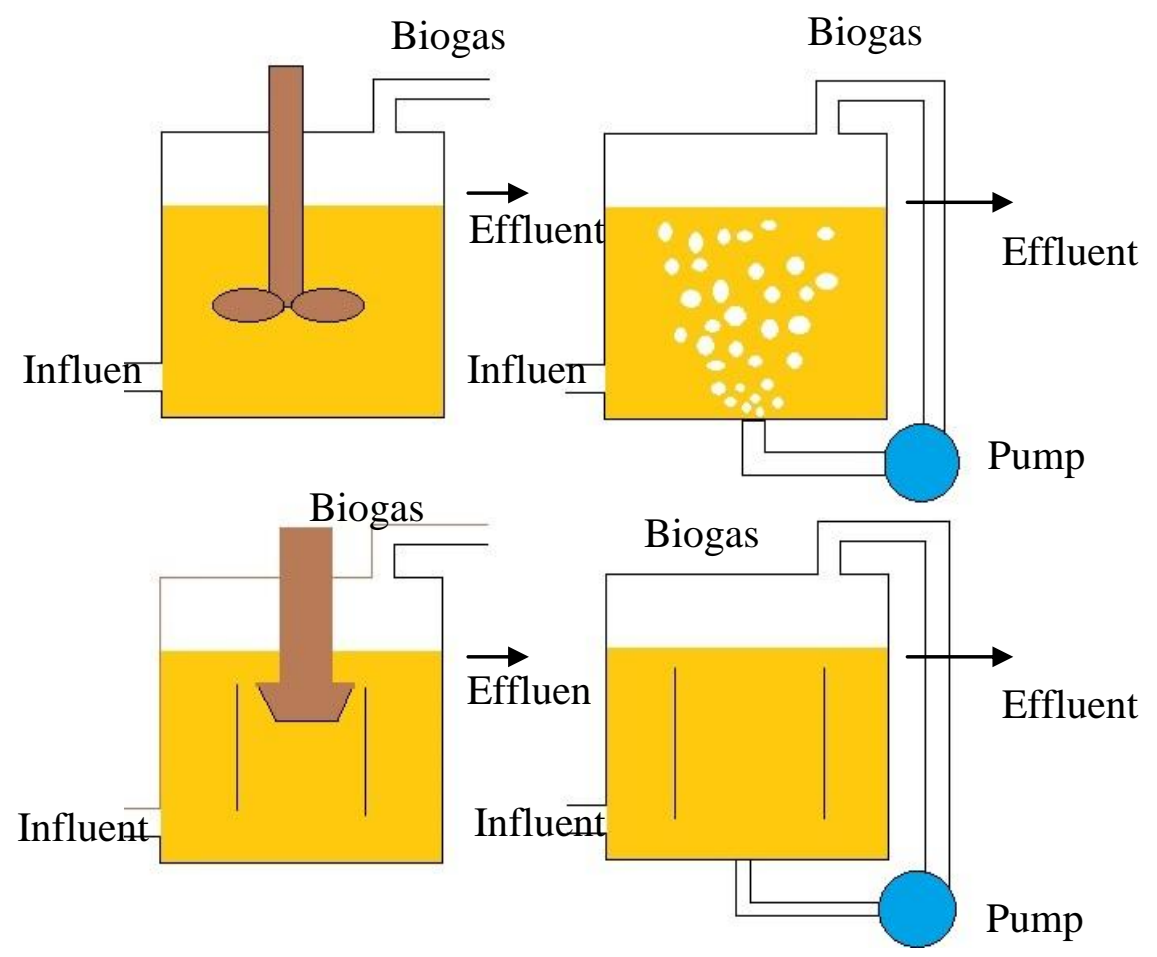

Figure 2.4. Digestion systems for waste with different total solid contents

Plug flow digesters are another example for law rate digestion systems. This digester has the capability of working with wastes with higher TS concentration (10-12\%). It is a long horizontal digester that often build underground and the anaerobic digestion steps (Hydrolysis, Acidogenesis, Acetogenesis and Methanogenesis) are separated overt the length of the reactor. This reactor is suitable for wastes with high suspended solid concentration but low loading rate should be used.

UASB is one of the highly used technology for high rate anaerobic digestion system treating wastewater. It has the ability to retain high concentration of biomass, operate in short HRT and due to its compact design, it occupies a small space. A dense granular sludge bed is in the middle of a UASB reactor and it is formed by accumulation of microbial growth and suspended solids. Within the granular sludge bed the organic part of a waste or wastewater converts to biogas and in the top part of the reactor a three phases separator is used to separate the biogas and the solids from the liquid. More than $65 \%$ of the industrial wastewater is being treated by using the UASB technology worldwide. 
In anaerobic digestion, the processing parameters for microorganism have different optimum conditions in each stage of the process. For example, the shorter HRT and lower pH which is a suitable condition for acid forming bacteria while it is different for methanogenesis bacteria. Thus, it is difficult to provide the optimum processing parameters for all stages of anaerobic digestion in a single reactor. In a conventional system the acid forming and methane forming microorganisms are in a single environment while having widely difference in optimal parametric conditions like growth kinetics, physiology, nutritional needs and environmental conditions (Demirel \& Yenigün, 2002).

Two stage and multistage digestion systems are favorable comparing to single stage AD. In two stages digestion, the hydrolysis and acidogenesis phase is separated with acetogenesis and methanogenesis stage. Optimizing the two stage anaerobic reactors leads to a higher biogas

yield, higher reaction rate and higher solid reduction (Demirer \& Chen, 2005). Two stage digestion systems need higher capital and operating cost comparing with single stage digestion system. Two stage digestion systems are more effective in waste with suspended solid concentration $>10 \%$ which are less biodegradable, its effect on readily biodegradable waste is negligible (Liao et al., 2006).

\subsection{Pretreatment Methods}

Anaerobic digestion is valuable treatment methods for organic waste but the one problem associated with $\mathrm{AD}$ process is the long retention time and low degradation efficiency which result in large reactor volume. As explained $\mathrm{AD}$ is a microbiological process involving different steps, the first step of $\mathrm{AD}$ (Hydrolysis) that microorganisms solubilize the organic matter is considered the rate limiting stage for waste with high total solid content such as waste activated sludge. In hydrolysis stage the macromolecular organic matters degrades by rapturing cell walls and releasing intracellular matters readily available for acidogenesis bacteria. This process is vital for $\mathrm{AD}$ and improving it can help the overall process objectives. In order to enhance the AD different pretreatments have been studied to improve the hydrolysis stage by increase the specific surface area of the substrate using mechanical pretreatment and converting insoluble organic polymers to soluble monomers and make it available for microorganisms to accelerate the AD. All Pretreatment methods can cause the followings to the substrate; reduce the particle size, 
improve solubilization and biodegradability, improve dewaterability of the waste and formation of refractory substances (Carlsson et al., 2012).

\subsubsection{Mechanical pretreatment}

The particle size of organic waste has an important role in the efficiency of AD process and biogas production. Mechanical pretreatment is one of the effective ways to improve the AD by breaking down the particles and increase the availability of active surface area of substrate to microorganisms and accelerate the digestion process. It has been widely studied and there are different technologies available for reducing the particle size such as stirred ball mills, simple grinders, ultrasonic pressure, high pressure homogenizers and shear-gap homogenizers.

A study was done on mechanical pretreatment and size reduction of WAS using stirred ball mills, high pressure homogenizers and shear gap homogenizers. It is findings suggest that the degradation improved by $20 \%$ in 4 days and the digestion time reduced (Raman et al., 2013). Although mechanical pretreatment of waste enhances the proportion of soluble COD and increase the biogas production rate but cannot increase the VSS removal efficiency of AD which means ultimate biodegradability of waste was not changed. Another observation reported in mechanical pretreatment is that it cannot improve the dewaterability of sludge. This finding is in contrast to other pretreatment technologies that increase not only the solubilization and biogas production but also the dewaterability (Toreci, 2008).

Ultrasound is a mechanical pretreatment that is basically sound waves with frequencies higher than the audible limit of human hearing. The range of frequency for ultrasound is between 20 $\mathrm{kHz}$ and $10 \mathrm{MHz}$. Ultrasonic pretreatment use cavitation process to disintegrate the cell walls. Application ultrasound in lower frequency range 20 to $40 \mathrm{kHz}$ creates small bubbles called cavitation bubbles in an aquatic environment and causes cavitation by pressure decrease lower than the evaporation pressure. Cavitation causes shear stress forces by compression and rarefaction on the substrate and temperature raise that can rapturing the cellular wall and increase the solubilization of the biomass feedstock.

Research studies have reported that ultrasonic pretreatment disintegrate particulate matter and enhance the biomethane production and VS reduction. In a study on WAS ultrasound pretreatment for $30 \mathrm{~min}$ in $9 \mathrm{kHz}$ frequency result in $64 \%$ increase in methane production 
comparing to the control (Ge et al., 2010). In another experiment it was reported that ultrasound pretreatment in $41 \mathrm{kHz}$ improved the WAS disintegration by $80 \%$ and by increasing the frequency it negatively impacted the disintegration process which shows lower frequencies are more suitable than higher frequencies and it was also report that the ultrasound pretreatment time is an effective parameter in the process (Raman et al., 2013).

High pressure homogenizer is another technology used as mechanical pretreatment that increase the pressure of the substrate to 900 bars and lead it to a homogenization valve with a high force of depressurization. This method has been utilized in large scale where sludge is exposed to a pressure of $150 \mathrm{bar}$ and later send to digester. This method enhanced the biogas production by $30 \%$ and volume of sludge reduced by $23 \%$ (Carrère et al., 2010). Using pressure as the base of pretreatment has been carried out in other technologies like Micro-sludge process. In this process, first the $\mathrm{pH}$ is increased to 11 or decreased to 2 in order to increase the fragility of the cellular walls to pressure. In this process after $\mathrm{pH}$ control a pressure of $850 \mathrm{bar}$ is introduced to the sludge and this method is already used in Los Angles WWTP.

\subsubsection{Chemical Pretreatment}

Some chemicals also used as a pretreatment method for dissolution of cell walls and increasing the solubility of organic matters. The most common chemicals used to hydrolyze the cell walls are acid and alkali, hydrogen peroxide, ozonation and fenton reaction which is an oxidation method. Alkaline pretreatment has been more investigated in $\mathrm{AD}$ as it is also required in the $\mathrm{AD}$ process and mostly they used alkaline as $\mathrm{NaOH}$ and $\mathrm{Ca}(\mathrm{OH})_{2}$. In alkaline pretreatment, the cell wall of extracellular polymeric substances disrupted and it release solubilize intercellular organics. It is reported as an effective pretreatment method to improve the hydrolysis of WAS and increase the soluble COD (Neumann et al., 2016). In a study that evaluate the effect of alkaline on dissolution of hemicellulos in wheat straw concluded that $1.5 \%$ of alkaline $(\mathrm{NaOH})$ for 144 hours at a moderate temperature of $20{ }^{\circ} \mathrm{C}$ could result in release of lignin and hemicellulose by $60 \%$ and $80 \%$ respectively. Sodium hydroxide pretreatment also shows an improve biogas production of $37 \%$ from corn stover comparing to non-pretreated. In a research that used lime for pretreatment of leafstar rice straw it c exclude the solid liquid separation step and using the carbon dioxide as neutralizer end up in $89 \%$ glucose recovery. 
A pilot-scale study on the effect of low alkaline addition as $\mathrm{NaOH}$ for a co-digestion of primary sludge and WAS has been performed and it was reported that VSS destruction was not improved although biogas production was enhanced (Xu et al., 2014). The effect of alkaline pretreatment on WAS was also studied in a pilot scale showing a reduction in SRT from 25 to 10 days without affecting the quality of the effluent (Alqaralleh, 2012). A study has conduct an experiment to study the thermal, chemical and thermochemical pretreatment and it was reported that combination of thermal and chemical pretreatment increased the anaerobic digestion of waste activated sludge (Dhar et al., 2012).

Ozonation is also a chemical pretreatment method. Ozone is a strong oxidant that oxidize soluble and particulate matter in the feedstock and only $5 \%$ of the organics present in feedstock shows resistant to it. Ozone oxidation happens by interacting with the unsaturated bonds and also creating radicals to react with other organics. It helps to reduce the particle size, enhance solubilization by disintegrating the cell membrane and releasing intercellular water. Ozonation also reduce the viscosity of the substrate and enhance the settling properties of the sludge (Bougrier et al., 2007). But high concentration of ozone in the pretreatment can negatively impact the solubilization as it can react with solubilized compound. The optimum range of adding ozone was suggested to be $0.1 \mathrm{~g}$ of ozone / $\mathrm{g}$ COD. Hydrogen peroxide can also be used as an oxidant for pretreatment of sludge. Hydrogen peroxide with heat could enhance the COD removal efficiency at $90{ }^{\circ} \mathrm{C}$ while with the same concentration in $37{ }^{\circ} \mathrm{C}$ its effect is negligible (Carrère et al., 2010).

Decreasing the value of $\mathrm{pH}$ using an acid is also a chemical pretreatment to enhance the biogas production and dewaterability of the sludge. For acidic hydrolysis different acids like $\mathrm{HCl}$, $\mathrm{H}_{2} \mathrm{SO}_{4}, \mathrm{H}_{3} \mathrm{PO}_{4}$ and $\mathrm{HNO}_{3}$ can be used to reduce the $\mathrm{pH}$, in a study that used $37 \% \mathrm{HCl}$ to control the $\mathrm{pH}$ of TWAS and after reaching the desired $\mathrm{pH}$ it was kept for 24 hours. In this study, the effect of $\mathrm{pH}$ on TWAS was concluded that decreasing the $\mathrm{pH}$ to 2 can enhance the solubilization of carbohydrate and protein which result in higher biogas production in batch and semi continuous $\mathrm{AD}$ systems. It was also observed that in this $\mathrm{pH}$ value it increase the sludge dewaterability as 40\% lower polymer was required (Devlin et al., 2011). The primary characteristics determine the effectiveness of pretreatment. Acidic pretreatment has higher effectiveness for lignocellulosics biomass comparing to alkali pretreatment. The chemical 
reaction in acidic pretreatment is the hydrolysis of hemicelluloses that degrades to sugar and soluble oligomers. But this method can also provoke the formation of inhibitory compounds like furfural which hinder microbial fermentation. Another problem associated with this pretreatment method is the corrosion as the $\mathrm{pH}$ is low it needs special material for the vessel and also it can cause a toxic environment for bacteria. For solving this problem and keeping the efficiency of the process acidic-thermal pretreatment is suitable (Devlin et al., 2011).

\subsubsection{Biological Pretreatment}

Degradation of substrate by enzymatic method using different types of fungi and bacteria to prepare it for anaerobic digestion is called biological pretreatment. In this approach, the type of substrate for example house hold waste or industrial waste is an important factor in selecting the types of microorganism and enzyme. Biological pretreatment process can be aerobic, anaerobic and specific enzyme addition like peptidase and lipase. This first stage of a two stage anaerobic digestion is also considered as a biological pretreatment method as physical separation of amidogens from methanogens results in higher methane production in shorter HRT (Hartmann \& Ahring, 2006).

Aerobic pretreatment such as micro-aeration and composting induces the production of hydrolytic enzymes, therefore it is considered an efficient method for waste with complex organic matter. As it is reported in a study that composting can enhance the microbial growth rate to $160-205 \%$ in a comparison to untreated organic fraction of municipal solid waste (The effect of different pretreatments on biomethanation kinetics of industrial). In another study that aerobically the residual of sisal leaf decortication and pure culture of fungi was added it showed that aerobically incubation of the feedstock for 4 days increased the methane composition and result in higher cumulative biogas production.

Two stage AD which includes the hydrolytic acid-genic stage and methanogenic stage has can enhance biogas production. In an experimental research on easily biodegradable waste (vegetable waste) was used as a feedstock in a mesophilic and thermophilic two stages AD and the results show that two stage convert $90 \%$ of waste to biogas. A two stage AD has many advantages like easier $\mathrm{pH}$ control, higher organic loading rate, higher methane production, enhanced VS reduction and pathogen removal (Hartmann \& Ahring, 2006). 
Biological pretreatment is considered an effective way for pretreating the waste regarding the energy use and no chemicals addition which has mild environmental effects, but in most biological treatments the efficiency of pretreatment is lower comparing to other pretreatments.

\subsubsection{Hydrothermal Pretreatment}

Hydrothermal pretreatment (heat pretreatment) is a process of temperature increase to a certain limit for a certain time (retention time) to improve the solubilization, degradability (biogas production) and dewaterability of the waste. It is a well-established and one of the most successful pretreatment methods that have been applied in large scale within wastewater treatment plants. Thermal pretreatment enhance the anaerobic degradability of waste, remove pathogens, reduce the viscosity and particle size, increase the dewaterability of digestate which leads to enhancement of subsequent digestate management and also one of most feasible pretreatment according to energy (Ariunbaatar et al., 2014). Hydrothermal pretreatment reduces the fuel consumption in sludge dewatering and also lower transportation cost as it reduces volume and also can produce class A biosolids that can present in market as a valuable product (Climent et al., 2007).

In hydrothermal pretreatment, rapid rise in temperature cause the particulate matters to break down and release the soluble cell components. During the high temperature pretreatment, the released soluble organics can reacts physically and chemically and form new components. Physical properties after pretreatment like dewaterability, particle size and viscosity are used as a qualitative measurement of hydrothermal pretreatment. For example the dewaterability of sludge relates to the availability of extracellular components; high concentration of extracellular polymers makes it difficult to dewater the sludge (Neyens \& Baeyens, 2003). Extracellular matters in waste are very hydrated, almost $98 \%$ water which prevents the desiccation in regular conditions. Thermal treatment can help to release the bound and intercellular water from extracellular matter as many different physical and chemical reactions happens when temperature increases. For example, fast temperature raise increases the molecular activity and cause the collision of particle matters which break the gel structure and release bound water. This raise in temperature also rapture the cell walls of microorganisms and particulate matters which release the intracellular water (Pilli et al., 2015). The temperature is one of the parameters that can be used in some chemical reactions as a catalyst. In order to discuss the effects of 
temperature on chemical properties of the waste it has to be discussed on its effect on soluble organic compounds and its biodegradability. The raise in temperature can break the wall and release intercellular water and break the bonds of polymers like proteins and polysaccharides and solubilize the organic components of the waste. The main composition of wastes are fats, carbohydrates and protein. The effect of temperature on each component is different as the strength of the cell wall varies. Carbohydrate exposed to rapid temperature increase shows higher degradation comparing to protein and fats but overall the concentration of sugar and soluble protein shows a rapid increase after thermal pretreatment. In a study on effect of temperature on physical and chemical properties of the waste it was reported that by temperature increase above $170{ }^{\circ} \mathrm{C}$ melanoidins forms and it is relative to carbohydrate concentration (Liu, Wang, Gao, Zhou, \& Shen, 2012b). It was also reported that temperature increase after a certain degree (temperature reported varies according to the substrate properties) inhabits the biomethane production due to some reactions between soluble protein and soluble carbohydrate called Millard reaction, during the thermal pretreatment.

Hydrothermal pretreatment breakdown the particle matters and disintegrates cell membrane which release intracellular organics and increase the solubilization of organic matters. The main effecting parameters to achieve this objective are the pretreatment temperature and retention time, COD solubilization shows a direct relation with temperature increase and longer retention time (Ariunbaatar et al., 2014). Mostly hydrothermal pretreatment is used to increase the dewaterability and enhance anaerobic biodegradability of sludge.

The thermal energy to increase the temperature of the substrate in industry mostly achieved by steam injection to the heat exchangers. The pretreated substrate passes again through heat exchangers in the cooling process to decrease the substrates temperature to the digester and use its heat to preheat the new substrate. This is an effective way to decrease the amount of energy and increase energy efficiency of hydrothermal pretreatment and make it economically more feasible.

The SI is an important parameter for system design as it helps to evaluate the two important variables of temperature and retention time during thermal pre-treatment into one single parameter and it also might show the energy balance of operation. 
Hydrothermal pretreatment generally divided into two main group regarding to the pretreatment temperature. Pretreatment conditions which is below $100^{\circ} \mathrm{C}$ is considered low temperature pretreatment and pretreatment conditions above $100^{\circ} \mathrm{C}$ is high temperature pretreatment.

High Temperature Pretreatment: During the years of 1960s and 1970s hydrothermal pretreatment become the main method to increase the dewaterability of the sludge. The Operating temperature for hydrothermal pretreatment were between $200^{\circ} \mathrm{C}$ and $250^{\circ} \mathrm{C}$ but due to problems like high odor production and corrosion in heat exchangers later it was stopped, but one of the project called Zimpro modified the treatment temperature and it is still operating to improve the dewaterability of sludge (Pilli et al., 2015). Later the combined pretreatment methods using thermal and chemical technologies emerged in 1980s but could not commercialized due its economic feasibility. Later in 1990s another hydrothermal pretreatment was developed which is called CAMBI and BIOTHELYS. They are both high temperature pretreatment method which become commercialized. CAMBI process is a three stages process starting with a preheating tank which increase the temperature of sludge to nearly $100^{\circ} \mathrm{C}$ and eliminate the pumping and corrosion problems. The process is shown in figure 2.5 (Pilli et al., 2015). The second stage is the steam reactor (steam under pressure introduced to the sludge) and the third stage is the flash tank that release the pressure briskly. The sludge pre-dewatered in CAMBI process to $14-18 \%$ dry solid and preheating tank receive its thermal energy from returning steam from second and third stage. In the steam reactor, the sludge is heated by direct steam for $20-30$ mins in batch mode to reach $160^{\circ} \mathrm{C}$ and 12 bar pressure than the pressure decrease to 2 bar and sludge goes to the third stage (flash tank). This rapid decrease in pressure and flashing the sludge to flash tank rapture the cell and increase the solubilization. The sludge temperature decreases in the flash tank to the digester and this process reduces the SRT from 1530 days to 10-12 days and it enhance the biogas production and dewaterability of sludge by 3040\% (Pilli et al., 2015). 


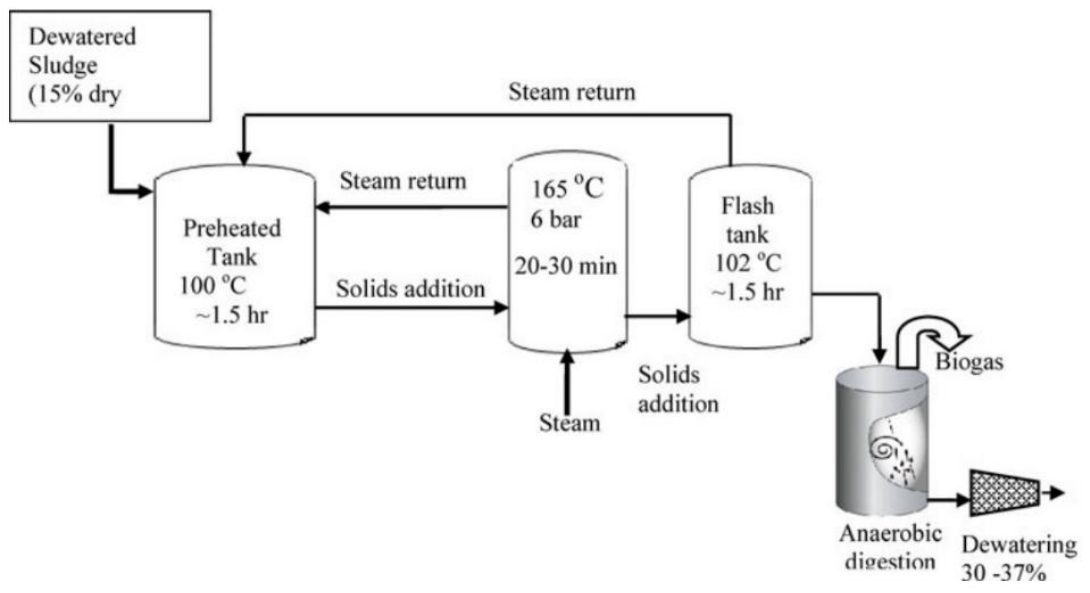

Figure 2.5. Process flow diagram (Cambi Process)

The objective of BIOETHELYS process which is the result of a decade work by Veolia Water Solutions and Technologies is to increase the digestibility of sludge by improving the solubilization of organics in the waste and overall enhance the biomethane production during anaerobic digestion. In BIOETHELY process same as Cambi, it is pre-dewatered to $15-16 \%$ dry solid and it is consists of a hydrolysis reactor that the temperature of sludge increases to 150 $180^{\circ} \mathrm{C}$ with direct steam injection. The sludge is heated for 30-60 mins and the hydrolyzed sludge is removed by the remaining pressure and cool down to the $35^{\circ} \mathrm{C}$ for anaerobic digestion. For energy efficiency two batch reactors work in parallel and the released steam from one reactor is used to preheat the other reactor. BIOETHELY process reduce the volume of sludge by $80 \%$ comparing to non-pretreated sludge and increase the biogas production and sludge retention time (Pilli et al., 2015).

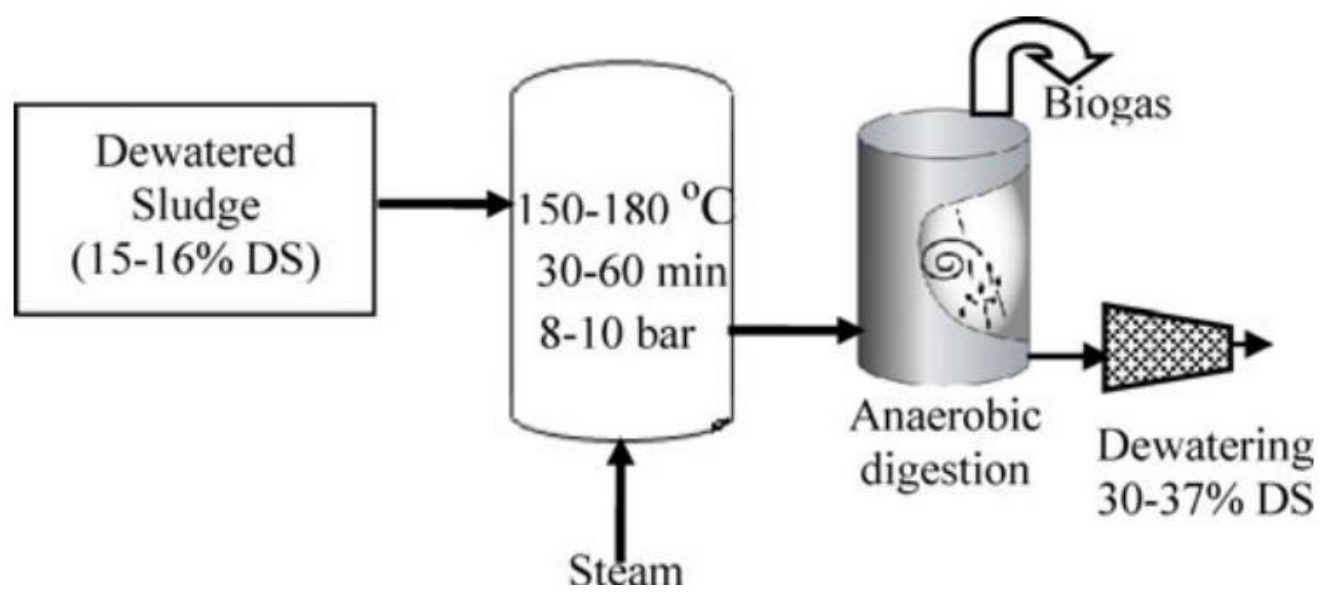

Figure 2.6. Process flow diagram (BIOTHELYS Process) 
Low Temperature Pretreatment: Low temperature pretreatment of organic waste is not effective in degrading complex organic matters comparing to the high pretreatment temperatures. Barjenbruch and Kopplow reported that pretreatment at temperature lower than $90^{\circ} \mathrm{C}$ only prevents the flocculation of macromolecules and Neyens and Bayens concluded that lower temperature results in solubilization of carbohydrates and proteins. Although low temperatures cannot enhance the biodegradability of waste or dewaterability of digestate comparing to high temperature pretreatment but it has a vital effect on pathogen removal. The EU regulation EC1774/2002 mandates pretreatment of organic solid waste in a temperature of $70{ }^{\circ} \mathrm{C}$ for an hour to pasteurized/sterilized before or after anaerobic digestion (Ariunbaatar et al., 2014). Many studies have investigated the low pretreatment temperature on various waste.

Research show that range of optimal temperature varies according to the prime characteristics of the feedstock. In a thermal pretreatment study on food and fruits waste and vegetable waste pretreatment temperature of $175^{\circ} \mathrm{C}$ obtained lower biomethane yield by $7.9 \%$ and $11.7 \%$ respectively (Liu et al., 2012a). Some other studies on sludge show that thermal pretreatment temperature higher than $180^{\circ} \mathrm{C}$ improved the sludge dewaterability and lead to $40-80 \%$ biogas production increase (Bougrier et al., 2008). It was also reported in some experimental studies that pretreatment temperature higher than $200^{\circ} \mathrm{C}$, it negatively affects and the AD produce toxic and refractory compounds and result to polymerization (Liao et al., 2006; Dhar et al., 2012). (Kim et al., 2015a) shows that pretreatment temperature of $210^{\circ} \mathrm{C}$ is the optimal condition for biomethane production from waste activated sludge.

Microwave Pretreatment: Beside conventional thermal pretreatment, microwave pretreatment is also an efficient thermal pretreatment method that has been widely studied. In conventional heating the mechanism of heat transfer occur due to the thermal gradient which particles with higher heat energy transfer its heat to particles with lower heat energy. This kind of heat transfer can cause a problem in pretreatment of the substrate as it cannot distribute the heat uniformly. Microwave heating has been studied to solve this problem associated with conventional heating. Microwave heating is a pretreatment method that use microwaves for example for sludge decomposition a frequency of $2.45 \mathrm{GHz}$ is being used to save energy and also to destroy pathogens (Koupaie et al., 2018). Microwave radiations produces rapidly directed heat that 
ensure loss of energy and also by changing the orientation of polar molecules it causes athermal effect which combine with its thermal effect it can break hydrogen bond from organic macromolecules. In a study on TWAS the effect of microwave pretreatment was observed on the soluble COD and its result shows that soluble COD increased from 0.06 to 0.18 after pretreatment in $96{ }^{\circ} \mathrm{C}$. Microwave pretreatment is an effective method to produce class A digested as it has shown a crucial effect on destruction of pathogens. In another study on WAS after microwave pretreatment at $85{ }^{\circ} \mathrm{C}$ and mesophilic AD in 2006 it produced class A digested (Koupaie et al., 2018).

The only problem that is associated with microwave pretreatment is the depth of its penetration. Electromagnetic waves cannot penetrate deeply in the substrate and the heating effect is uninformed. Studies shows that the method of thermal pretreatment does not significantly impact the solubilization and biomethane production. In a study that observe the impact of microwave and conventional heating it shows that the solubilization rate were symmetrical although the biogas production was higher in microwave heating. In another study that compare the steam heating with electric heating it shows that their effects are equal. A study in university of British Columbia in 2018 observed the effect of three thermal pretreatment methods; conventional heating, microwave heating and radio frequency. It also concluded that the method of thermal pretreatment is not the determining factor in AD performance (Koupaie et al., 2018).

\subsection{Effect of Hydrothermal Pretreatment on Anaerobic Biodegradability of Waste}

The properties of waste differ according to the source, location and even season of the year. But the overall composition of waste shows that it consists of organic and inorganic matters. The organics which are important component in anaerobic digestion is mostly composed of carbohydrates, proteins, lipids and ribonucleic acids (RNA). In a wastewater treatment plant, produced sludge has following percentage compositions; 10\% Carbohydrates, 50\% Protein, 10\% lipids and 30\% others while for different waste stream the combination varies (Pilli et al., 2015). In an organic processing facility like food waste the properties of the component can vary according to the food culture, for instance, vegetable and fruit waste in China and Turkey has different composition, representing $80 \%$ and $70 \%$ of food waste respectively. In food waste which forms the large portion of organic waste has 2-3\% meat component and $\mathrm{C} / \mathrm{N}$ ratio varies between the ranges of 14 to 37 (Parthiba et al., 2017). The studies reveal that elevated 
temperature on waste can end up to various effects on the properties of waste and its biodegradability in anaerobic digestion process, because waste has a complex composition that shows different reaction with temperature increase. To the best knowledge of author thermal pretreatment of SSO has not been studied in this regard the effect of thermal pretreatment on kitchen waste and food waste as the main portion of SSO will be discussed in the following pages.

Different studies have investigate the hydrothermal pretreatment on a wide range of organic waste (mainly sludge and lignocellulosics waste) within diverse pretreatment temperature (range $60-270{ }^{\circ} \mathrm{C}$ ) and retention time, although no systematic research has been done on various temperature and retention time (Climent et al., 2007). In a research study by Stuckey in imperial college of London that evaluate the effect of thermal pretreatment on WAS it was reported that pretreatment can enhance the biodegradability of WAS up to $27 \%$ comparing to the control. This study evaluated the anaerobic bioconvertability of WAS after pretreatment in a range of (150$275^{\circ} \mathrm{C}$ ) and the optimum condition for enhanced biogas production was reported to be $175^{\circ} \mathrm{C}$ and 1 hour retention time. In the thermal pretreatment, the temperature raise increase $3{ }^{\circ} \mathrm{C}$ per minute and at the end of the pretreatment the temperature was rapidly decreased and the sludge was exposed to nitrogen to prevent oxidation of volatile matter. It is reported that higher pretreatment temperature harshly decrease the biogas production and lower temperatures cannot release the organics present in bacterial cell to expose it for degradation during AD (Stuckey \& McCarty, 1984). In a more recent study in 2015 on WAS in Konkuk University that evaluate the enhancement of biogas production in $\mathrm{AD}$ by hydrothermal pretreatment also reported that $\mathrm{AD}$ enhances the solubilization of WAS which end up to higher biogas production. In this study WAS was exposed in a wide range of pretreatment temperature $\left(150-270{ }^{\circ} \mathrm{C}\right.$ ) that shows hydrothermal pretreatment improved the SCOD concentration by 30-37\% comparing to nonpretreated and the optimum pretreatment condition according to the temperature was suggested to be $180{ }^{\circ} \mathrm{C}$ and $210{ }^{\circ} \mathrm{C}$ by $130 \mathrm{ml} / \mathrm{mg}$ VS and $126 \mathrm{ml} / \mathrm{mg}$ VS. It was also observed that after thermal pretreatment the methane composition in biogas increased (58\%-60\%) (Kim et al., 2015b). In another study carried out in China evaluate the low and high temperature thermal pretreatment on sludge and it was observed that thermal pretreatment increased the soluble organic concentration after long time low temperature thermal pretreatment after 24 hours. The low temperature pretreatment ranged from $60{ }^{\circ} \mathrm{C}$ to $90{ }^{\circ} \mathrm{C}$ and retention times were 24 to 72 
hours. In high temperature pretreatment $90{ }^{\circ} \mathrm{C}$ to $180{ }^{\circ} \mathrm{C}$ it was reported that retention time could not impact the SCOD significantly although 180 min including the heating time was reported to be the optimum retention time. In this study the optimum thermal pretreatment condition for the biogas production was $160{ }^{\circ} \mathrm{C}$ with $16.5 \%$ increase in biogas production and $180{ }^{\circ} \mathrm{C}$ adversely affect the biogas production and shows 6.3\% increase comparing to non-pretreated sample (Li et al., 2014).

(Donoso-Bravo et al., 2011) studied the effect of thermal pre-treatment on primary and secondary sludge, different temperature ranging from $120^{\circ} \mathrm{C}$ to $220^{\circ} \mathrm{C}$ and 1 hour retention time were investigated. This study revealed that pretreated temperature until $180^{\circ} \mathrm{C}$ showed a considerable increase in biogas yield; however, for temperature higher than $180^{\circ} \mathrm{C}$, it adversely impacted the biogas production (Carrère et al., 2010). On the other hand, (Kim et al., 2015a) studied the thermal hydrolysis pre-treatment on waste activated sludge in a range of $\left(150-270^{\circ} \mathrm{C}\right)$ and the results of the study announced that the optimal pre-treatment temperature for biogas production is $210^{\circ} \mathrm{C}$.(Xue et al., 2015) also studied the effect of thermal hydrolysis on high solid sludge concluded that best pre-treatment temperature for Biomethane production from high solid sludge is $120^{\circ} \mathrm{C}$ and $160^{\circ} \mathrm{C}$. All studies have focused on the enhancement of soluble organics with raise in temperature as in a study that evaluate the effect of temperature in a range 95-210 ${ }^{\circ} \mathrm{C}$ on five WAS samples collected from urban, industrial and slaughter house conclude that the solubilization increases with increase in temperature. Hydrothermal pretreatment also impact the biodegradability of the waste as it is reported that there is a linear relation between temperature increase and biomethane production although severe temperature can negatively impact the AD process (Liu et al., 2012b).

The effect of thermal pretreatment on municipal biomass waste that consists of kitchen waste, fruit waste and WAS have been studied and in this study it was observed that the biodegradability of WAS has been increased from $157.1 \mathrm{~mL} \mathrm{CH}_{4} / \mathrm{g}$ VS to $211.7 \mathrm{~mL} \mathrm{CH}_{4} / \mathrm{g}$ VS that shows $34.8 \%$ increase in biomethane production after exposing in pretreatment condition of $175{ }^{\circ} \mathrm{C}$ for 1 hour (Liu et al., 2012b).

The effect of thermal pretreatment of Kitchen waste on its anaerobic biodegradability as a major source of high organic waste has been also evaluated by a study in Tsinghua University in China. In this study kitchen waste with $90 \%$ composition of food waste and $10 \%$ paper and plastic was 
exposed to pretreatment temperatures of $55-160{ }^{\circ} \mathrm{C}$ with a retention time range $15-120$ minutes. This study observed that thermal pretreatment result in anaerobic digestion efficiency and the optimum pretreatment temperature and retention time was reported to be $120{ }^{\circ} \mathrm{C}$ and 15 minutes retention time (Li et al., 2016). The effect of Source Separated Kitchen Waste was pretreated by microwave high temperature and pressure with a heating rate of $7.9{ }^{\circ} \mathrm{C} / \mathrm{min}$ and mesophilic digestion shows a significant enhancement in organic solubilization and biogas production by $40 \%$ and $11 \%$ respectively.

Many research have also studied the thermal pretreatment effects on food waste. It was investigated in a research study that the concentration ratio of carbohydrate, protein and lipids significantly affect the biodegradability of the food waste and the optimum ratio for the highest biomethane production was reported to be carbohydrate $>8.3 \%$, protein $<5 \%$ and lipids $<5.6 \%$ ( $\mathrm{Li}$ et al., 2017). In a two stages fermentation study that investigate the pretreatment temperature on the biodegradability of food waste in six pretreatment temperature from $100{ }^{\circ} \mathrm{C}$ to $200{ }^{\circ} \mathrm{C}$ and short retention from 5 minute to 30 minutes has concluded that thermal pretreatment can enhance the organic solubilization and subsequently increase the biomethane production. In this study, the highest carbohydrate solubilization was observed in $140{ }^{\circ} \mathrm{C}$ and further increase in pretreatment temperature result in lower soluble carbohydrate due to Millard reaction and formation of melanoidins. It was also observed that thermal pretreatment can also increase the soluble protein. The highest biomethane production reported in this study was observed in pretreatment condition of $140{ }^{\circ} \mathrm{C}$ with a $31.9 \%$ increase comparing to the non-pretreated sample. Pretreatment temperature beyond $140{ }^{\circ} \mathrm{C}$ shows an antagonistic effect on biomethane yield (Ding et al., 2017). In a study by Ariunbaatar that explore the thermal pretreatment effect on food waste, determined that heat can result in significantly higher biomethane production. In this study, the pretreatment condition was set from $70-150{ }^{\circ} \mathrm{C}$ with 30 minutes and 1.5 hours retention time. In this study all the pretreatment conditions result in higher efficiency of biomethane production and the optimum condition was reported to be $80{ }^{\circ} \mathrm{C}$ and 1.5 hour retention time and $52 \%$ higher methane yield comparing to the untreated sample (Ariunbaatar et al., 2014).

In hydrothermal pre-treatment two main variables that manipulate the process are temperature and retention time. Many studies have investigated the effect of thermal pre-treatment temperature on WAS reduction and methane production and most of the studies reported that 
thermal pre-treatment increases the hydrolysis of sludge up to a certain range of temperature, however, if the temperature exceeds beyond the optimum conditions $\left(160-180^{\circ} \mathrm{C}\right)$, the biodegradability of sludge decreases (Han et al., 2017; Eskicioglu et al., 2006; Zhang et al., 2014). Some researchers reported that if the pre-treatment temperature exceeds $200^{\circ} \mathrm{C}$, it negatively affects and the $\mathrm{AD}$ produce toxic and refractory compounds and result to polymerization (Liao et al., 2006), (Dhar et al., 2012), while findings from (Kim et al., 2015a) shows that pre-treatment temperature of $210^{\circ} \mathrm{C}$ is the optimal condition for Biomethane production from waste activated sludge.

Pre-treatment retention time comparing to temperature shows insignificant effect on hydrolysis of feedstock for high pretreated temperatures above $100^{\circ} \mathrm{C}$, but for low pre-treatment temperature the holding time can considerably affect the solubilization and degradability of organic matters of the feedstock (Wilson \& Novak, 2009; Han et al., 2017).

One of the objective of hydrothermal pretreatment is the dewaterability enhancement of the waste to decrease the sludge disposal and shipment cost. Many studies have evaluated the solubilization and dewaterability of the waste after hydrothermal pretreatment and reported the thermal pretreatment enhance the dewaterability of waste. In WAS that comes after the secondary treatment and aeration tank the extracellular polymers are an important factor for bioflocculation and settling of sludge but it is a major obstacle on dewatering the sludge. The concentration of extracellular polymers can vary in WAS and it has a diverse linear relation with the dewaterability of sludge, higher extracellular polymers means lower dewaterability. These matters are vary hydrated up to $98 \%$. In a study that investigate the availability of extracellular polymers and the dewaterability of WAS it shows that up to a level extracellular polymers can help the dewaterability of WAS and when the extracellular polymers reach higher and decrease the number of small size particles it highly influence the dewaterability of WAS (Neyens \& Baeyens, 2003).

In another study that evaluate the effect of thermal pretreatment on Municipal Biomass Waste that consists WAS, kitchen waste and fruit waste it shows that thermal pretreatment can enhance the dewaterability of the waste. After pretreatment, dewatered cake from WAS showed the highest dewaterability enhancement by $60.4 \%$ and it was followed by fruit waste and kitchen waste by $55.1 \%$ and $46.7 \%$ respectively. The dewatered cake for non-pretreated samples of 
waste for kitchen waste, fruit waste and WAS evaluated was $66.5 \%, 68.1 \%$ and $80 \%$ respectively (Liu et al., 2012a). The dewaterability improvement of sludge by thermal pretreatment in a study in France by Bougrier was observed and a threshold temperature of $150^{\circ} \mathrm{C}$ was reported. In this study five different activated sludge was exposed to thermal pretreatment range from $20^{\circ} \mathrm{C}$ to $210^{\circ} \mathrm{C}$ to investigate the pretreatment effect on solubilization, degradability enhancement and sludge physical properties including the viscosity, settleability and dewaterability (Bougrier et al., 2008).

Beside many research on the effect of thermal pretreatment in an anaerobic digestion process and large-scale plants performing thermal pretreatment on sludge, still there is not a general consensus on the optimal pretreatment condition due to the complexity of waste composition. There has not been a comprehensive study on thermal pretreatment of SSO and TWAS that involve a wide range of pretreatment temperature. This research aimed to fill this gap and studied the effect of thermal pretreatment on two main streams of waste in a wide range of pretreatment temperature, retention time and SI (fifteen pretreatment conditions) to optimize the thermal pretreatment of SSO and TWAS. 


\section{Material and Methods}

\subsection{Substrates and inoculum characteristics}

In this study, the biomass resource for biogas production which is called feedstock or substrate comes from two distinct sources presenting two different urban waste streams. The characteristics of both feedstock used in this study are widely different according to the concentration of organic matter and their biodegradability potential. The first feedstock used for hydrothermal pre-treatment represents the organic fraction of municipal solid waste called source separated organics (SSO) which is a composition of food waste and leaf and yard waste. In SSO food waste represents highly rich organic waste generated by residential, industrial, commercial and institutional sector and yard waste includes all green wastes such as grass clippings, leaves, weeds, brush and small trees. Thickened Waste Activated Sludge (TWAS) was also used as feedstock in this study. TWAS is the product of activated sludge process (secondary clarifier) in a wastewater treatment plant that comes after the aeration tank and composed of mostly biological flocs of bacteria and protozoa and goes through a thickening process.

The SSO used in this study was collected from Disco Road organics processing facility (Toronto, Canada). The facility is the first full-scale plant in North America for processing SSO using anaerobic digestion and has been operated since 2014. It is one of the municipality's diversion program, the facility is capable of processing up to 75,000 tons per year of organic waste from City of Toronto (Ontario, Canada) homes and public buildings, but the ultimate capacity of the facility will increase to 130,000 tons in the near future. Food waste, pet waste, paper food packaging, houseplants, diapers, and biodegradable plastics are the acceptable materials in Disco facility. The process of SSO at Disco facility shown in figure 3.1 starts by SSO delivery and storage and visual inspection of the received materials to remove large unwanted items. Next, the materials undergo the BTA® hydro-mechanical technology through which the organics will eventually turn into a liquid (slurry) pulp. The BTA® employs screens and hydropulpers to separate the unwanted materials such as plastic bags, glass shards, sand, and metals from the pulp. In this study, the SSO was collected after the hydro-mechanical process and brought to the lab in a slurry form (pulp). 
Figure 3.1. SSO process in Disco Road Organic facility

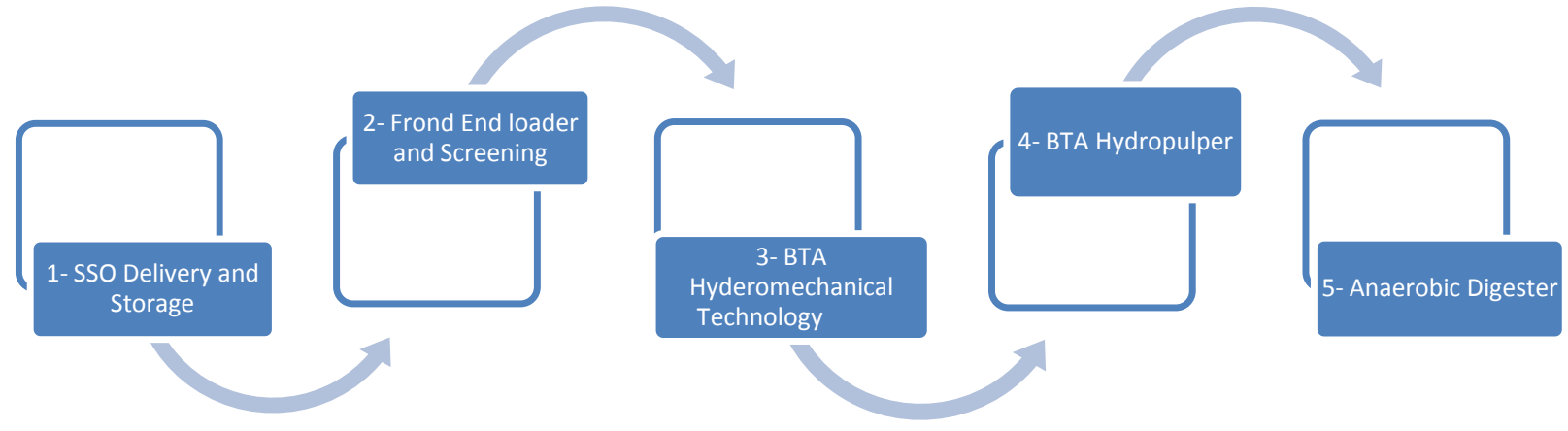

Thickened Waste Activated Sludge (TWAS) were taken from Ashbridge Bay Wastewater Treatment Plant in Toronto, Ontario which is one of the four wastewater treatment plant operating in Toronto and also one of the largest wastewater treatment plant operating in Canada. Wastewater received in the treatment plant comes from Mid-Toronto, high level, low level and Lakefront interceptor Sewers and also from Coxwell and Queen Street trunk sewers. Biosolids generated at Ashbridge Bay Wastewater treatment Plant reach to 149733 wet tones in 2016 with $28.1 \%$ Total Solid (TS). Influent received to the treatment plant goes through treatment processes like preliminary treatment (screening and grit removal), primary treatment, secondary treatment, phosphorus removal, effluent disinfection, waste activated sludge thickening, anaerobic digestion, biosolids dewatering and biosolids management. The plant has a treatment capacity of $818 \mathrm{ML} /$ day with influent Total Suspended Solids (TSS) $318.6 \mathrm{mg} / \mathrm{L}$ and Biological Oxygen Demand (BOD) of $244.6 \mathrm{mg} / \mathrm{L}$. Inoculums was taken from mesophilic anaerobic digesters performing at $\left(34-38^{\circ} \mathrm{C}\right)$ and fed by mixed of Primary Sludge (PS) and TWAS with $6420 \mathrm{~m}^{3} /$ day and $1600 \mathrm{~m}^{3} /$ day respectively. The process of TWAS produced in a typical wastewater treatment plant is shown on figure 3.2 and the thickening of activated sludge happens by gravity thickening process. The principle process of activated sludge consists of three steps which are aeration tank, settling tank and return activated sludge. The aeration tank which is a bioreactor the atmospheric air or pure oxygen is introduced to the primary treated wastewater and biological mass that form biological flocs called waste activated sludge. The produced sludge goes through thickening process using different mechanisms to produce TWAS. 
The inoculum was taken from the effluent of the anaerobic digesters operating at mesophilic condition $\left(34-38^{\circ} \mathrm{C}\right)$ and fed of around $6500 \mathrm{~m}^{3} / \mathrm{d}$ primary sludge and $1600 \mathrm{~m}^{3} / \mathrm{d}$ TWAS. The average of the SRT and organic loading rate of the anaerobic digesters are $18 \mathrm{~d}$ and $1.1 \mathrm{~kg}$ $\mathrm{VS} / \mathrm{m}^{3}$, respectively. The main characteristics of the substrates (SSO and TWAS) and the inoculum used in this paper are summarized in Table 3.1.

Table 3.1. Characteristics of Feedstock and Inoculums

\begin{tabular}{llll} 
Parameters & Inoculum & SSO & TWAS \\
\hline Total COD $(\mathrm{mg} / \mathrm{L})$ & $18,700 \pm 220$ & $100,000 \pm 6300$ & $49,600 \pm 1500$ \\
\hline Soluble COD $(\mathrm{mg} / \mathrm{L})$ & $480 \pm 60$ & $42,100 \pm 2900$ & $2,583 \pm 10$ \\
\hline TSS (mg/L) & $15,300 \pm 430$ & $66,000 \pm 2,100$ & $34,100 \pm 500$ \\
\hline VSS (mg/L) & $10,200 \pm 280$ & $49,000 \pm 1,900$ & $25,400 \pm 100$ \\
\hline Total Protein (mg/L) & $\mathrm{ND}^{\mathrm{b}}$ & $1,600 \pm 150$ & $200 \pm 50$ \\
\hline Soluble Protein (mg/L) & $\mathrm{ND}^{\mathrm{b}}$ & $200 \pm 30$ & $50 \pm 30$ \\
\hline Ammonia (mg/L) & $600 \pm 60$ & $1,700 \pm 170$ & $2,51 \pm 71$ \\
\hline Alkalinity (mg/L) & $3,600 \pm 230$ & $5,500 \pm 330$ & $10,63 \pm 126$ \\
\hline pH & $7.8 \pm 0.1$ & $5.9 \pm 0.2$ & $6.3 \pm 0.3$ \\
\hline
\end{tabular}

COD: chemical oxygen demand; TSS and VSS: total and volatile suspended solids; TS and VS: total and volatile solids ND: Not determined 


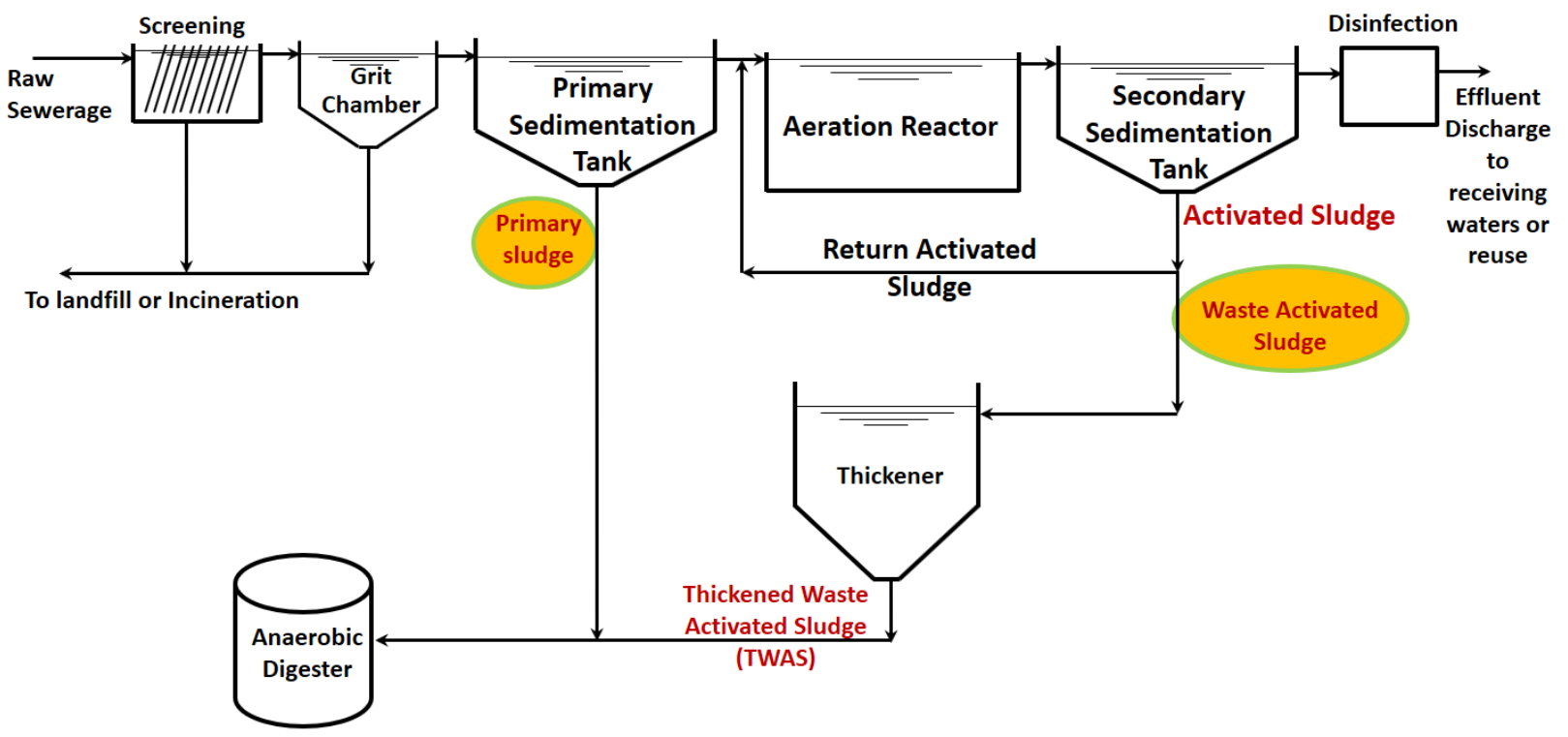

Figure 3.2. Process description of TWAS in a wastewater treatment plant

\subsection{Hydrothermal Pre-treatment}

The hydrothermal pre-treatment of the substrates SSO and TWAS were carried out using a Parr 4848 stirred reactor (Parr Instrument Company, IL, US) shown in figure 3.3. The pre-treatment system was equipped with an automatic controller with proportional integral derivative (PID) programming with auto-tuning capabilities for precise control of temperature, pressure, heating ramp, and soak (retention time). The reactor had a mechanical mixer connected to a speed controller, which allowed for a homogeneous mixing condition resulted in an evenly distributed temperature across the load (i.e. SSO) during the heating process. The reactor controller was connected by a computer software called SpecView to control parameters in eight different loops while providing real-time plotting. The Parr4848 was capable of heating up to $2 \mathrm{~L}$ of SSO to the maximum temperature and pressure of $275^{\circ} \mathrm{C}$ and 1310 , respectively.

In this study, for each round of pre-treatment, one liter of substrates was placed in the reactor vessel. The reactor was then sealed and the mechanical mixer was set to $150 \mathrm{rpm}$ and kept stirring until the end of the cooling cycle. The SSO heating was started with a ramp of $3^{\circ} \mathrm{C} / \mathrm{min}$ until the reactor temperature reached $30^{\circ} \mathrm{C}$ below the target temperature (cycle \#1). Afterwards, the heating was continued at the lower rate of $1{ }^{\circ} \mathrm{C} / \mathrm{min}$ until the reactor temperature reached the 
target temperature (cycle \#2). Then the temperature was kept constant for the desired retention time (cycle \#3). Finally, the heater was turned off but the mechanical mixer kept running until the temperature reached below $50^{\circ} \mathrm{C}$ (cycle \#4) and the reactor vessel was opened. It is noteworthy that the heating rate was reduced from $3{ }^{\circ} \mathrm{C} / \mathrm{min}$ in cycle \#1 to $1{ }^{\circ} \mathrm{C} / \mathrm{min}$ in cycle \#2 to avoid increasing the temperature above the target temperature due to the thermal transitional lag. The only difference for hydrothermal pre-treatment of SSO and TWAS was the cooling rate, as for SSO there was no cooling mechanism to decrease the temperature of pretreated substrate's while for TWAS a cooling mechanism was used to help and increase cooling by a closed system inside the vessel circulating cold water. The Figure 3-3 (b) shows the heating and cooling rate of SSO and TWAS recorded by SpecView software.

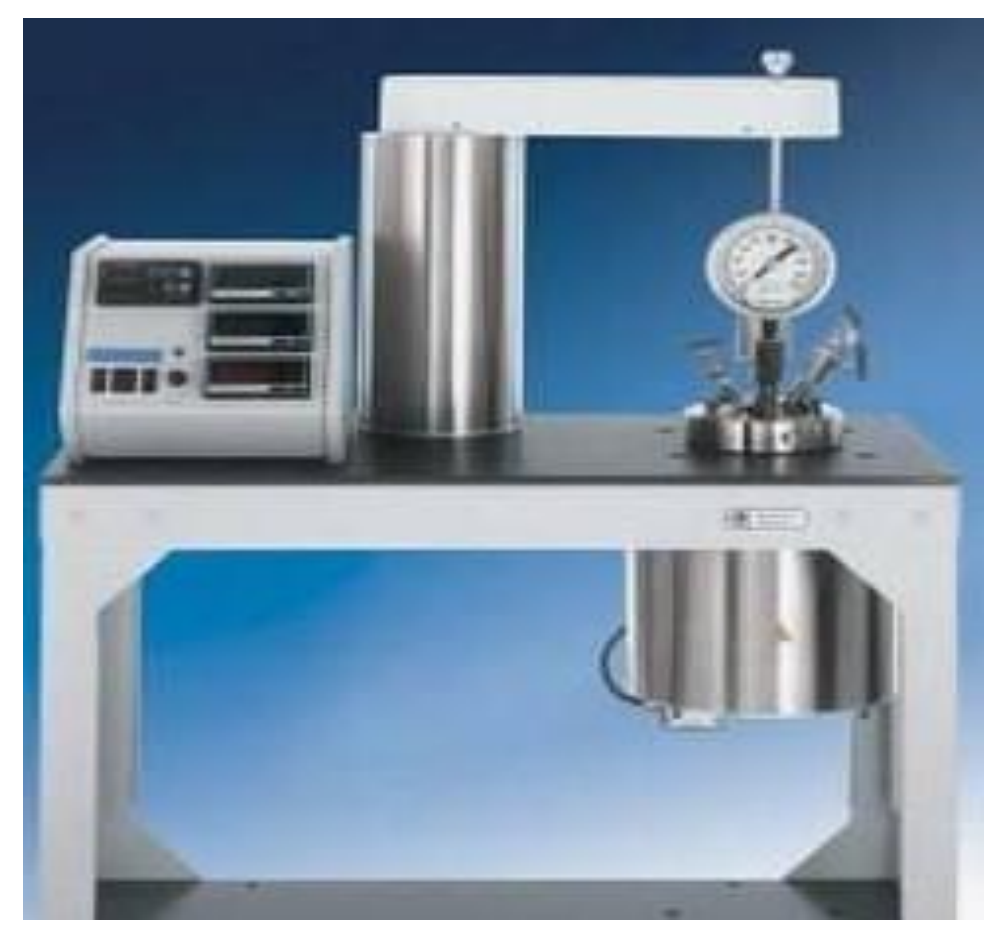

Figure 3.3. Parr4848 Hydrothermal Reactor 


\section{Parr 4848 Controller}

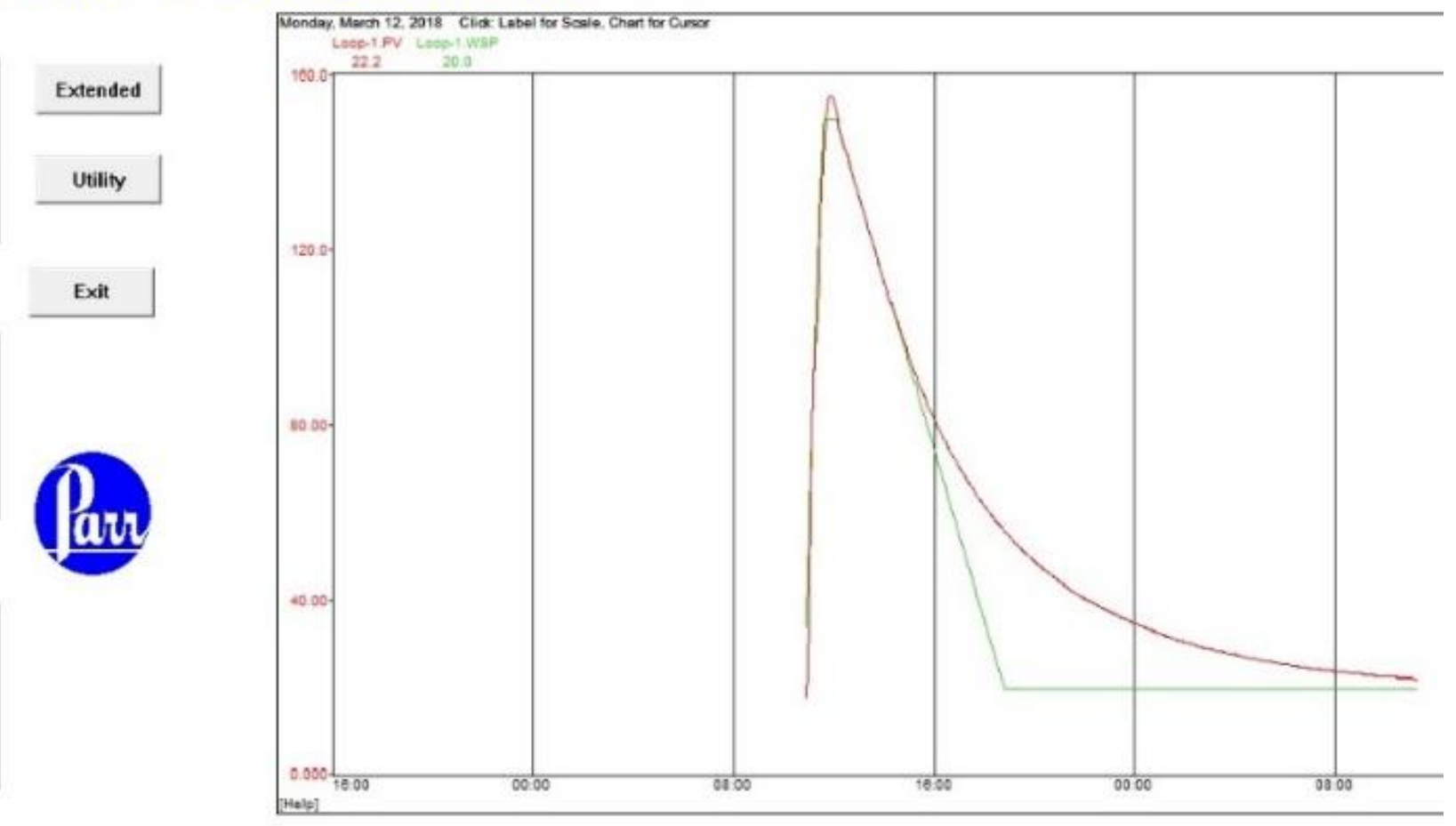

Figure 3.4. Parr4848 Hydrothermal Reactor Real time plotting by SpecView Software 


\subsection{Experimental design and procedure}

\subsubsection{Solubilization study}

Table 3.2 shows the experimental design used in this study to investigate the effect of the hydrothermal pre-treatment on the solubilization of SSO. In this study, the experimental design was done considering five different severity index (SI) values of 3, 3.5, 4, 4.5 and 5. Severity index is a parameter widely adopted in industrial application that combines the efficacy of reacting temperature and retention time into one single parameter. It helps to evaluate different conditions of temperature and retention time with one single parameter during the hydrothermal pre-treatment experiment. It has been used for modeling the chemical processing of lignocellulosics materials like solubilization of raw material, behavior of hemicelluloses during the reaction and lignin removal. (1) The SI was calculated via Eq. (1) which was used by other researchers as well (Wang et al., 2018); (Ariunbaatar et al., 2014).

\section{Severity Index $(S I)=\log \exp [(T-100) / 14.75 \times t]$}

Where, $\mathrm{T}$ is the pre-treatment temperature $\left({ }^{\circ} \mathrm{C}\right)$ and $\mathrm{t}$ is the retention time (min). As seen in Table 3., under each SI, three different pre-treatment scenarios were defined using various combinations of temperature, pressure, and retention time. This resulted in a total number of fifteen different pre-treatment conditions. The temperature, pressure, and retention time ranged between $150-240^{\circ} \mathrm{C}, 47.57-336.46 \mathrm{kPa}$, and 5-30 min, respectively. In addition to the pre-treated scenarios, one control (non-pretreated) scenario was included in the experimental design. The percentage improvements in the SCOD concentration $(\mathrm{P})$ values and suspended solid reduction (R) values were calculated using Eq (2) and (3) respectively.

$\mathbf{P}(\%)=\left(\mathbf{S C O D}_{\mathrm{HTP}}-\mathbf{S C O D}_{\mathbf{R}}\right) / \mathbf{S C O D}_{\mathbf{R}} \times \mathbf{1 0 0}$

Where $\mathrm{SCOD}_{\mathrm{R}}$ and $\mathrm{SCOD}_{\mathrm{HTP}}$ are the SCOD concentration before and after pre-treatment $(\mathrm{mg} / \mathrm{L})$.

$\mathbf{R}(\%)=\left(\mathbf{S S}_{\mathbf{R}}-S S_{H T P}\right) / \mathbf{S S}_{\mathbf{R}} \times \mathbf{1 0 0}$

Where $\mathrm{SS}_{\mathrm{R}}$ andSS $\mathrm{HTP}_{\mathrm{HT}}$ are the suspended solids (TSS or VSS) concentration before and after the hydrothermal pre-treatment $(\mathrm{mg} / \mathrm{L})$. 
Table 3.2. Hydrothermal Pre-treatment conditions (Temperature, Severity Index and Retention Time)

\begin{tabular}{llllll}
\hline Severity Index $(\mathbf{S I})$ & $\mathbf{3 . 0} \pm \mathbf{0 . 0 5}$ & $\mathbf{3 . 5} \pm \mathbf{0 . 0 5}$ & $\mathbf{4 . 0} \pm \mathbf{0 . 0 5}$ & $\mathbf{4 . 5} \pm \mathbf{0 . 0 5}$ & $\mathbf{5 . 0} \pm \mathbf{0 . 0 5}$ \\
\hline & Pre-treatment pressure $(\mathrm{kPa})$, temperature $\left({ }^{\circ} \mathrm{C}\right)$, retention time $(\mathrm{min})$ & \\
\hline $\begin{array}{l}\text { Pre-treatment } \\
\text { Scenarios \#1 }\end{array}$ & $47.5,150,30$ & $78.6,170,30$ & $124.7,190,20$ & $156.5,210,20$ & $232.3,220,30$ \\
\hline $\begin{array}{l}\text { Pre-treatment } \\
\text { Scenarios \#2 }\end{array}$ & $61.3,160,20$ & $99.9,180,15$ & $155.1,200,10$ & $232.3,220,10$ & $280.6,230,15$ \\
\hline $\begin{array}{l}\text { Pre-treatment } \\
\text { Scenarios \#3 }\end{array}$ & $78.6,170,10$ & $124.7,190,10$ & $190.9,210,5$ & $280.6,230,5$ & $336.4,240,8$ \\
\hline
\end{tabular}

\subsubsection{Biomethane Potential Study}

To assess the effect of the hydrothermal pre-treatment on SSO and TWAS digestion and also to determine the optimum conditions, three digesters were set for all fifteen different scenarios of pretreatment for both TWAS and SSO. Also, one set of control (non-pretreated TWAS and SSO) digester was included in triplicates in the experiment that was used as a benchmark for the comparison purpose. The inoculum was degassed for SSO biomethane experiment before starting the digestion for about 10 days, in order to calculate the exact amount of biogas produced from the substrate only, three additional digesters were set up with inoculum only (no substrate). Therefore, a total number of fifty-one batch digesters were operated simultaneously for SSO. For conducting the experiment on TWAS, the inoculum was not degassed as the substrate and inoculums come from same treatment plant operating in the same condition and also inoculum was not kept in fridge and it was used in the experiment in the same day.

To set up the batch digesters, a specific amount of the pretreated and non-pretreated substrates (SSO) was added to $200 \mathrm{~mL}$ glass bottles along with the mesophilic inoculum. The amount of the added SSO and its ratio to the inoculum was calculated considering the food to microorganism $(\mathrm{F} / \mathrm{M})$ ratio of $1 \mathrm{~g}-\mathrm{TCOD} / \mathrm{g}-\mathrm{VSS}$. The total volume of substrate and inoculums for TWAS was $250 \mathrm{~mL}$ but the same F/M ratio was used in the experiment. Additional 4000 $\mathrm{mg} / \mathrm{L}$ alkalinity in form of $\mathrm{NaHCO}_{3}$ was added to each digester to increase the buffering capacity 
of the medium in order to prevent the $\mathrm{pH}$ drop during the digestion process and provide an optimal condition for methanogenesis bacteria. To discharge the excess oxygen and also maintain a fully- anaerobic condition, the digesters were purged by the nitrogen gas and then sealed by rubber septa and plastic caps. The digesters were finally placed in a shaker set at a mesophilic temperature of $38^{\circ} \mathrm{C}$ and a rotational speed of $120 \mathrm{rpm}$.

\subsubsection{Analytical Methods}

Pretreated, non-pretreated substrate and inoculums were analysed before and after anaerobic digestion to evaluate the effect of hydrothermal pre-treatment. The analysis that were carried out on all samples are Total Suspended Solid (TSS), Volatile Suspended Solid (VSS), Soluble Carbohydrate, Total Carbohydrate, Total Protein, Soluble Protein, Total Chemical Oxygen Demand (TCOD), Soluble COD, pH, Alkalinity, Ammonia, Particle Size distribution and gas composition. The values of TSS and VSS of the inoculum and substrates were determined by the Standard Methods procedures using $5 \mathrm{~mL}$ of the samples and filter it by microfiber filter with pore size of $\mu \mathrm{m}$ and disposing the dishes to $105^{\circ} \mathrm{C}$ for 2 hours for TSS and to $550^{\circ} \mathrm{C}$ for $30 \mathrm{~min}$ for VSS. The analysis of chemical oxygen demand (COD), carbohydrate, and protein was carried out on both the total and soluble phases. The soluble fraction was prepared by centrifuging the samples at $9000 \mathrm{rpm}$ for $30 \mathrm{~min}$ and then passing the supernatant through microfiber filters with a pore size of $0.45 \mu \mathrm{m}$. A Hach spectrophotometer model 3900 was used to measure the absorbance at the wavelengths of $600,490,595,560$ and $650 \mathrm{~nm}$ for the analysis of COD, carbohydrate, protein, ammonia, and alkalinity, respectively. For the COD analysis, $2 \mathrm{~mL}$ of samples were added to the Hach COD reagent, mixed and then placed in a COD reactor set at a temperature of $150^{\circ} \mathrm{C}$ for two hours. The carbohydrate and protein concentrations were measured following the procedure developed by Dubios and Frolund in 1956 and 1995, respectively. The particle size distribution (PSD) of the samples was determined using a LS 13320 laser diffraction particle size analyzer (Beckman Coulter, Indianapolis, US) by light scattering method that simply uses laser light source to illuminate the particles. The scattered light then absorbed by silicon photo detector and using the intensity of light on each detector demonstrate the angle and using complex algorithm it finds out the volume of particle in percentage of discrete size classes.

The volume of the produced biogas was measured manually with a100-mL gas-tight glass syringe every day at the beginning of the digestion period. The measurement was continued 
every couple of days later on when the gas production rate slowed down. A ThermoScientific Trace 1310 gas chromatograph (GC) equipped with a thermal conductivity detector was used to measure the methane content of the biogas during the AD process. The oven, detector, and filament temperature were set to 80,100 , and $250^{\circ} \mathrm{C}$, respectively. The column used in the GC was a TG-Bond Msieve 5A model with length and diameter of $30 \mathrm{~m}$ and $0.53 \mathrm{~mm}$. 


\section{Experimental Results}

After the exposure to hydrothermal pretreatment conditions the results were evaluated to assess the effect of temperature, retention time and severity of the pretreatment on solubilization, biodegradability and solid reduction.

\subsection{TWAS Result and Discussion}

\subsubsection{Effects of Hydrothermal Pretreatment on COD Solubilization of TWAS}

TWAS samples were hydrothermally pretreated in fifteen different temperature and retention time within five different SI as it shows in table 3.2. Figure 4.1 graphically represent the SCOD concentration of each pretreated condition in a comparison to non-pretreated and Figure 4.2 demonstrate the percentage improvement in COD solubilization.

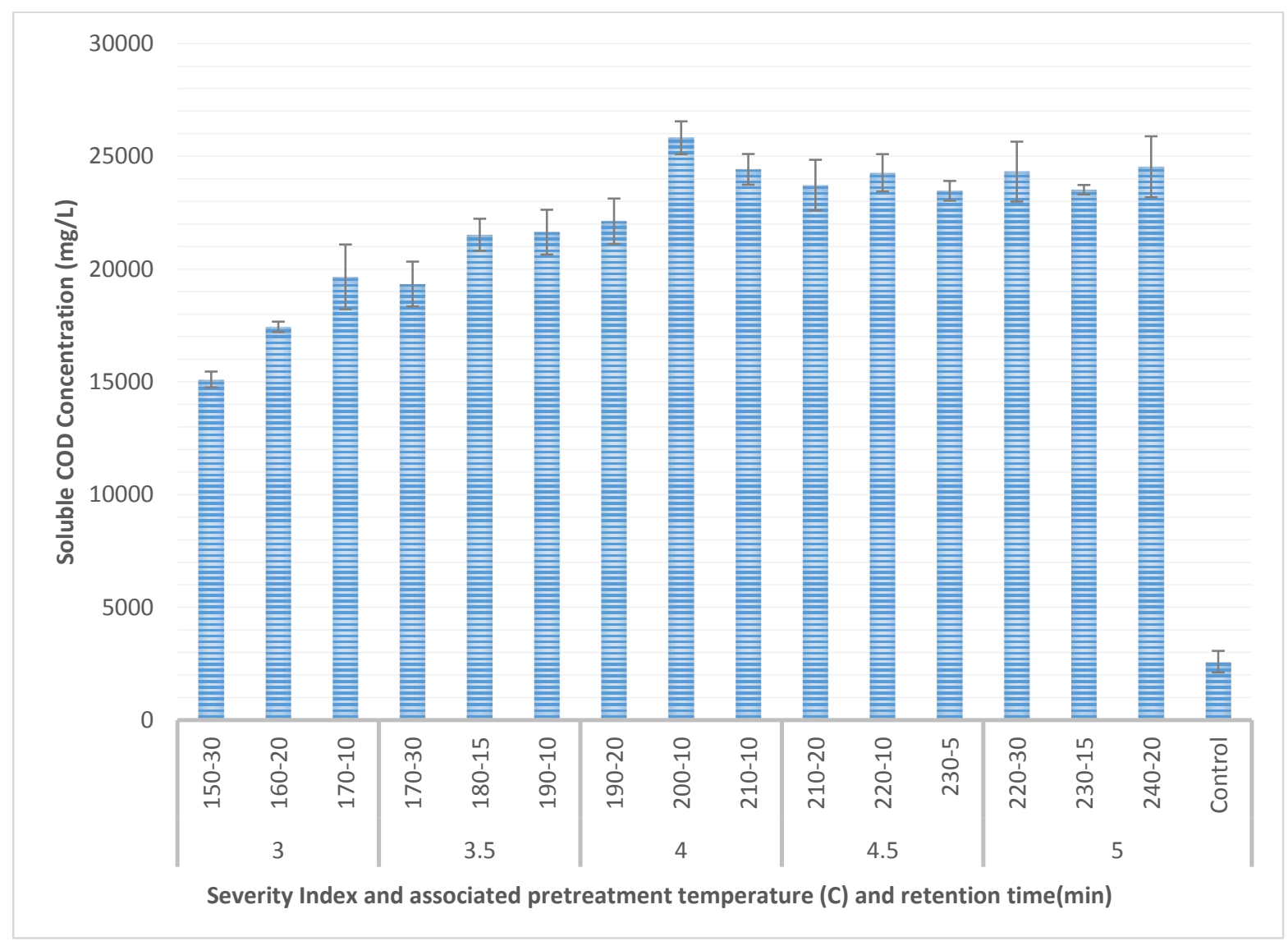

Figure 4.1. Effect of Hydrothermal Pretreatment on Concentration of Soluble COD 


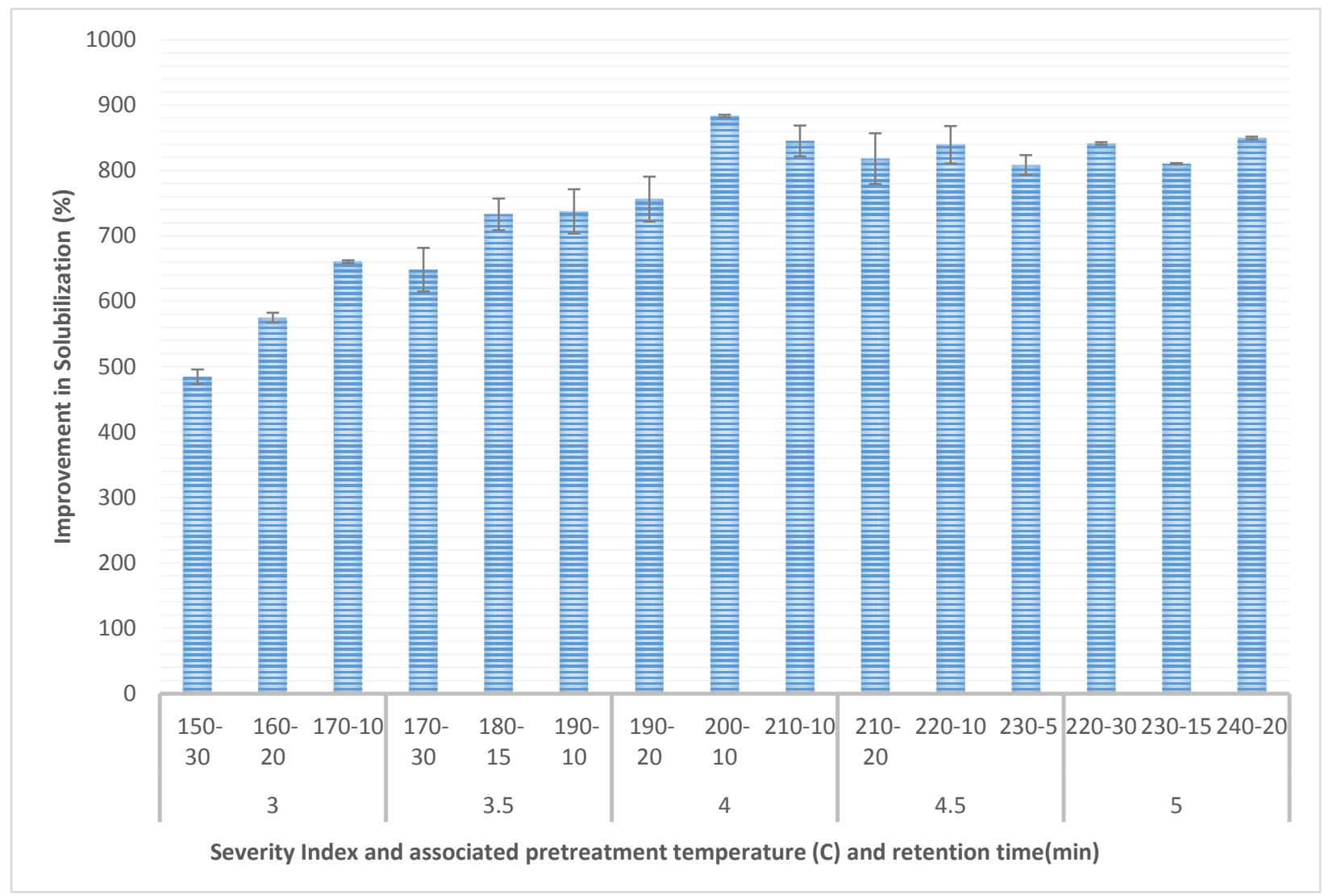

Figure 4.2. Effect of Hydrothermal Pretreatment on Soluble COD improvement comparing to non-pretreated

The results of the experiment reveal that solubilization enhancement of TWAS was achieved in all hydrothermal pretreated conditions and the SCOD improvement reached from $2583 \mathrm{mg} / \mathrm{L}$ SCOD of non-pretreated to $25400 \mathrm{mg} / \mathrm{L}$. The SCOD enhancement is caused by transformation of insoluble organic polymers to monomers and to liquid phase as it was also reported by previous research (Li et al., 2014; Bougrier et al., 2008).Within all fifteen pretreatment conditions the solubilization rate happened in a range of 485 to $883 \%$ with the highest solubilization of 25400 $\mathrm{mg} / \mathrm{L}$ was achieved in pretreatment condition of $200^{\circ} \mathrm{C}$ and $10 \mathrm{~min}$ within the $\mathrm{SI}=4$ and lowest solubilization of $15100 \mathrm{mg} / \mathrm{L}$ was inspected in pretreatment condition of $150^{\circ} \mathrm{C}$ and $30 \mathrm{~min}$ within $\mathrm{SI}=3$. Organics fractionations that represent COD in TWAS are mostly protein 40\%, 25\% lipids and $15 \%$ polysaccharide (Wilson \& Novak, 2009). According to previous study the effect of temperature on lipids solubilization is negligible (Razavi et al., 2019), so the improvement in solubilization is mostly from hydrolysis of protein and polysaccharide. During hydrolysis stage 
of anaerobic digestion, protein converts to peptides and amino acids which later changes to Volatile Fatty Acids (VFA). The same process happens during thermal hydrolysis and macromolecular proteins convert to small molecules of peptides and amino acids. Thermal hydrolysis also degrades the polysaccharides like cellulose and starch to smaller molecules of glucose and in higher temperature smaller carbohydrate molecules can interact with amino acids and form Millard reaction or cause non-enzymatic browning of sugar by caramelization (pyrolysis). As it was also hypothesised by other research carbohydrate is easier degradable comparing to protein during the hydrothermal pretreatment so in hydrothermal pretreatment with lower SI the SCOD improvement is referred more to carbohydrates degradation but higher intensity of pretreatment disintegrates protein to smaller organic compounds like amino acids (Bougrier et al., 2008) . The availability of degraded carbohydrate like glucose and amino acids with suitable temperature can form Millard reaction which is an inhibitory COD solubilization. As it can be also observed in Figure 4.1 the severity of pretreatment condition improves the soluble COD up to a certain limit $\mathrm{SI}=4$ and pretreatment intensity beyond this range adversely affect the process of solubilization. This observance can be also explained by formation of insoluble protein and carbohydrate (caramelization) or further degradation of amino acids to ammonia. The results that higher intensity of hydrothermal pretreatment condition can negatively affect the solubilization of COD were also reported in previous research. According to the literature review higher pretreated temperature of WAS increased the ammonia concentration as a consequence of protein solubilization and decrease in concentration of carbohydrate due to Millard reactions. During hydrothermal pretreatment two main parameters that can affect the solubilization are pretreated temperature and retention time. As it is illustrated in Figure 4.1 the retention time has minimal effect on solubilization of COD and the pretreated temperature is the dominant parameter in the hydrothermal pretreatment. In a nutshell, lower pretreatment temperature cannot increase the solubilisation of TWAS effectively and higher pretreatment temperature with SI beyond 4 adversely affect the process of solubilisation.

The organics component in feedstock which is available for AD are carbohydrates, protein and fats or lipids. Fats degradation are limited by oxidation ( $\beta$-Oxidation) while the other two main components of organics degradation are limited by hydrolysis (Liu et al., 2012a). Thus, the solubilization of the TWAS is related to the carbohydrate which is mostly in form of polysaccharides and proteins. The concentration of soluble proteins and carbohydrates are 
illustrated in Figure 4.3 and shows a higher solubilization of carbohydrate in hydrothermal pretreatment comparing with proteins. Carbohydrates are more easily solubilized by temperature increase than proteins also explained by other research. In the Figure 4.3 it shows that the highest carbohydrate concentration happened in pretreatment condition of $160^{\circ} \mathrm{C}-20 \mathrm{~min}$ and beyond this point the severity of pretreatment end up in decreasing the concentration of soluble carbohydrates. The concentration of soluble protein also follows the same trend and it might be the result of mediate reactions between soluble carbohydrate and soluble protein with the availability of heat and pressure.

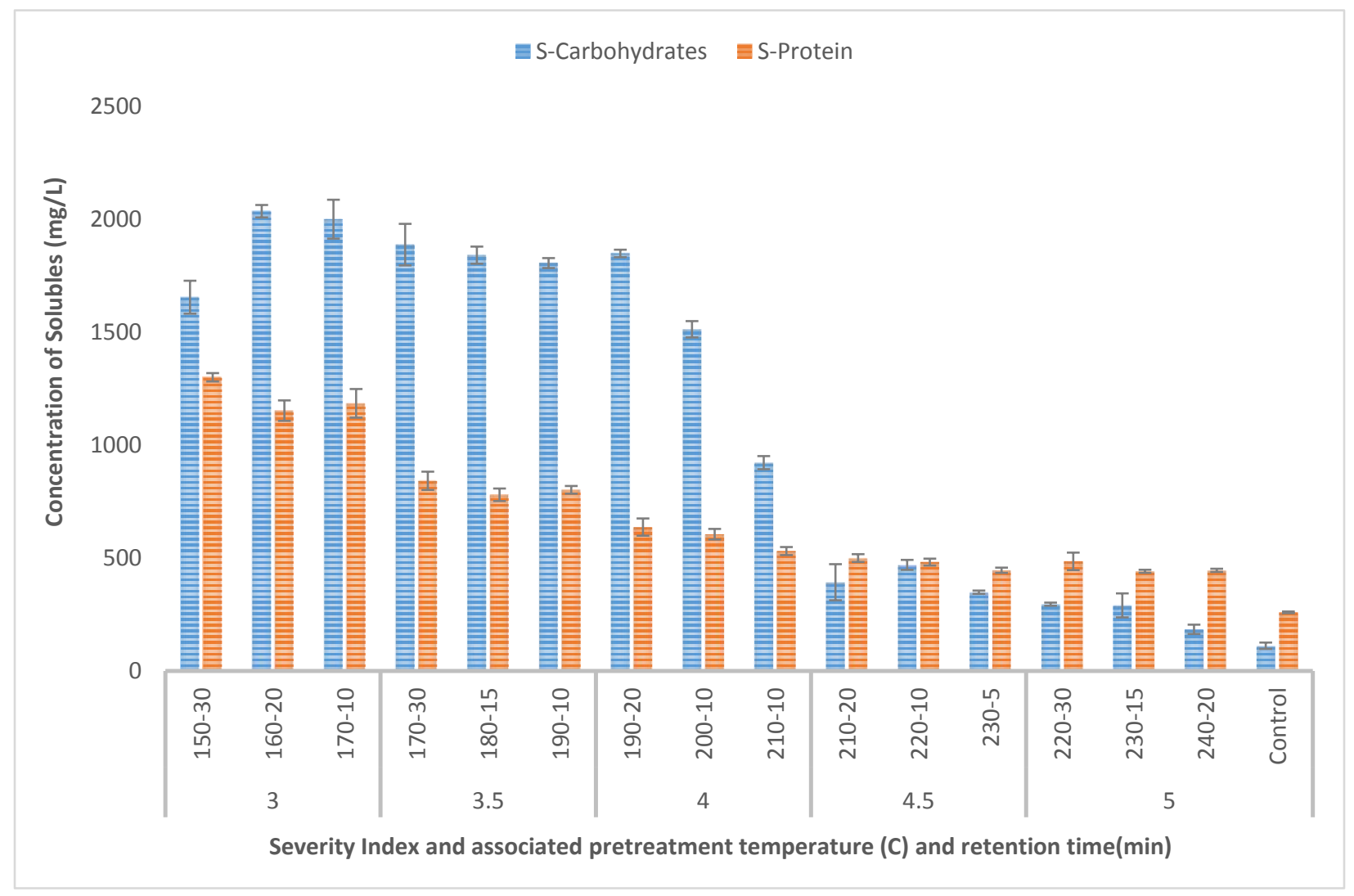

Figure 4.3. The Concentration of Soluble Protein and Carbohydrate 


\subsubsection{Suspended Solid Reduction of TWAS}

The Total Suspended Solid (TSS) and Volatile Suspended Solid (VSS) concentration is illustrated in Fig 4.4 and Fig 4.5 demonstrate the TSS and VSS reduction efficiency after hydrothermal pretreatment. As Figure 4.4 shows the hydrothermal pretreatment has considerably reduced the TSS and VSS concentration comparing to the non-pretreated samples.

The highest TSS and VSS reduction occurred in pretreated condition of $220^{\circ} \mathrm{C}$ and $10 \mathrm{~min}$ retention time with a reduced concentration of TSS from $34.1 \pm 3.4 \mathrm{~g} / \mathrm{L}$ to $11.4 \pm 5.4 \mathrm{~g} / \mathrm{L}$ and reduced VSS concentration from $25.4 \pm 2.5 \mathrm{~g} / \mathrm{L}$ to $6.8 \pm 2.7 \mathrm{~g} / \mathrm{L}$. As per Figure 4.3 , the TSS and VSS reduction efficiency increased between the SI of 3 and 4.5 in a range of 25 to $67 \%$ reduction efficiency for TSS and 31.4 to $73.2 \%$ for VSS. The TSS and VSS reduction efficiency shows an increasing trend until the SI of 4.5 and the intensity of pretreatment beyond SI of 4.5 have decreased the efficiency of pretreatment.

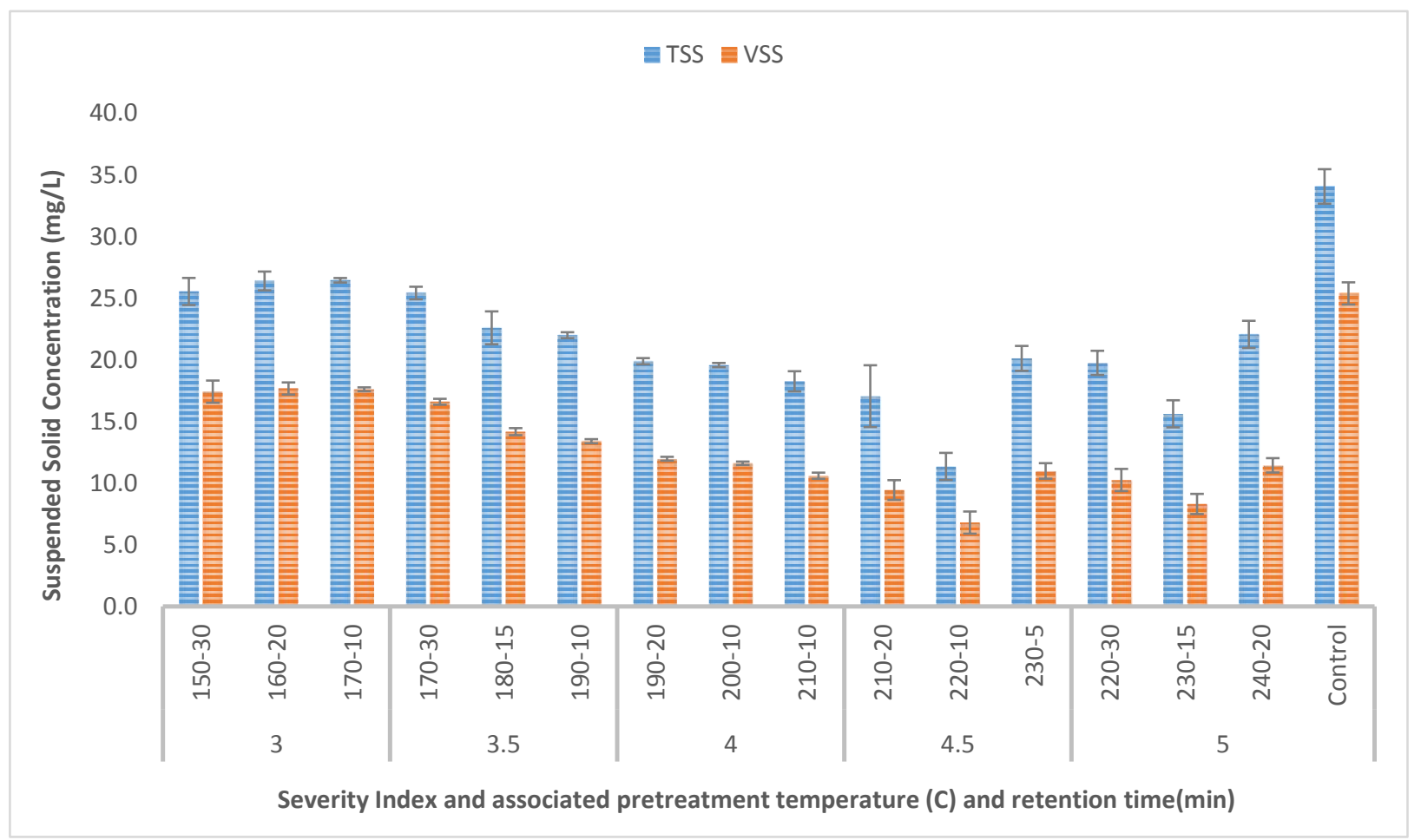

Figure 4.4 The effect of hydrothermal pretreatment on Suspended Solids Concentration 


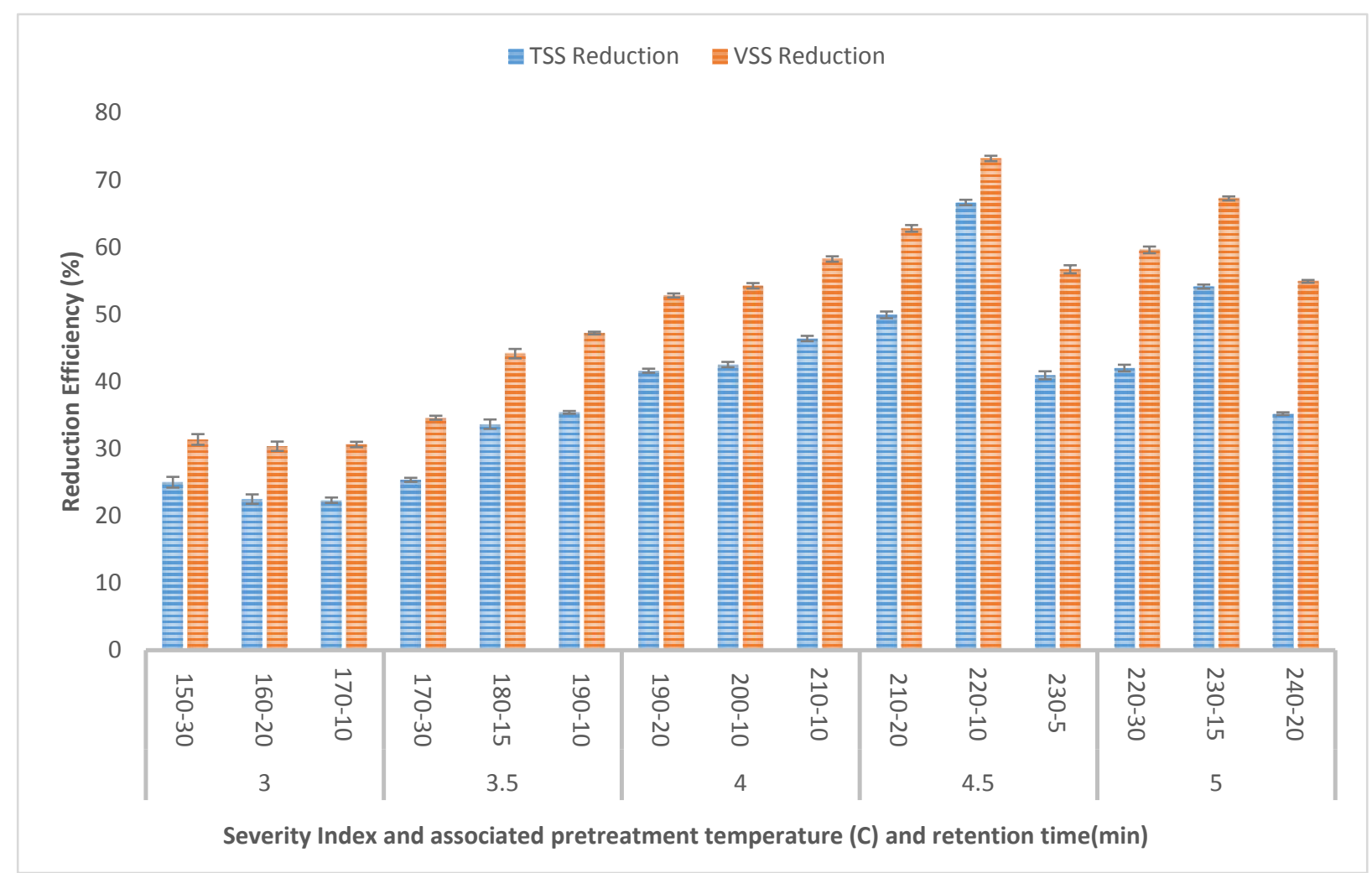

Figure 4.5 The effect of hydrothermal pretreatment on Suspended Solids Reduction

The decrease in TSS and VSS reduction efficiency in more intense pretreated condition higher than 4.5 can be explained as a result of polymerization of inorganic compounds with organics and formation of insoluble macromolecular polymers that reduce the overall efficiency of hydrothermal pretreatment. The polymerization can be as a result of Millard reaction that happens between degraded carbohydrates such as glucose and fructose with degraded protein like amino acids or formation of hybrid polymers by reaction of organic and inorganic compounds.

The results of particle size distribution support the suspended solid reduction by showing a mild reduction in particle size of pretreated TWAS comparing to non-pretreated sample. The reduction of particle size distribution of samples was evaluated by measuring the diameter of 10 , 50 and 90\% (D10, D50, D90) of particles and comparing with other samples. This assessment revealed the particle size reduction of D10, D50 and D90 from 27, 76 and $152 \mu \mathrm{m}$ for nonpretreated to the highest reduction of 12,39 and $75 \mu \mathrm{m}$ for the pretreatment with highest intensity. 
According to the results illustrated in Figure 4.5 the hydrothermal pretreatment had higher affect in VSS reduction comparing to TSS and it can be explained as result of temperature intensity cause the destruction of organic matters such as protein and carbohydrate rather than the inorganic compounds and this findings have also been reported by other research (Razavi et al., 2019; Jin et al., 2016)

Retention time as one of main parameters of hydrothermal pretreatment shows less effect on TSS and VSS reduction and the leading parameter in the hydrolysis of sludge is the intensity of pretreatment temperature. This finding is in an agreement with a study that evaluate the effect of retention time in thermal pretreatment and it reveal that reaction time is up to 15 min can influence the solubilization and beyond that the effect of retention time is negligible (DonosoBravo et al., 2011).

With respect to the results of the TSS and VSS reduction efficiency it can be concluded that the lower temperature and SI is not a suitable condition for hydrothermal pretreatment to disintegrate all the possible higher molecular components and also pretreated condition with SI above 4.5 result in polymerization and reduce the TSS and VSS reduction efficiency.

\subsubsection{Impact of hydrothermal pretreatment on anaerobic digestion of TWAS}

The biomethane yield test of TWAS was performed in an anaerobic condition within batch reactors for all 15 pretreated conditions shown in table 3.2 and one non-pretreated samples.

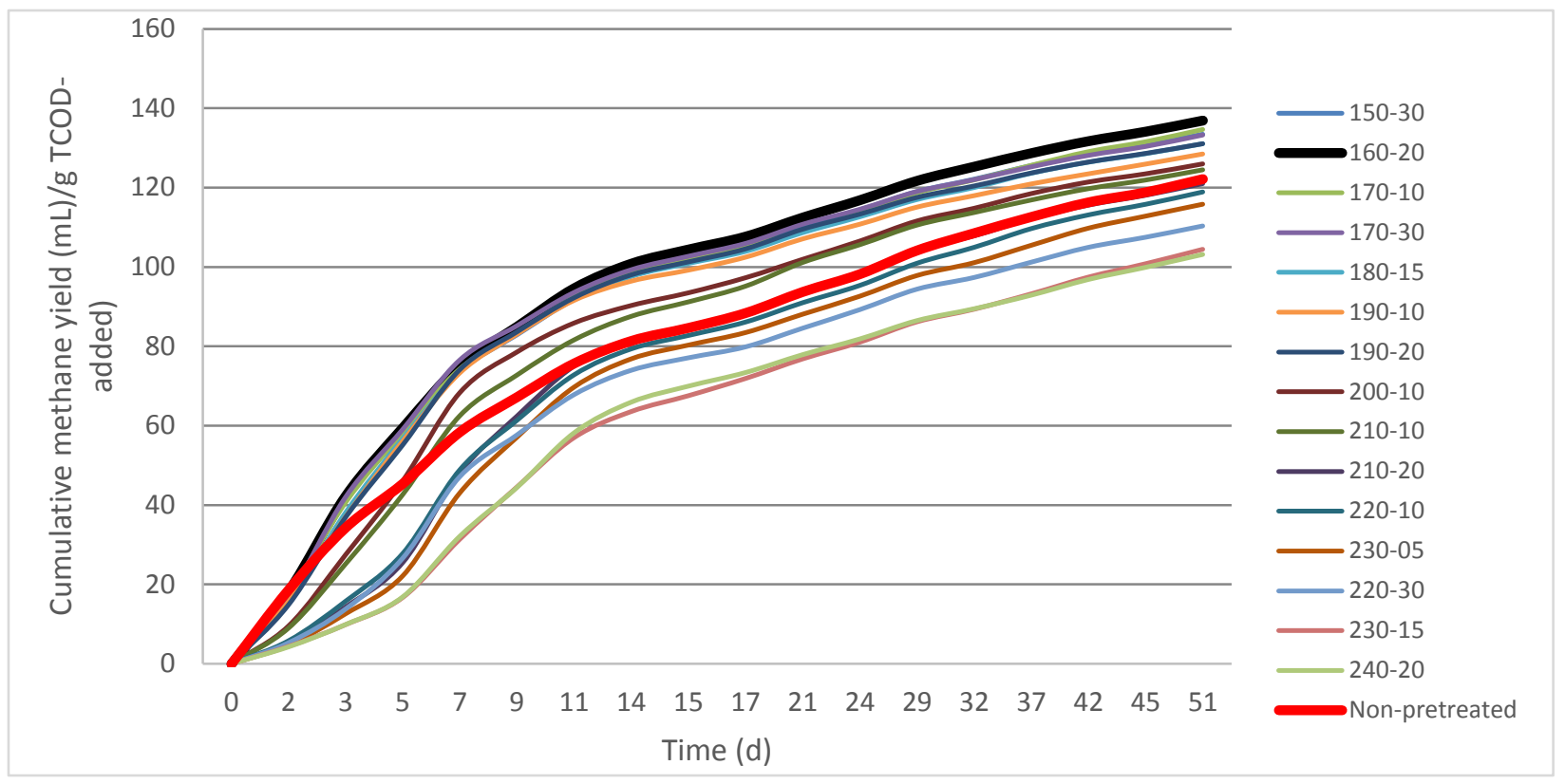

Figure 4.6. The cumulative methane production of the BMP digesters 


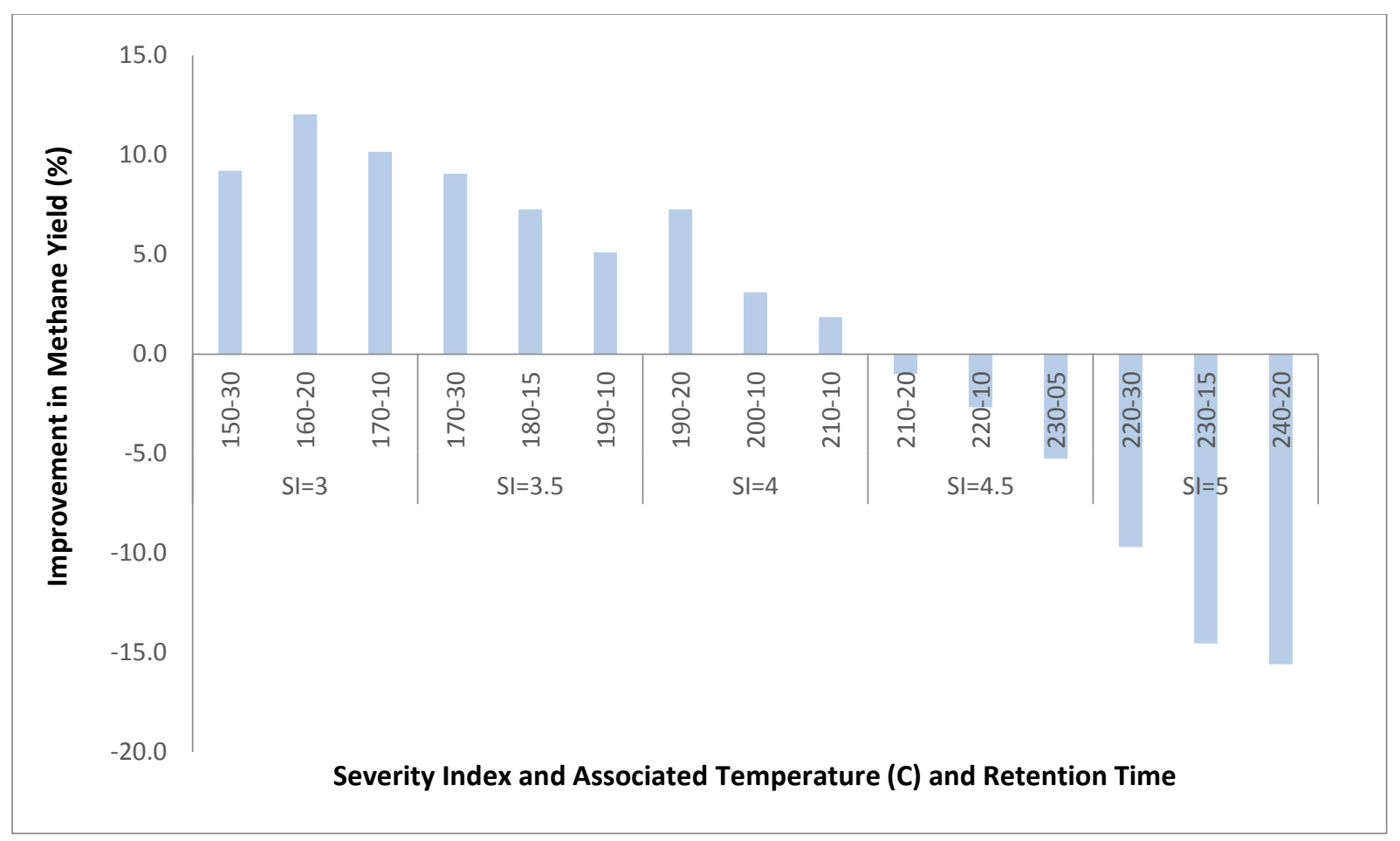

Figure 4.7. Methane Yield Improvement Comparing with Non-Pretreated

The biomethane production assay continued for 51 days and the results of cumulative methane yield per gram TCOD $_{\text {added }}$ for all pretreated and non-pretreated samples with the comparative improvement of methane yield of pretreated samples to non-pretreated are shown in Figure 4.6 and Figure 4.7 respectively.

According to the illustrated results in Figure 4.6 the biogas production followed the same trend for all pretreated and non-pretreated samples and lag phase which happens due to the adaptation of microbial populations to the new environment was not experienced during the experiment. This observation can be explained as both substrate and inoculums were collected from the same wastewater treatment plant which was operating in mesophilic anaerobic condition and the inoculums was used subsequently after receiving from the treatment plant. As the Figure 4.6 illustrates, the biodegradability of TWAS after hydrothermal pretreatment was not improved in all pretreated condition and methane production improvement shows a different trend comparing to the solubilisation of COD. The highest solubilisation was observed in pretreated condition with $\mathrm{SI}=4$ and soluble COD improved in all pretreated condition while TWAS exposed to intense hydrothermal pretreated condition with $\mathrm{SI}>=4.5$ shows less methane yield comparing to non-pretreated samples explaining that TWAS biodegradability decreased after pretreated in 
more severe condition and it adversely affect the overall procedure. This result is supported by a previous study, ( $\mathrm{Li}$ et al., 2014) reported that biogas yield increased by $16.5 \%$ in pretreatment condition of $160^{\circ} \mathrm{C}$ and higher pretreatment temperature $180^{\circ} \mathrm{C}$ decreased the biogas yield. This observation of decrease in methane production after pretreatment with SI>4 can also be explained by the concentration of soluble protein and carbohydrate illustrated in figure 4.2. The temperature increase results in lower soluble protein and carbohydrate that might be as a result of reactions between them with the availability of heat and pressure.

The methane production improved by 1.9\%-12\% within pretreated condition between SI 3 to 4 . The highest methane yield produced at SI of 3 with hydrothermal pretreated temperature of $160^{\circ} \mathrm{C}$ and $170^{\circ} \mathrm{C}$ with 20 and 10 min retention times, respectively. The increased bio-methane production by hydrothermal pretreatment was also reported by other research but with a higher efficiency, (Valo et al., 2004) reported a $45 \%$ improvement after WAS pretreated in $170^{\circ} \mathrm{C}$. The pretreatment condition with SI beyond 3 and pretreatment temperature higher than $170^{\circ} \mathrm{C}$ shows a mild reduction in bio-methane yield and decrease relates to the intensity of pretreatment, while the pretreatment condition reaches to $\mathrm{SI}=4$ and pretreated temperature $210^{\circ} \mathrm{C}$ and $20 \mathrm{~min}$ the methane production yield gets lower than the non-pretreated TWAS. The anaerobic digestion is a complex and delicate process involving different clusters of bacteria with a sensitivity to several processing parameters like $\mathrm{pH}$, ammonia, volatile fatty acids and hydrogen (Appels et al., 2008). The decrease in bio-methane yield for pretreated TWAS with more intense pretreated condition might be as a result of free ammonia enhancement after pretreatment. According to the results, concentration of ammonia increased when the pretreatment temperature increased from $251 \mathrm{mg} / \mathrm{L}$ for non-pretreated to $900 \mathrm{mg} / \mathrm{L}$ for pretreated condition of $240^{\circ} \mathrm{C}$ and $20 \mathrm{~min}$ retention time and it can act as an inhibitory for methanogenesis stage. This result can also be caused by the formation of toxic refractory compounds such as Amadori and melanoidins causing by high pretreatment temperature which has been also reported by previous studies (Pilli et al., 2015).

According to the result, in the first four days the highest biomethane production happened in non-pretreated and pretreated condition with lower intensity. This observation is with accordance to total carbohydrate concentration, according to results of pretreatment highest total carbohydrate concentration observed in $160^{\circ} \mathrm{C}$ and $170^{\circ} \mathrm{C}$, pretreatment conditions higher than $170^{\circ} \mathrm{C}$ exhibits a decrease trends in carbohydrate concentration and also biomethane production 
yield in first four days relative to the intensity of pretreatment temperature. After the first four days, the biomethane production seems comparatively similar for all samples. As it is reported before carbohydrate is the first component of organic matter that is consumed in AD to produce biogas and protein and lipids degradation are slower comparing to carbohydrate disintegration (Ariunbaatar et al., 2014), considering this it is hypothesised that biogas production improvement in lower pretreatment temperature is due to the high availability of total carbohydrate. Protein hydrolysis starts by increase in pretreatment temperature and protein degrades to its smaller molecules and high temperature with availability of small carbohydrate molecules make a suitable condition for formation of Amadori compound or Melanoidins which is not degradable biologically (Jin et al., 2016).

\subsubsection{Methane Production Rate}

During the AD experiment TWAS reached to its maximum biomethane production rate after 3 days for all pretreated and non-pretreated samples and after that it shows a huge reduction in daily production rate. Figure 4.6 shows the biomethane production rate in a comparison between pretreated and non-pretreated TWAS.

The highest methane production rate was observed in lowest pretreated condition of $160^{\circ} \mathrm{C}-20$ min with $22 \mathrm{~mL} / \mathrm{g} \mathrm{COD}_{\text {added }} / \mathrm{d}$ and the lowest methane production of $7 \mathrm{~mL} / \mathrm{g} \mathrm{COD}_{\text {added }} / \mathrm{d}$ was obtained in the most severe pretreated condition of $240^{\circ} \mathrm{C}-20 \mathrm{~min}$. The biomethane production rate shows a decreasing trend with the increase in pretreatment severity condition. In pretreatment conditions with SI>4 the highest methane production rate is lower than the control. This finding is in an agreement with the result of biodegradability, the biomethane improvement shows that pretreatment condition with severity higher than $210^{\circ} \mathrm{C}-10$ min has a negative impact on the biodegradability of pretreated TWAS and same result can be seen in biomethane production rate. One of the component in the TWAS is the carbohydrates which are the fastest degradable matter in AD. The highest concentration of soluble carbohydrate was obtained in the same condition that has the highest methane production rate and degradability illustrated in figure 4.2. This can be explained as the produced biomethane in AD process of TWAS mostly came from digestion of carbohydrates and protein. A huge portion of biomethane produced in this process between $60-70 \%$ among different pretreated conditions happened in the first 11 days of the experiment. Observing this it can be concluded that most of the biogas was produced by carbohydrate being the fastest biodegradable component of organic waste. After the day 20 that 
typically the degradation of other organics like fats and particulate protein is assumed to start, the biomethane production shows a reduced trend.

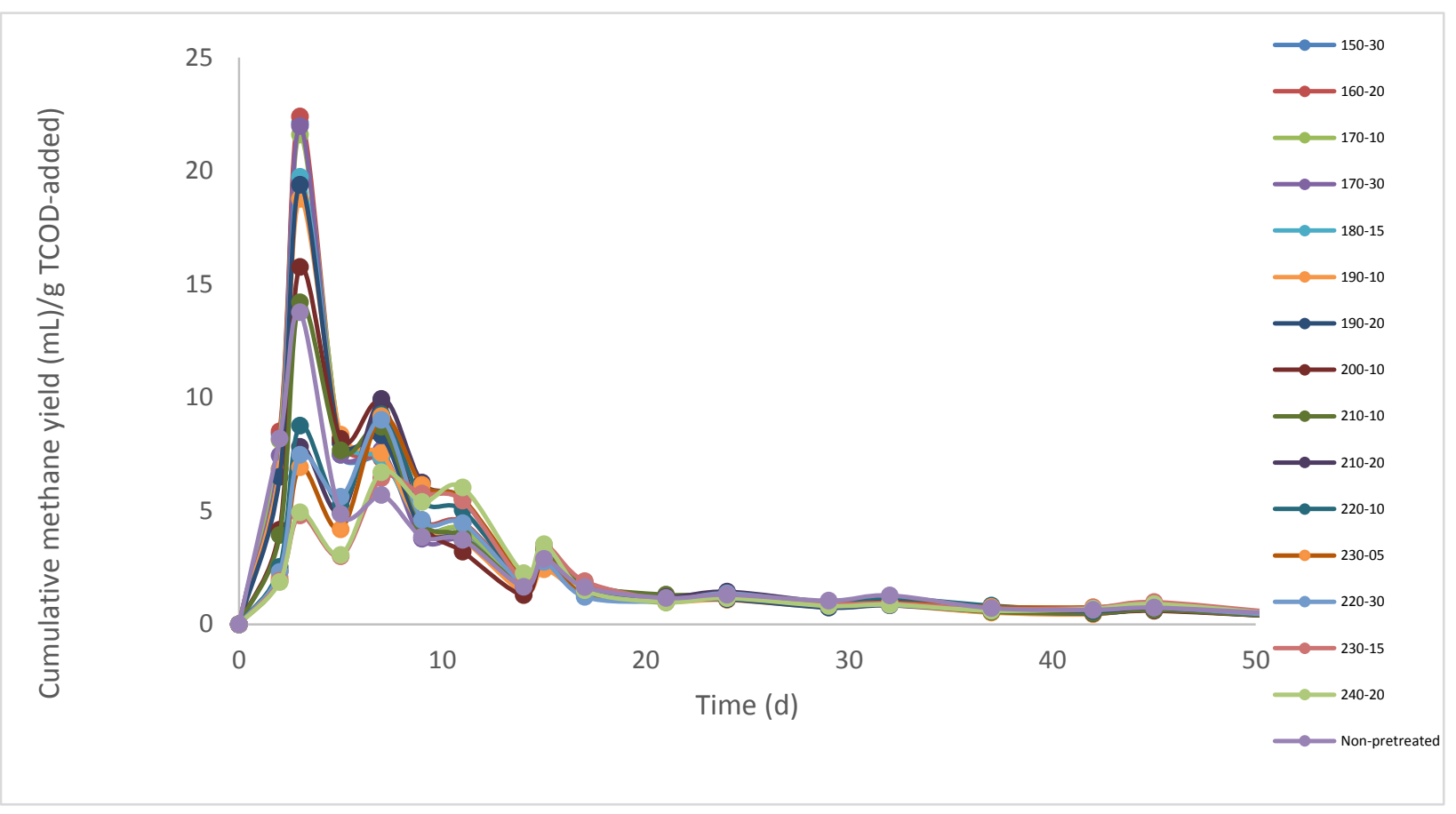

Figure 4.8. Effect of Hydrothermal Pretreatment on Methane Production Rate

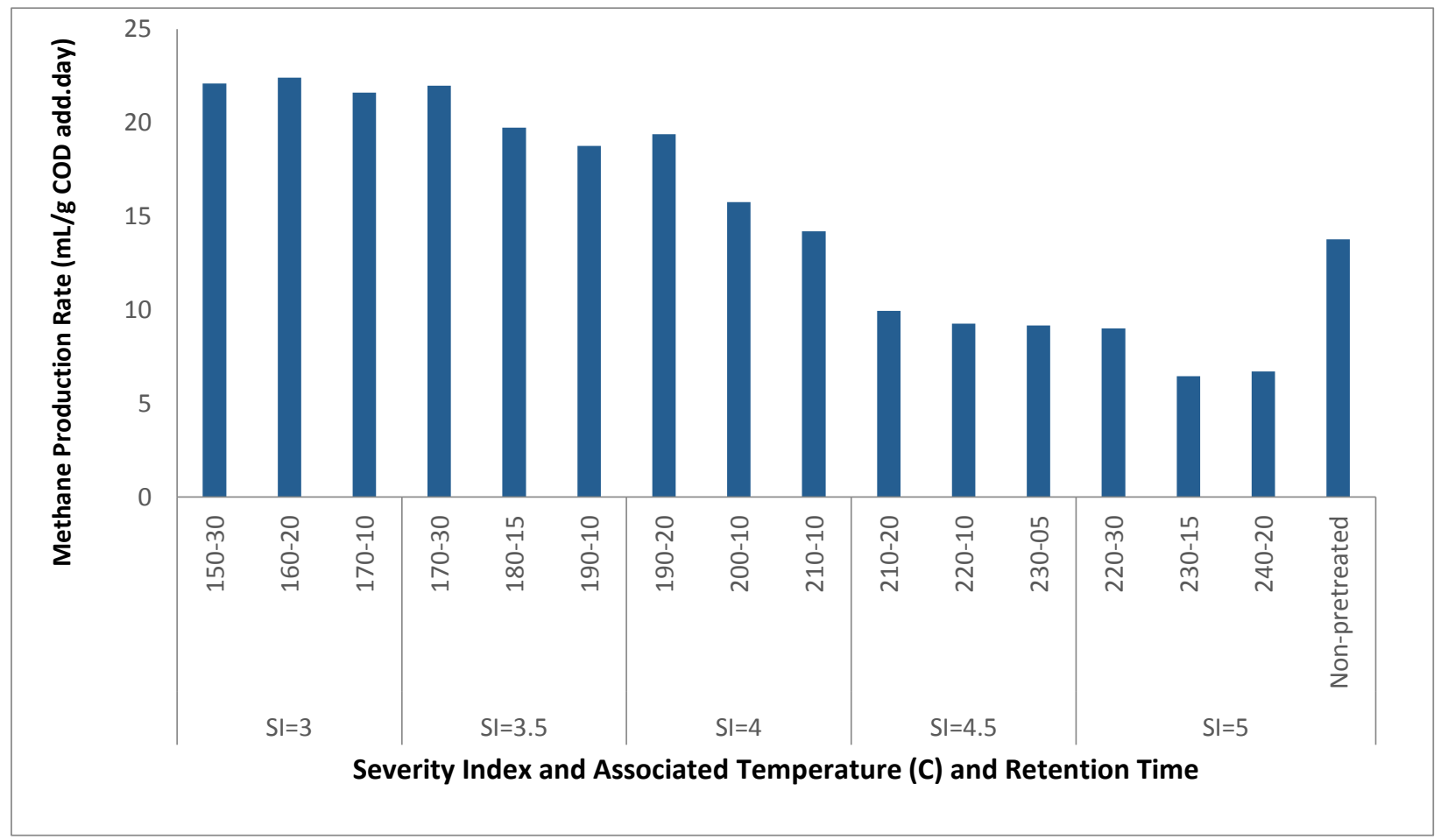

Figure 4.9. Effect of Hydrothermal Pretreatment on Highest Methane 
For pretreated conditions that has lower production rate comparing to the non-pretreated sample it is as a result of Millard reaction happened between soluble protein and carbohydrate that form non-biodegradable matter. As carbohydrate and amino acids is the main component of melanoidins and the formation of this refractory matter in $\mathrm{AD}$ is reported to have a relation with the concentration of carbohydrate and amino acid (Liu et al., 2012a).

\subsection{SSO Results and Discussions}

\subsubsection{Effects of hydrothermal pretreatment on SSO disintegration}

As previously shown in Table 3.2, the SSO samples were subjected to fifteen different hydrothermal pretreatment conditions under five severity index values (3.0, 3.5, 4, 4.5, and 5.0). Figure 4.8 compares the concentration of soluble COD (SCOD) for the non-pretreated (control) and pre-treated samples.

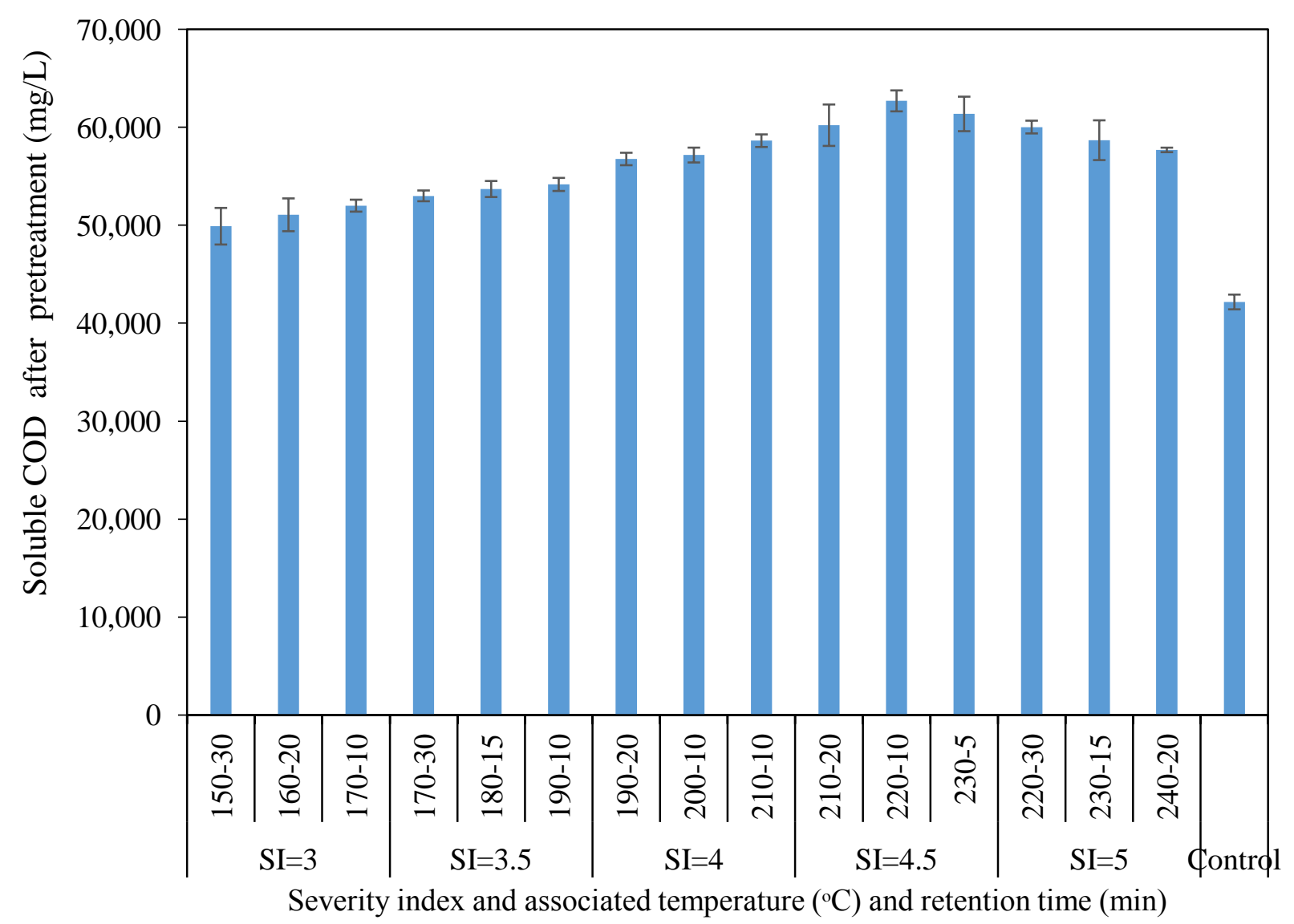

Figure 4.10. The effect of hydrothermal pretreatment on SSO Solubilization-SCOD concentration 


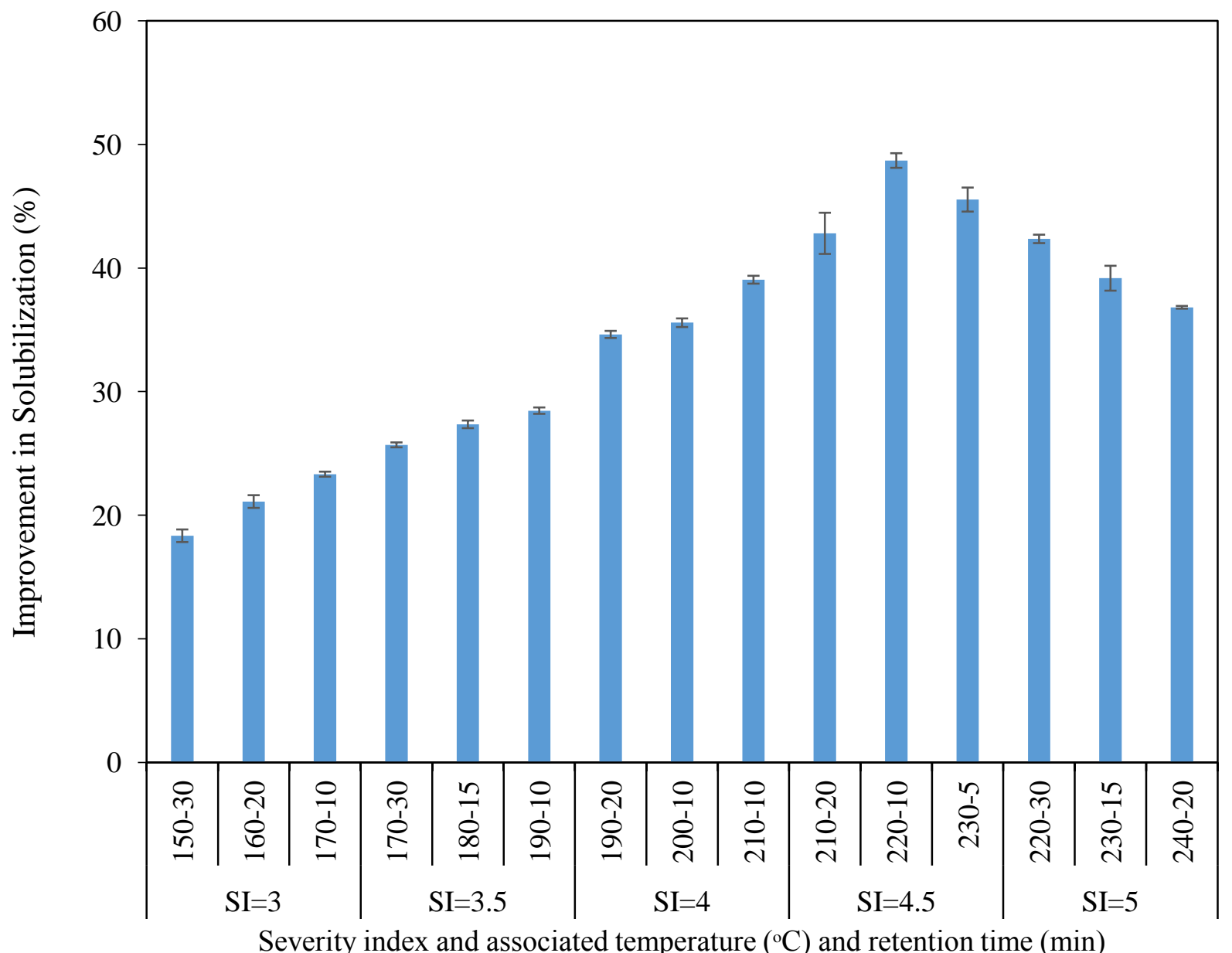

Figure 4.11. The effect of hydrothermal pretreatment on SSO solubilization improvement (relative to control)

The percentage improvement in the SCOD concentration $(\mathrm{P})$ of the pre-treated samples compared to the non-pretreated sample is also shown in Figure 4.9. According to the Figure 4.8 and Figure 4.9, from the SI of 3 to 4.5, increasing the pretreatment intensity increased the SCOD concentration. The maximum SCOD concentration of $62,700 \pm 1,100 \mathrm{mg} / \mathrm{L}$ was achieved at the pretreatment condition of " $220^{\circ} \mathrm{C}-10 \mathrm{~min}$ " under the $\mathrm{SI}=4.5$. This pretreatment condition resulted in $49 \pm 2 \%$ improvement in the SSO solubilization compared to the non-pretreated sample. As observed in Figure 4.7, further increasing the intensity of the pretreatment beyond SI $=4.5$ not only did not enhance the SSO solubilization, but also reduced the SCOD concentration. Other researchers have also observed the adverse effect of high-temperature pretreatment conditions on the solubilization of other organic wastes. In this regard, Shahriari reported the 
formation of non-soluble refractory compounds during microwave pretreatment of the organic fraction of municipal solid waste above $175^{\circ} \mathrm{C}$ (Shahriari, 2011). A similar observation has been reported in another study where the carbonization of food waste at temperatures above $220^{\circ} \mathrm{C}$ resulted in the formation of insoluble organic compounds (Li et al., 2013b).

This observation can be explained by the formation of melanoidins that has carbohydrate and protein in form of amino acid as the base of its structure. SSO is reach in carbohydrate and protein in its composition and a high concentration of it with temperature increase can encourage Millard reactions.

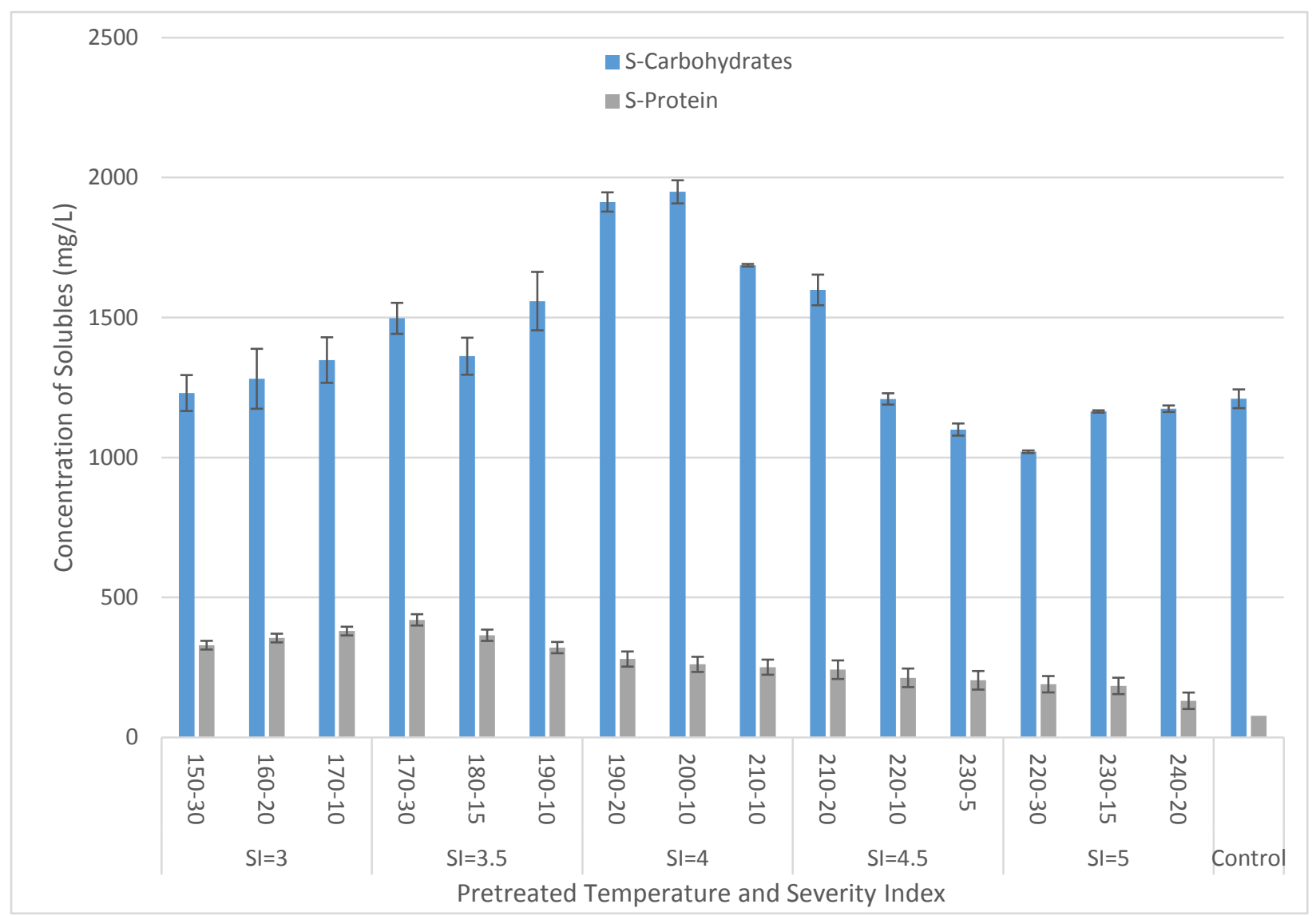

Figure 4.12. Soluble Carbohydrate and Protein Concentration Comparing to the NonPretreated Sample

SSO is a complex matter with carbohydrates, protein, crude fiber and fats. Temperature increase has the highest effect on the solubilization of carbohydrate and protein as it can be seen in figure 4.8 , with the severity of pretreatment the solubilization of carbohydrates increased up to $\mathrm{SI}=4$ and pretreated temperature of $200{ }^{\circ} \mathrm{C}$. The highest solubilization of protein happened in lower 
temperature $170^{\circ} \mathrm{C}$ and by further increase in temperature the concentration of soluble protein reduced. This finding supports the COD solubilization and shows the same trend with a difference that COD solubilizing continue to increase up to pretreatment temperature of $210^{\circ} \mathrm{C}$. This might be for the reason of crude fiber available in the SSO which solubilize in more severe pretreated condition comparing to polysaccharide and protein.

\subsubsection{Suspended solids reduction of SSO}

Figure 4.11 shows the TSS and VSS concentration of the non-pretreated and pretreated SSO samples. The suspended solids reduction efficiency (R) after hydrothermal pretreatment are also shown in Figure 4.12.

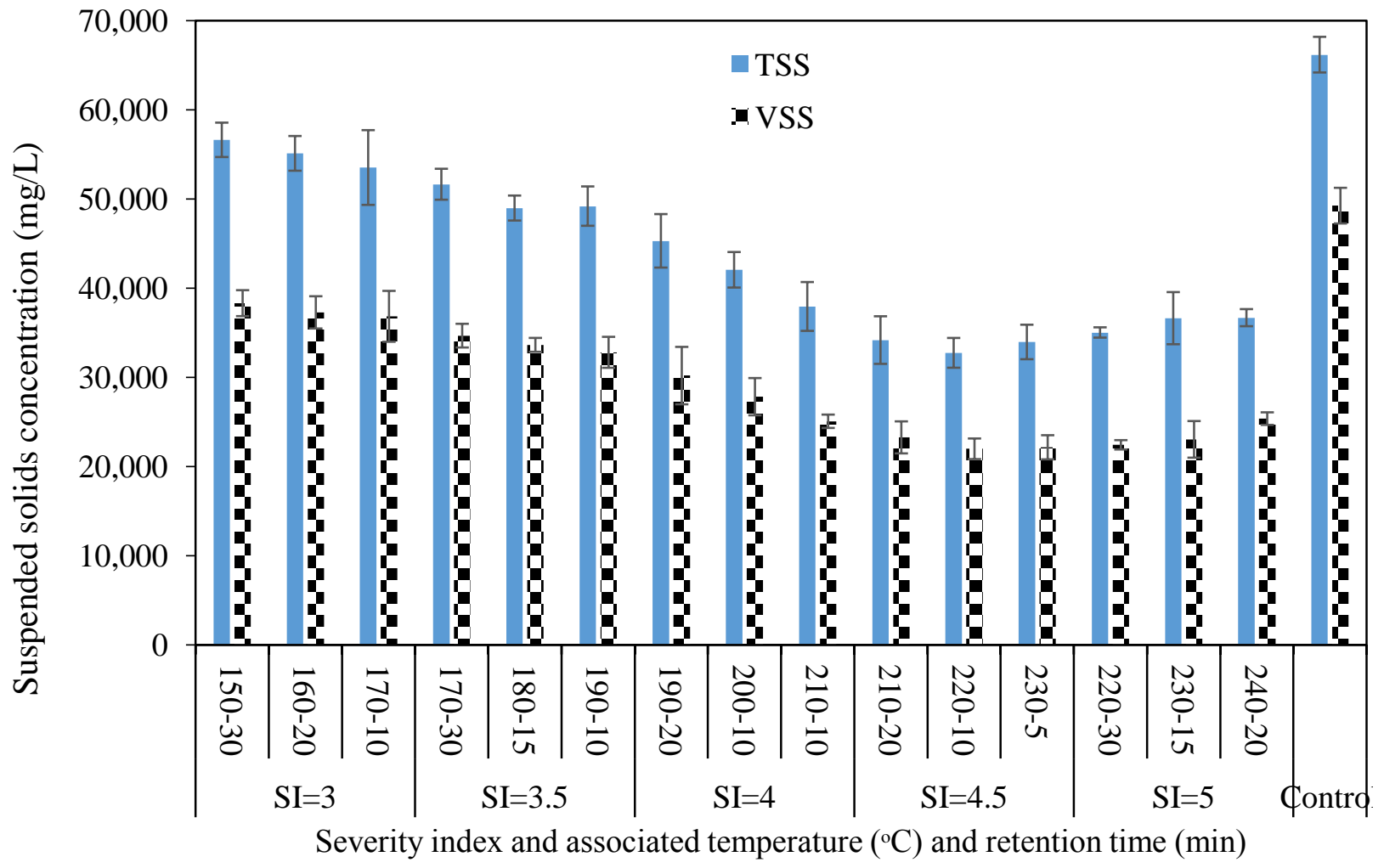

Figure 4.13. The effect of hydrothermal pretreatment on suspended solids; suspended solids concentration 


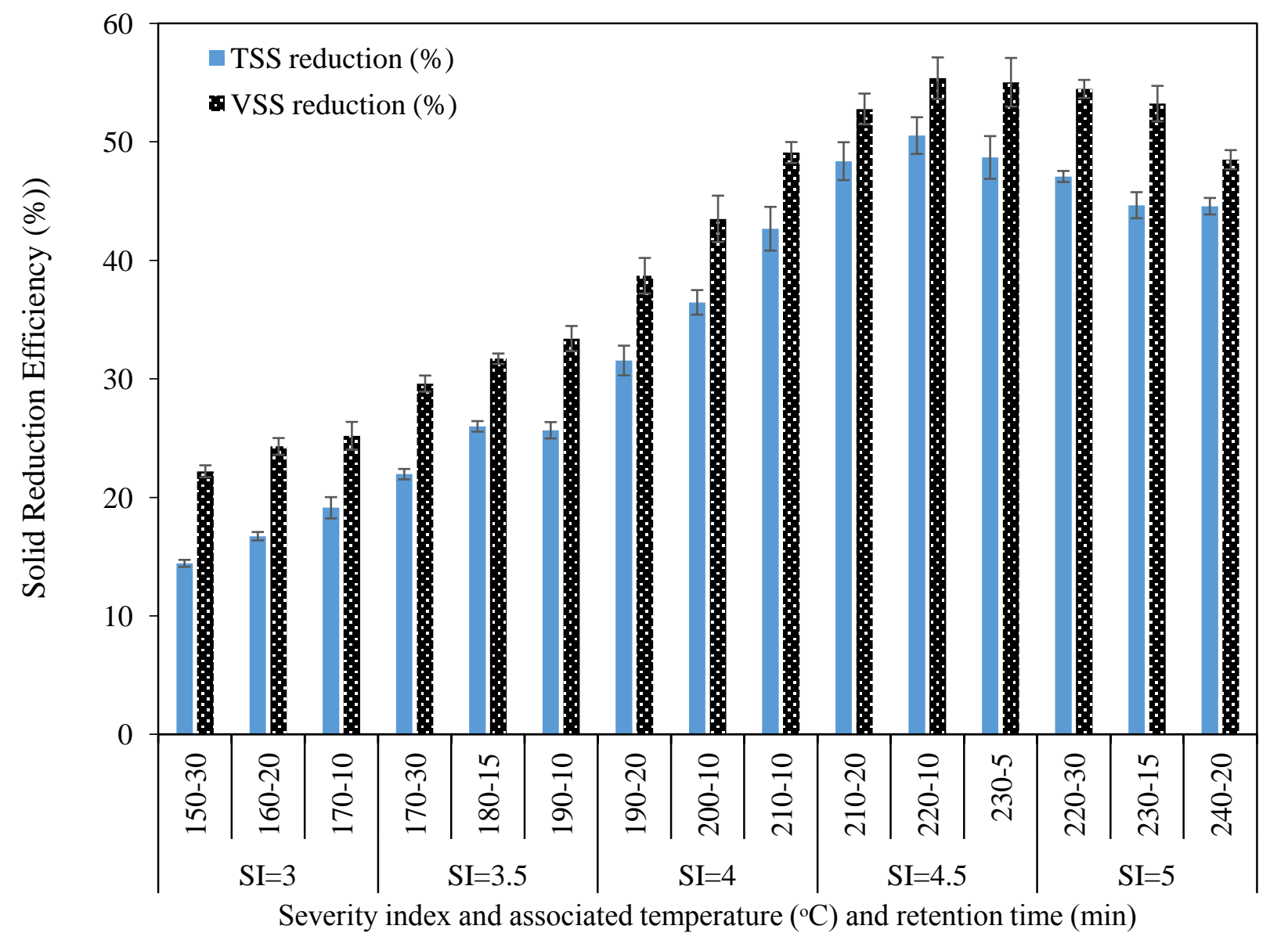

Figure 4.14. The effect of hydrothermal pretreatment on suspended solids; suspended solids reduction efficiency

According to the results, the hydrothermal pretreatment had a considerable effect on the reduction of TSS and VSS of the SSO samples. As per Figure 4.11, between the SI of 3 and 4.5, increasing the pretreatment temperature from $150^{\circ} \mathrm{C}$ to $220^{\circ} \mathrm{C}$ was inversely proportional to the TSS and VSS concentration. However, increasing the pretreatment intensity beyond the SI of 4.5 resulted in the increase of the TSS and VSS concentration, decreasing the overall efficiency of the pretreatment in terms of the suspended solids reduction. According to Figure 4.12, the effect of the pretreatment on the TSS reduction was less than that of the VSS. This observation can be explained by the fact that the hydrothermal pretreatment mainly targets the organic matter (i.e., fats, proteins, carbohydrates, etc.) rather than inorganic (Lin et al., 2018). The application of hydrothermal pretreatment at the temperature of $220^{\circ} \mathrm{C}$ and retention time of $10 \mathrm{~min}$ reduced the VSS concentration from $49,300 \pm 2000 \mathrm{mg} / \mathrm{L}$ in the non-pretreated sample to $22,000 \pm 1300$ 
$\mathrm{mg} / \mathrm{L}$. The applied pretreatment condition resulted in TSS and VSS reduction efficiencies of $50 \pm$ $1.5 \%$ and $55 \pm 2 \%$, respectively. In agreement with the results of the COD solubilization study, the statistical analysis proved the meaningful effect of SI, pretreatment temperature, and retention time on the reduction of SSO suspended solids contents $(\mathrm{P}<0.05)$. It was also revealed that the effect of pretreatment temperature on suspended solids reduction was higher than that of the retention time. The comparison of the PSD of the non-pretreated samples with that of the pretreated ones also confirmed the significant effect of the hydrothermal pretreatment on solubilization and reducing the size of the SSO particles. As per the PSD analysis results, the D10, D50 and D90 were reduced from $23 \mu \mathrm{m}, 132 \mu \mathrm{m}$, and $1440 \mu \mathrm{m}$ in the non-pretreated SSO samples to the lowest values of $14 \mu \mathrm{m}, 70 \mu \mathrm{m}$, and $210 \mu \mathrm{m}$ after hydrothermal pretreatment, corresponding to 40,47 , and $85 \%$ reduction, respectively. It is noteworthy that the D10, D50, and D90 is the value (in $\mu \mathrm{m}$ ) at which 10,50 , and $90 \%$ of the sample particles have a diameter less than this value, respectively.

Considering the overall results of the SSO disintegration study, it can be inferred that the application of hydrothermal pretreatment at a temperature of $150^{\circ} \mathrm{C}$ or less will not be effective enough to transform the significant portion of the macromolecular organics from the particulate (suspended) form into the soluble phase. On the other hand, the pretreatment temperatures of above $220^{\circ} \mathrm{C}$ most likely result in the formation of insoluble high-carbon polymers reducing the overall degree of solubilization. It is noteworthy that in addition to the adverse effect on solubilization, some researchers observed reduced biogas/biomethane production from various organic compounds pretreated under high-temperature conditions (Ariunbaatar et al., 2014 ;Lin et al., 2018; Ma et al., 2011). These observations will be evaluated in the next sections.

\subsubsection{Effect of hydrothermal pretreatment on anaerobic digestion of SSO}

The BMP assay was continued for about 40 days when the biogas production became nearly negligible. The cumulative methane yields of the non-pretreated and thermally-pretreated digesters are shown in Figure 4.13. As per Figure 4.13, no lag phase as a result of the late respond of the microbial population to the unexpected environmental conditions was observed at the beginning of the digestion period. However, it was observed that depending on the range of pretreatment temperature used, the pretreated digesters followed different patterns of the cumulative methane yield. 


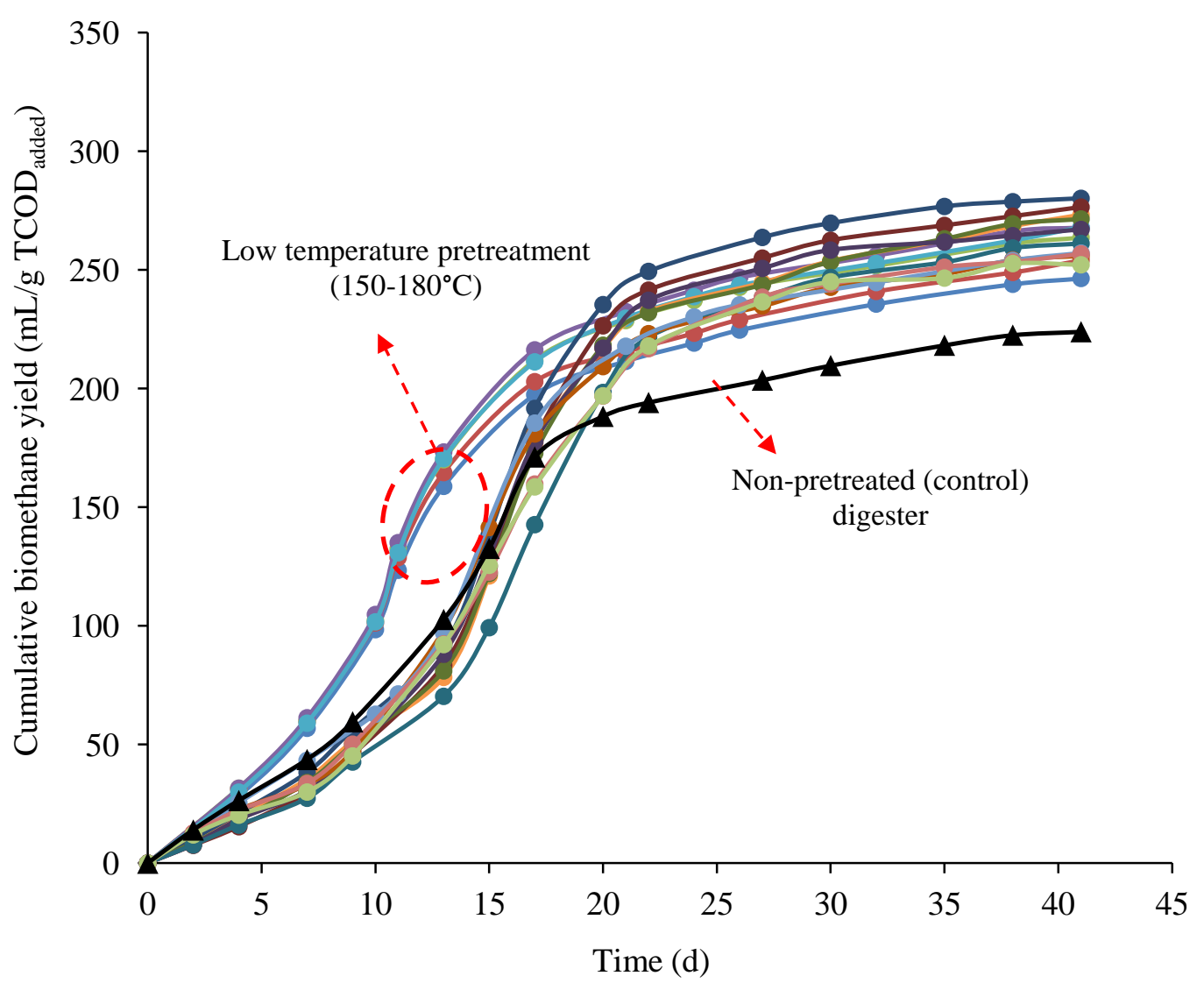

Figure 4.15. The cumulative methane production of the BMP digesters (@ the STP)

According to Figure 4.13, the plot of cumulative methane yield associated with the control digester and also the digesters fed with the pretreated SSO at a temperature range of 190 to $240^{\circ} \mathrm{C}$ were shifted to the right compared to that of the low-temperature (150 to $180^{\circ} \mathrm{C}$ ) pretreated digesters. In another word, during the first two weeks, to produce a given amount of methane, more time was required for the non-pretreated digester as well as the ones fed with the high-temperature pretreated substrate. It is also observed that although during the first fifteen days, the cumulative methane yield of the non-pretreated digester was higher than that of the high-temperature $\left(>=190^{\circ} \mathrm{C}\right)$ pretreated digesters, all the pretreated digesters achieved higher ultimate methane yield at the end of the BMP assay compared to the control digester. Among the digesters with higher cumulative biomethane production during the first 15 days, the application of hydrothermal pretreatment at a temperature of $170^{\circ} \mathrm{C}$ for 30 and 10 min resulted in the highest initial biomethane yield of 216 and $212 \mathrm{~mL} / \mathrm{g} \mathrm{TCOD}_{\text {added. }}$. The lowest 15-d biomethane yield belonged to the pretreatment condition of " $220^{\circ} \mathrm{C}-10 \mathrm{~min}$ ". 


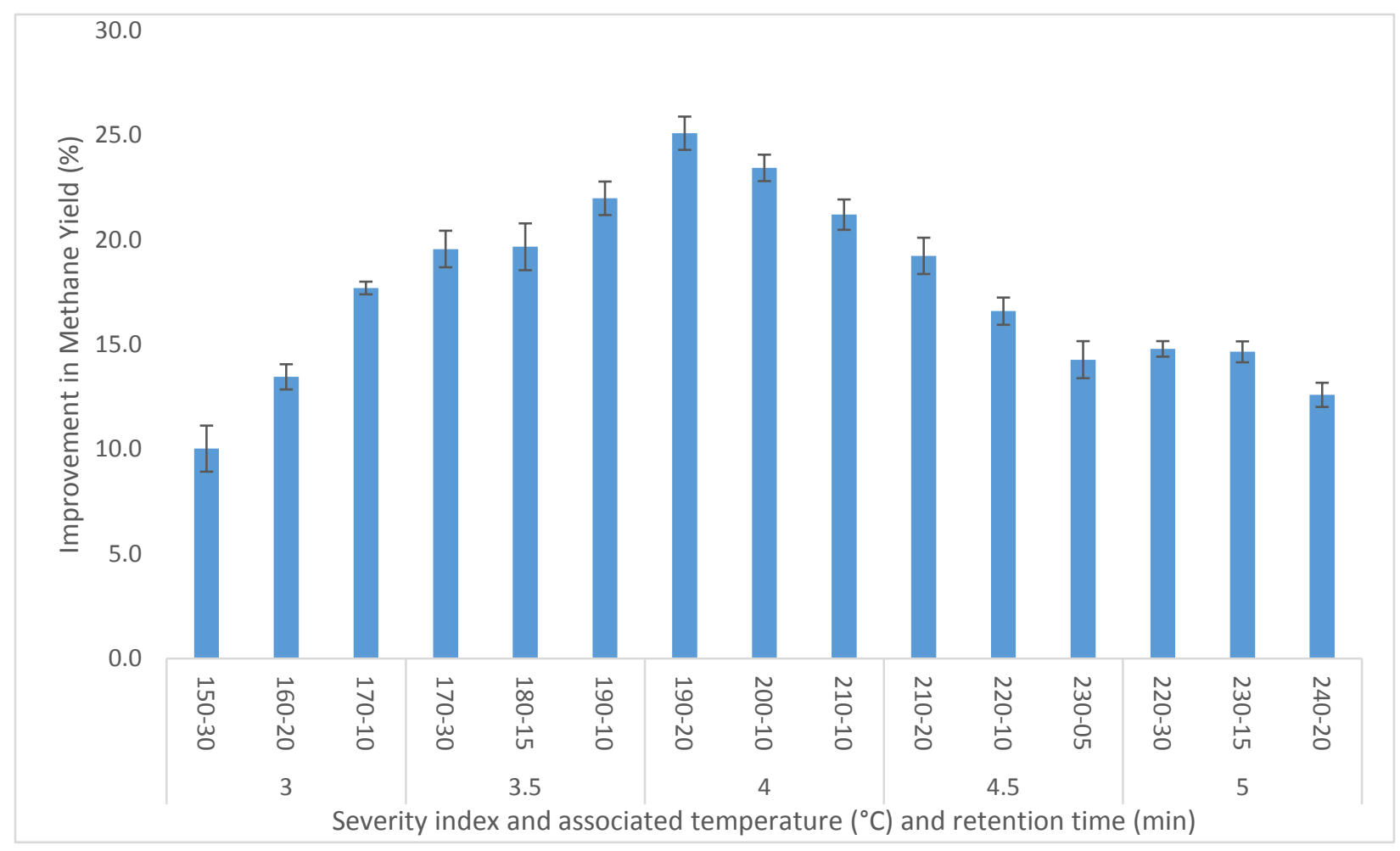

Figure 4.16. The effect of hydrothermal pretreatment on methane yield improvement (@ the STP)

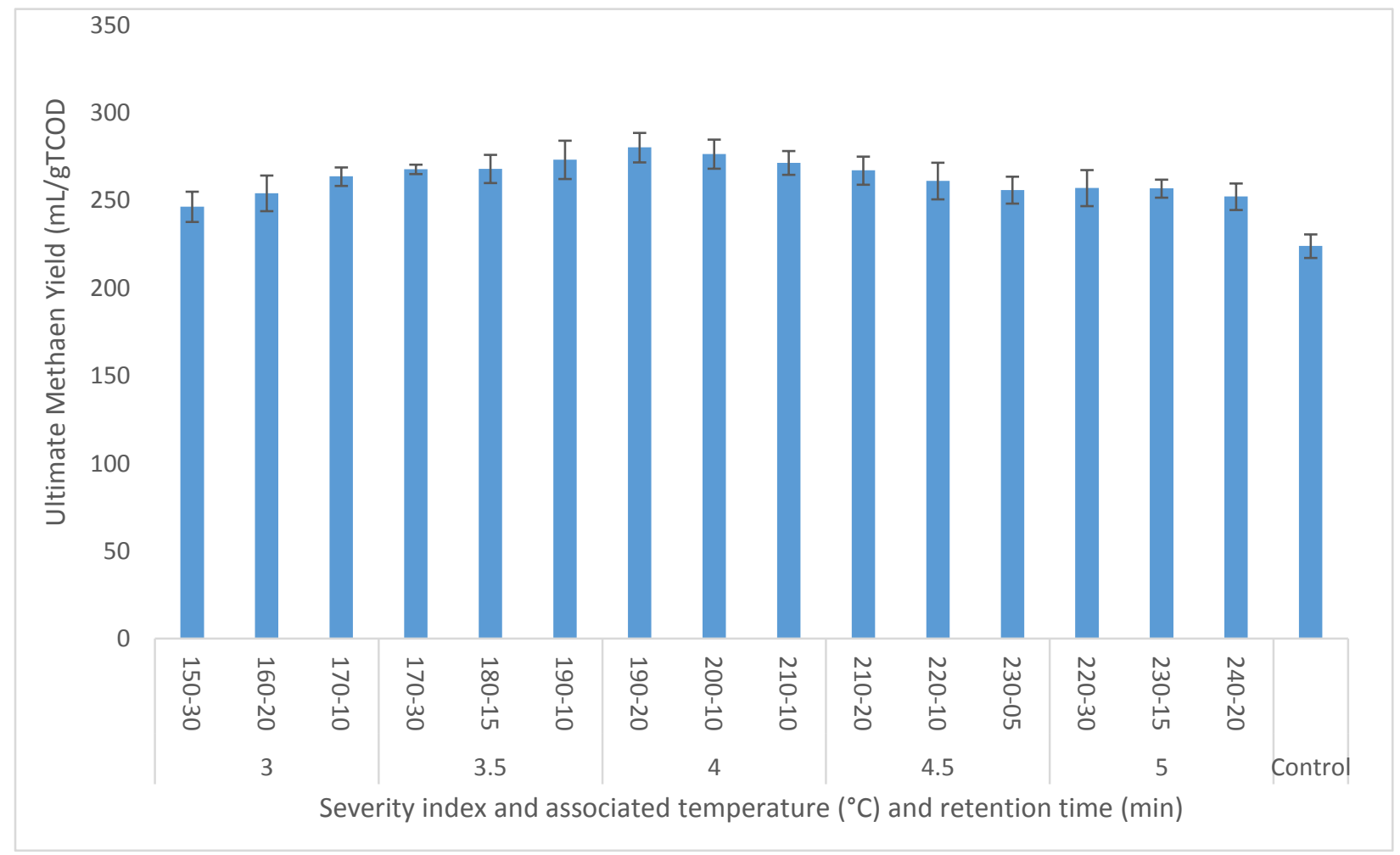

Figure 4.17. Effect of hydrothermal pretreatment on ultimate methane yield (@ the STP) 
Figure 4.15 compares the ultimate methane yield of the digesters after 40 days of the operation. The relative (to control) improvements in the methane yield of the pretreated digesters are also compared in Figure 4.14. According to the results, the methane yield was increased by $10-25 \%$ depending on the pretreatment condition. The maximum methane yield of $280 \pm 8 \mathrm{~mL} / \mathrm{g}$ $\mathrm{TCOD}_{\text {added }}$ was obtained under a pretreatment temperature of $190^{\circ} \mathrm{C}$ and a retention time of 20 min which was $25 \pm 1 \%$ more than that of the control digester $\left(224 \pm 7 \mathrm{~mL} / \mathrm{g}\right.$ TCOD $\left._{\text {added }}\right)$. Following the non-pretreated SSO, the lowest methane production belonged to the digester fed with the substrate pretreated under the least intensive condition at a temperature of $150^{\circ} \mathrm{C}$ with 30 min retention time. The enhanced methane recovery observed in this study via hydrothermal pretreatment of SSO are in agreement with the findings of other studies exploring the effect of thermal (or hydrothermal) pretreatment on other organic wastes such as food waste, municipal sludge, and animal manure (Arelli et al., 2018)(Carrère et al., 2009) (Ding et al., 2017). In a study carried out by (Wang et al., 2006), the application of hydrothermal pretreatment on food waste increased the population density of methanogens in a mesophilic AD process that favoured the methane recovery by $12 \%$ over the non-pretreated digester. In comparison, the authors reported that the low-temperature thermal pretreatment at $70^{\circ} \mathrm{C}$ did not have any significant effect of biomethane recovery from food waste (Wang et al., 2006). (Arelli et al., 2018) reported that the application of thermal pretreatment at a temperature of $120^{\circ} \mathrm{C}$ on high solid content food waste (TS $=30 \%$ ) increased the methane production by more than $50 \%$. Similarly, the hydrothermal pretreatment of food waste at a temperature of $140^{\circ} \mathrm{C}$ achieved the methane yield of $510 \mathrm{~mL} / \mathrm{g} \mathrm{VS}_{\text {added }}, 38 \%$ higher than that of the methane yield in the non-pretreated digester (370 mL/g $\left.\mathrm{VS}_{\text {added }}\right)$ in another study conducted by (Ding et al., 2017).

As per Figure 4.11, the improvement in methane yield showed an increasing trend starting from the lowest SI (corresponds to the temperature of $150^{\circ} \mathrm{C}$ ) and peaked at the SI of 4 (corresponds to the temperature of $190^{\circ} \mathrm{C}$ ). However, further increase of the temperature resulted in an adverse effect on methane production. These findings suggest that as the intensity of pretreatment increases (beyond $190^{\circ} \mathrm{C}$ in the current study), the digestibility of some hydrolysates is reduced resulting in lower methane recovery. According to the literature, some low molecular weight intermediates (i.e., monosaccharide and amino acids) can be polymerized during maillard reaction at elevated temperatures, forming high molecular weight recalcitrant compounds such as melanoidins (Dwyer et al., 2008) (Gerrard, 2005). The formation of inhibitory/refractory 
compounds during high-temperature pretreatment conditions resulting in the reduced $\mathrm{AD}$ performance was also reported by other researchers (Shahriari et al., 2012) (Li et al., 2013a)(Li et al., 2014). In this regard, (Shahriari et al., 2012) reported a decrease in the biogas production through the digestion of organic fraction of municipal solid waste when the pretreatment applied at the temperatures above $175^{\circ} \mathrm{C}$. In another study conducted by ( $\mathrm{Li}$ et al., 2013a), 7.9 and $11.7 \%$ reduction was observed respectively through the $\mathrm{AD}$ of kitchen waste and vegetable/fruit waste, respectively, due to melanoidins formation at the pretreatment temperature of around $180^{\circ} \mathrm{C}$.

Considering the results of the solubilization and BMP studies, the overall trend of the effect of the hydrothermal pretreatment on methane yield (Figure 4.15) was the same as that of the SSO solubilization (Figure 4.8). However, the highest biomethane yield was obtained at a temperature of $190^{\circ} \mathrm{C}$, while the maximum solubilization was achieved at more intensive pretreatment condition (temperature of $220^{\circ} \mathrm{C}$ ). In agreement with the findings of this study, some previous studies also revealed that although thermal pretreatment can improve both the solubilization and biogas production, the highest SCOD concentration does not necessarily correspond to the highest methane yield (Cesaro \& Belgiorno, 2014; Nazari et al., 2017). Taking into account that the trend of temperature and SI effects on SSO solubilization and biomethane yield was similar until the temperature reached $190^{\circ} \mathrm{C}$, a correlation analysis was performed to evaluate whether there is any statistically meaningful correlation between the concentration of SCOD and biomethane yield or not (below $190^{\circ} \mathrm{C}$ ). According to the results of correlation analysis, the calculated Pearson correlation coefficients of 0.967 was obtained with a p-value of below 0.05 , suggesting a statistically significant correlation between the concentration of SCOD and methane yield for the temperature range of $150-190^{\circ} \mathrm{C}$.

According to the obtained results, in addition to the pretreatment temperature, the retention time had a statistically significant effect on SSO solubilization $(\mathrm{P}<0.05)$. For example, as seen in Figure 4.7, under the two SI values of 3 and 3.5 with the same temperature of $170^{\circ} \mathrm{C}$, increasing the retention time from $10 \mathrm{~min}(\mathrm{SI}=3)$ to $30 \mathrm{~min}(\mathrm{SI}=3.5)$ increased the methane yield by $2 \%$. It is noteworthy that despite the statistically significant effect of retention time, the results of the main-effect test revealed that the impact of the pretreatment temperature was more significant than that of the retention time. In another word, enhancing the methane yield from pretreated SSO by increasing the SI was primarily determined by the pretreatment temperature rather than 
the retention time. This observation is more apparent in Figure 5.3, where the main-effect plots of the methane yield improvement vs. pretreatment temperature, retention time, and SI are shown. As per Figure 5.3, the overall effect of the pretreatment temperature on methane yield followed a similar pattern as that of the severity index. These results suggest that it is more practical to reduce the retention time of the pretreatment to as low as $10 \mathrm{~min}$ and instead increase the pretreatment temperature until a desired methane yield is achieved. Reducing the retention time will decrease the volume of the required heating tank for a given flow rate.

\subsubsection{Biomethane production rate}

Figure 4.16 compares the change in the methane production rate of the control and pretreated digesters. The effect of the hydrothermal pretreatment on maximum methane production rate is shown in Figure 4.17. According to the results of this study, the effect of hydrothermal pretreatment on methane production rate was a factor of pretreatment condition. As seen in Figure 4.16, although all the digesters (control and pretreated) demonstrated an initial period during which the methane production rate was below $10 \mathrm{~mL} / \mathrm{g}$ TCOD $_{\text {added }} \mathrm{d}$, the length of the initial period was longer for the control digester as well as the ones fed with SSO pretreated at the temperatures above $180^{\circ} \mathrm{C}$. As per Figure 4.16, the maximum methane production rate of the digesters pretreated at the temperature range of $150-180^{\circ} \mathrm{C}$ was observed at around $10^{\text {th }}$ days from the start of the BMP assay, while it took 15-17 days for the control and high-temperature pretreated digesters to achieve to their maximum production rates. According to Figure 4.17, the maximum methane production rate improved by increasing the pretreatment temperature until it reached to $30 \pm 1 \mathrm{~mL} / \mathrm{g} \mathrm{TCOD}_{\text {added. }} \mathrm{d}$ at the temperature of $170^{\circ} \mathrm{C}$, and after that, it continuously decreased by increasing the pretreatment temperature beyond $170^{\circ} \mathrm{C}$. The lowest value of the maximum methane production rate $\left(17 \pm 1 \mathrm{~mL} / \mathrm{g}\right.$ TCOD $\left.{ }_{\text {added }} . \mathrm{d}\right)$ was obtained at a temperature of $240^{\circ} \mathrm{C}$. Considering the results of the ANOVA test, the pretreatment temperature and SI had statistically significant effects on the maximum methane production rate $(\mathrm{P}<0.05)$. Considering the results of the biomethane yield and rate analyses, increasing the intensity of the hydrothermal pretreatment beyond a certain level not only reduced the amount of the recovered methane from a unit mass of the substrate (SSO) but also decreased the rate of the AD process. In agreement with the findings of this study, the adverse effect of increasing the pretreatment temperature from $120^{\circ} \mathrm{C}$ to $160^{\circ} \mathrm{C}$ was reported on the rate of methane production from municipal sludge cake through thermophilic batch AD process (Hosseini Koupaie \& Eskicioglu, 2016). 


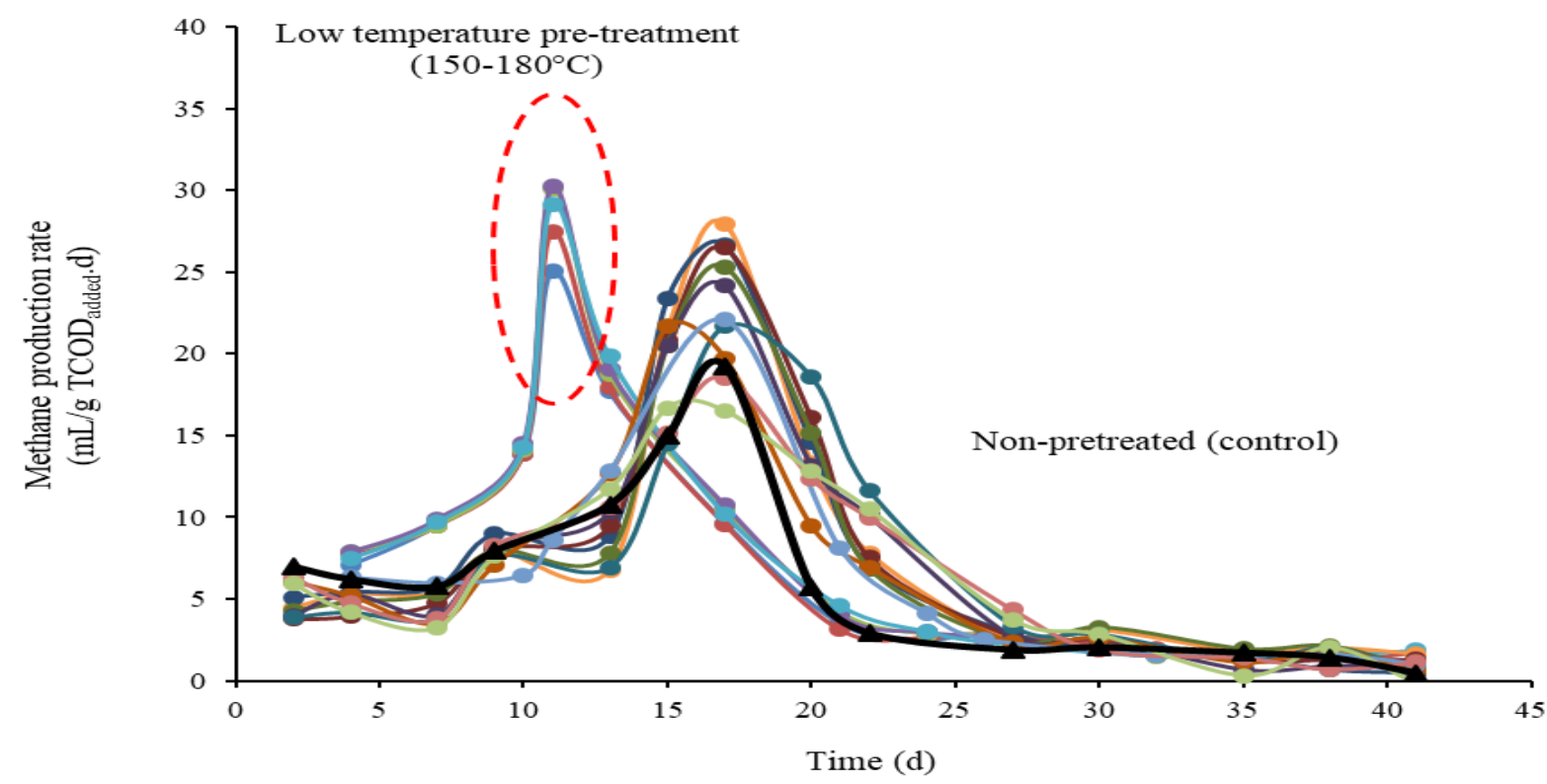

Figure 4.18. The effect of hydrothermal pretreatment on daily methane production rate

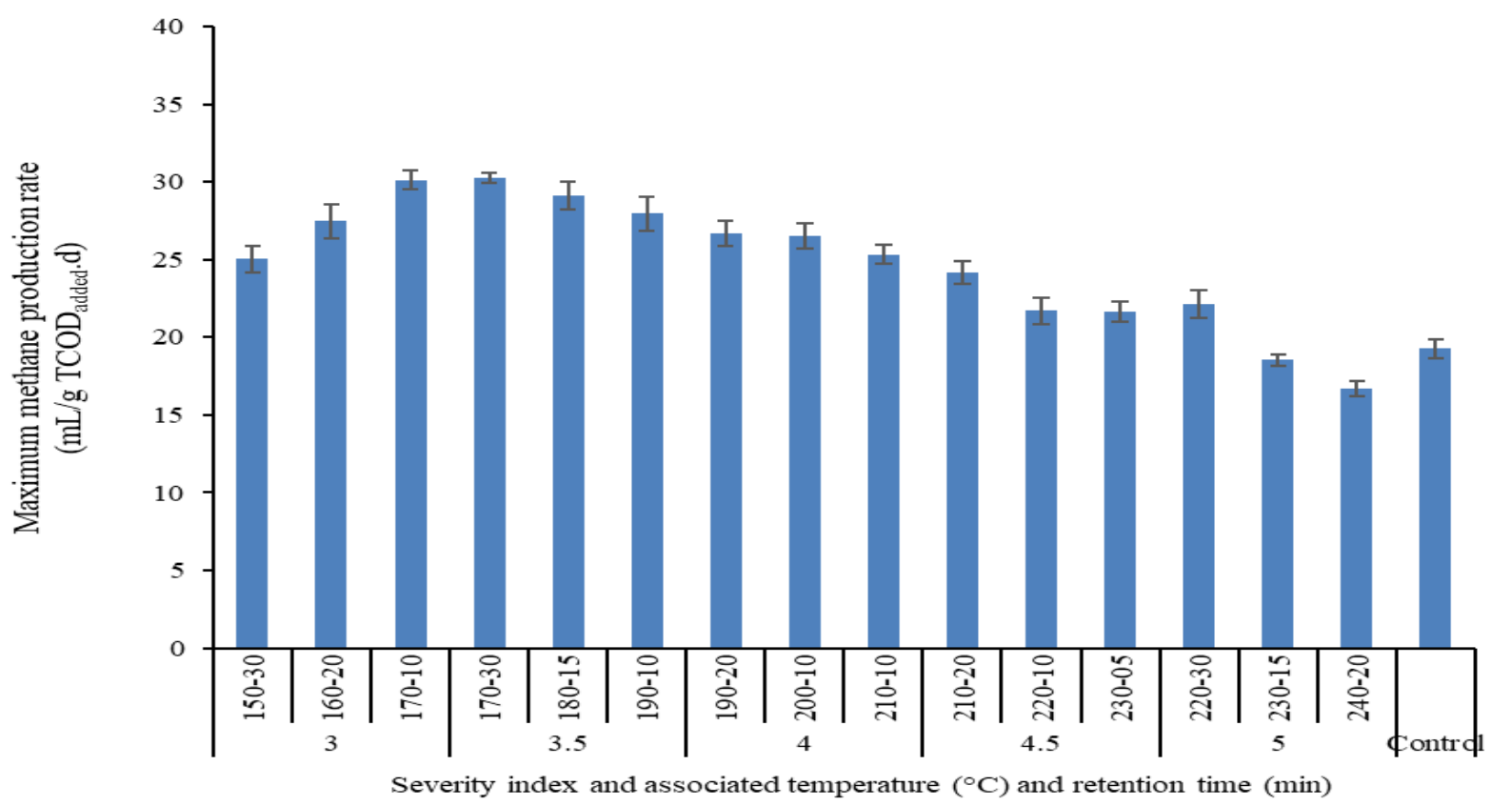

Figure 4.19. The effect of hydrothermal pretreatment on maximum methane production rate 
It is noteworthy that the mass balance of the digesters was carried out after the termination of the experiment considering the initial and the final TCOD concentration of the digester contents and the theoretical methane production from a unit mass of TCOD removed. Comparison of the actual methane production achieved in this research with that of determined from TCOD mass balance demonstrated a deviation of less than $10 \%$ for all the digesters. 


\section{Impact of Hydrothermal Pretreatment on TWAS and SSO}

Hydrothermal pretreatment is one of the promising approaches to improve substrates properties

of solubilizing the particulate organic matters and enhance the biogas production. It is also reported that it enhance the dewaterability $50-100 \%$ and reduce the viscosity that means substrate is more fluid and digester can receive higher solid concentration 8-12\% (Liu et al., 2012a). The feedstock properties in composition like homogeneity and its biodegradability can be influenced differently by thermal pretreatment prior to the AD process. In this study two different feedstock was used with completely different characteristics coming from two distinguished waste streams (TWAS and SSO). TWAS is activated sludge that comes after thickening process from secondary clarifier (aeration tank). Sewage sludge is one of the primary feedstock used for $\mathrm{AD}$ to decrease the volume of disposed sludge and still it is one of the most studied substrate for AD. TWAS has a low degradability consists of flocs of microbial biomass (cell membranes are not completely degradable) and exopolymeric matters like protein and carbohydrate (Carrere et al., 2016). In TWAS the ratio of $\mathrm{C} / \mathrm{N}$ is low and it is also considered an inhibition for AD (Habiba et al., 2009).

SSO that comes from organic fraction of municipal solid waste is one of the largest components of waste streams. A large portion of SSO comes from food waste which has a high characteristic variability regarding it is source, season and some other factors. Food waste is a biodegradable feedstock having high moisture content (70-80\%) and a TS to VS ranges from 18.1-30.9 and 17.1-26.35 respectively (Zhang et al., 2014). The other main portion of SSO comes from yard waste which are woody materials with high concentration of cellulosic material and due to the crystalline nature of cellulose it is not easily biodegradable.

Thermal pretreatment besides having advantages in $\mathrm{AD}$ process it is also responsible for formation of some dissolved organic matters called melanoidins which are not easily degradable by biological process. In order to comparing the effect of thermal pretreatment on different substrate used COD solubilization, solid reduction efficiency and biogas production are being compared. 


\subsection{Solubilization Comparison (TWAS and SSO)}

Hydrothermal pretreatment within all treatment scenarios show an increase on solubilization of TWAS and SSO, although the solubilization efficiency is widely different as shown in Figure 5.1.

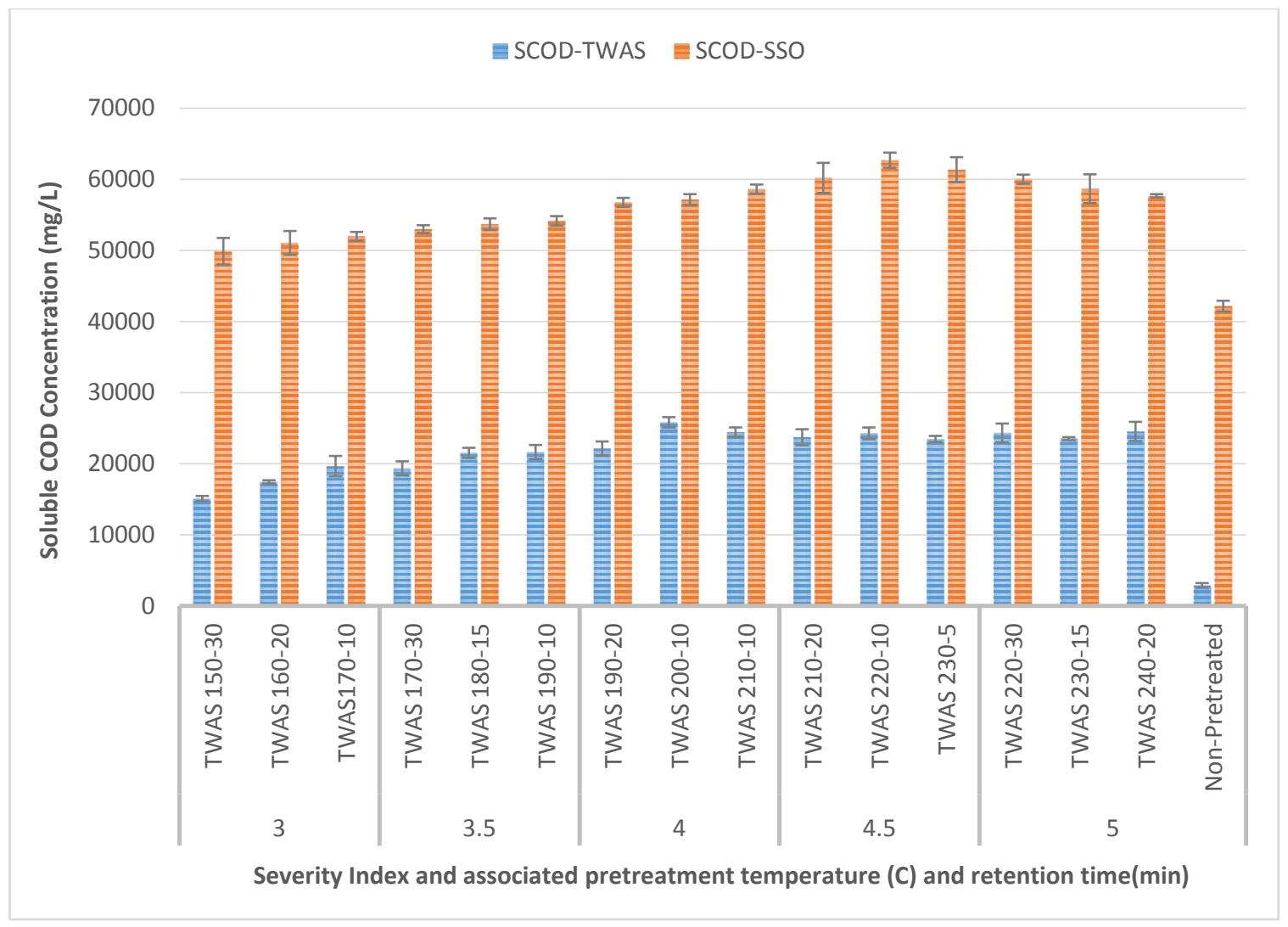

Figure 5.1. The effect of hydrothermal pretreatment on COD solubilization of TWAS and SSO comparison

In all pretreatment conditions soluble COD shows a huge improvement on TWAS comparing to the SSO. The COD solubilization of TWAS increased from $2867 \pm 321$ to $25817 \pm 700 \mathrm{mg} / \mathrm{L}$ for pretreatment condition of $200{ }^{\circ} \mathrm{C}$ and 10 min retention time showing the highest COD by 8.01 times increased comparing to non-pretreated TWAS. SSO also shows increased in COD solubilization with a lower efficiency comparing to TWAS. The highest COD solubilization occurred in pretreatment condition of $220{ }^{0} \mathrm{C}-10$ min by $49 \pm 2 \%$ increased comparing to nonpretreated sample. The primary characteristics of the SSO and TWAS sample explains this huge different in the solubilization improvement. The initial concentration of soluble COD in SSO is much higher than TWAS although after pretreatment the increase in solid destruction for both 
samples are almost in the same range. The percentage of volatile suspended solids (organics) comparing to total suspended solid for SSO and TWAS are in 78\% and 74\% respectively. This results shows that temperature increase break down organic matters with different properties and release the bound and intercellular water.

The highest TSS and VSS destruction for both samples SSO and TWAS occurred in the same pretreatment condition. The highest observed TSS and VSS reduction efficiency for TWAS and SSO were $67 \%$ and $73 \%$ and $51 \%$ and $55 \%$ in pretreatment condition of $220^{\circ} \mathrm{C}-10 \mathrm{~min}$. The hydrothermal pretreatment shows higher impact on VSS reduction comparing to TSS as temperature has higher influence in breaking the organic matters than inorganics. The solid reduction efficiency of SSO is higher comparing with TWAS and it supports the comparison of COD solubilization improvement.

\subsection{Particle Size Distribution}

The particle size of the feedstock can impact the biodegradability rate as it causes to increase the substrate utilization coefficient. One of the objective of the pretreatment is to reduce the particle size of substrates with high fiber content and to improve gas production and digestion rate. The active surface area is related to the particle size and by reducing the size more surface of the organics become available for the microorganisms and end up to biodegradability increase. Comparing the particle size distribution of SSO and TWAS in Figure 5.2 it shows that D90 of TWAS has smaller particles comparing to SSO while D10 for both feedstock is almost in the same range of size. This might be as a reason that TWAS goes through biological treatment and it decrease the particle size while SSO only goes though a mechanical pretreatment which convert feedstock to a homogenize slurries.

In a study by (Zhang \& Banks, 2013) on organics of municipal solid waste it shows that the particle size does not show any impact on biodegradability of the feedstock but when considering the particle size with the digestion system it can help the biomethane production. Although in another study the results conclude that smaller mean particle size can increase the biogas production by $28 \%$ and excessive size reduction causes reduced biomethane production by aggregation of volatile fatty acids (Izumi et al., 2010). 


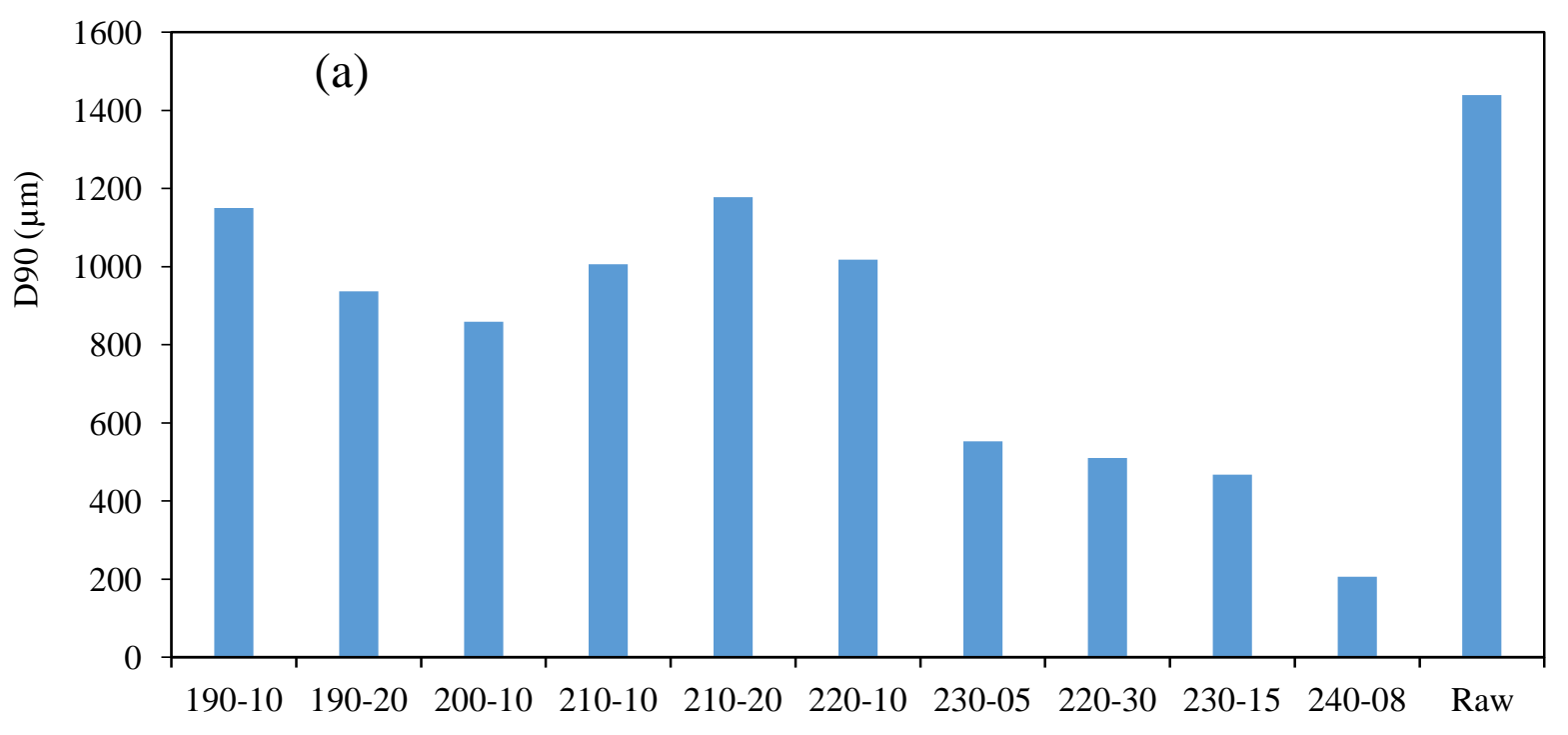

Pretreatment condition (temperature $\left({ }^{\circ} \mathrm{C}\right)$-retention time $(\mathrm{min})$ )

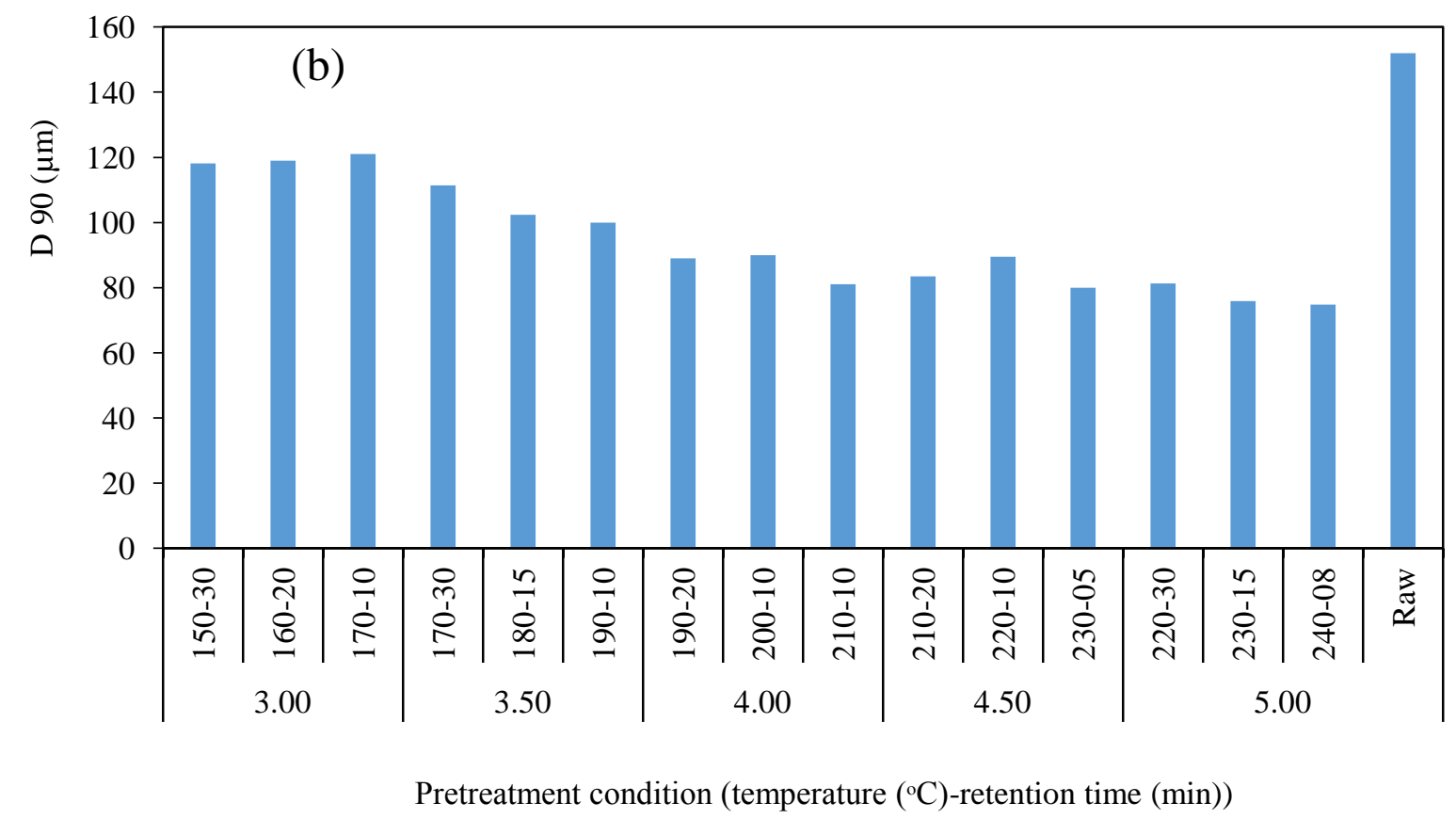

Figure 5.2. The effect of hydrothermal pretreatment on Particle Size of (a) SSO (b) TWAS 
Because of the complexity of the process it is not clear that the produced biomethane comes from which portion of the feedstock. The optimum size of the particles for higher efficiency of the AD process can relate to the primary characteristics of the feedstock. This can be a reason that SSO produced higher biomethane per gTCOD comparing to the TWAS, although TWAS has much smaller particles size than SSO.

\subsection{Comparison of TWAS and SSO Anaerobic Biodegradability}

The effect of temperature on degradability of the two substrate is widely different. In SSO thermal pretreatment shows an increasing trend in biomethane production up to a certain condition. Beyond it pretreatment in excessive temperature $\left(>190^{\circ} \mathrm{C}\right)$ it decreased the biogas production and feedstock digestibility. Hydrothermal pretreatment shows an increase in biological degradability of SSO in all conditions comparing to non-pretreated sample. The range of biomethane production improvement is between 10-25.1\% comparing to the control with the highest biomethane production of $280 \mathrm{~mL} / \mathrm{g} \mathrm{COD}_{\text {added }}$ in standard temperature and pressure. In TWAS hydrothermal pretreatment improved the biomethane production in some conditions and even in more excessive conditions it negatively impacted the digestibility of the substrate. The biomethane production improved between pretreatment temperatures of $150-190^{\circ} \mathrm{C}$. This improvement is in SI of 3, 3.5 and 4 and by increase in severity of thermal pretreatment it shows a negative impact on biomethane production as a decreasing trend from -1 to -15.6 for the low temperature to most severe pretreatment temperature or severity index.

The biomethane production rate enhanced in pretreatment condition with moderate temperature and with increase in pretreatment severity it shows a mildly decrease comparing to nonpretreated sample. The highest methane production rate in TWAS happened in the lowest pretreatment temperature $150^{\circ} \mathrm{C}$ by $23 \mathrm{~mL}$ /day and it shows a decreasing trend up to $7 \mathrm{ml} /$ day comparing with non-pretreated $14 \mathrm{~mL} / \mathrm{day}$. In SSO samples the methane production rate shows that pretreatment temperature of $170^{\circ} \mathrm{C}$ has the highest production rate with $30 \mathrm{~mL} / \mathrm{day}$. The methane production rate between pretreated conditions and non-pretreated sample are in 17-30 $\mathrm{mL} /$ day with the lost production rate in the most severe condition $240{ }^{0} \mathrm{C}-20 \mathrm{~min}$ and $19 \mathrm{~mL} / \mathrm{day}$ for non-pretreated sample. The decrease in production rate comparing to the control can be explained by the soluble carbohydrate concentration. The soluble carbohydrate is the fastest digestible component and having the highest degradability efficiency in substrate during the AD. 
Soluble carbohydrate is also sensible with increase in temperature forming caramelization which is an inhibitor for $\mathrm{AD}$ process. This can also be explained by the formation of melanoidins during the increase in temperature, soluble carbohydrate reacts with degraded protein (amino acids) and form a brown matter called melanoids which are not easily degradable in biological process. In TWAS, the concentration of carbohydrates are less comparing to SSO (consists of food waste). These facts reveal that increase in temperature highly decrease the soluble carbohydrate in TWAS which is readily degradable in AD while in SSO although the same reacts happens but newly degraded carbohydrate can produce biomethane in the process.

The main effect of pretreatment temperature, retention time and severity index on the methane yield is demonstrated in Figure 5.3. The pretreatment temperature is the determining effect on biomethane production of both substrates although the retention time also had a minor impact on the process. As illustrated in the Figure 5.3 the optimum pretreatment temperature for TWAS is lower comparing to SSO with the highest biomethane production in TWAS and SSO $160{ }^{\circ} \mathrm{C}$ and $190^{\circ} \mathrm{C}$ respectively. The decrease in biomethane production after pretreatment in a specific range can be observed in both substrates. The pretreatment temperature higher than the optimum resulted in lower biodegradability of SSO and TWAS which can be due to the reactions that cause the formation of refractory components. The optimum retention time for both feedstock TWAS and SSO were observed in the same range $10 \mathrm{~min}$. The increase in retention time can adversely impact the biodegradability of the feedstock. The optimum severity index for pretreatment of TWAS and SSO is different, as illustrated in Figure 5.3 the ideal severity index for pre-treating TWAS was noticed in the lowest severity index 3 while for SSO the severity index of 4 is suitable condition for hydrothermal pretreatment. 


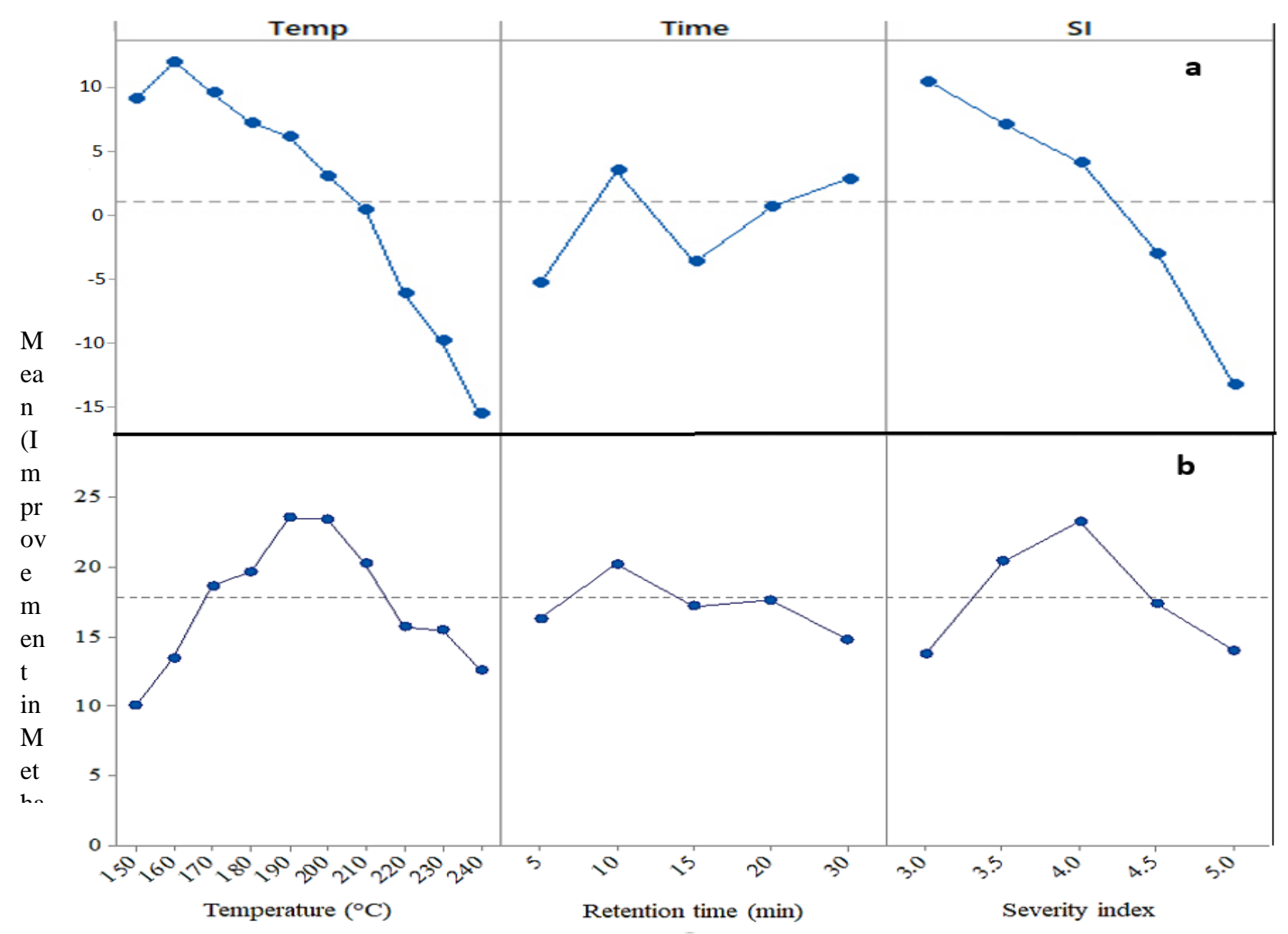

Figure 5.3. The main-effect plot of methane yield improvement vs. pretreatment temperature, retention time, and severity index (a) TWAS (b) SSO 


\section{Conclusion and Recommendations}

\subsection{Conclusion}

Anaerobic digestion is a biological approach for waste treatment and disposal. In a wastewater treatment plant, typically $50 \%$ of the cost goes to disposal and treatment of residuals. By enhancing the solubilization and biodegradability properties of the feedstock, the disposal cost can be reduced and also higher biomethane production can be ensured by AD. A limiting factor associated with $\mathrm{AD}$ is the long retention time that can be solve by pretreatment. This study was conducted to evaluate the hydrothermal pretreatment effect on solubilization and biodegradability improvement of two different feedstock TWAS and SSO in a wide range of temperature, retention time and severity index. The main conclusion of hydrothermal pretreatment on SSO and TWAS can be concluded by the following bullet points:

- The effect of hydrothermal pretreatment on waste can vary due to the primary characteristics and composition of the feedstock.

- The highest COD solubilization of the feedstock occur in more severe pretreatment condition comparing to its biodegradability.

- The most severe hydrothermal pretreatment condition does not represent the highest biomethane production or the highest COD solubilization.

- The effect of pretreatment temperature is the dominant parameter in biogas production improvement.

- The most effective retention time in the pretreatment conditions used in this study is 10 min and higher retention time can adversely impact the methane yield.

- The highest COD solubilization of TWAS was observed in a lower temperature than SSO. TWAS and SSO show the highest solubilization improvement in pretreatment conditions of $200{ }^{\circ} \mathrm{C}$ and $220{ }^{\circ} \mathrm{C}$ for $10 \mathrm{~min}$ respectively.

- The highest COD solubilization does not represent the highest biomethane production.

- The maximum methane production in SSO was observed in higher pretreatment temperature in compare with TWAS. The maximum methane production for TWAS observed was $137 \mathrm{~mL} / \mathrm{gTCOD}$ added with $12 \%$ in pretreated condition of $160^{\circ} \mathrm{C}-20 \mathrm{~min}$ improvement comparing to non-pretreated sample. 
- The maximum methane yield in SSO was produced in pretreatment condition of $190{ }^{0} \mathrm{C}$ 20 min with $25.1 \%$ improvement comparing to non-pretreated with a volume of 280 $\mathrm{mL}_{\mathrm{gTCOD}}$ added.

- The production rate reached to its maximum for TWAS after 3 days from the start of the biomethane production test while for SSO its highest production rate reached after 11-15 days for samples pretreated in different conditions.

The findings of this study revealed that the hydrothermal pretreatment significantly improved the disintegration of both feedstock used and AD performance but the highest pretreatment intensity does not necessarily correspond to the maximum degree of solubilization or the highest methane production yield and rate. According to the obtained results, the optimum pretreated condition for feedstock can be different and the severity of condition beyond the optimum point can adversely impact the objective of the overall process. 


\subsection{Future Recommendations}

Hydrothermal pretreatment is one of the oldest pretreatment methods that is used to improve the solubilization and biodegradability of waste specially wastewater sludge prior to AD. Today there are known thermal technologies which works in high scale treatment plants and so many studies have also been done on researching the effect of thermal pretreatment on different waste but still there is not a general consensus on the result. The complexity of waste with a wide range of different composition made it difficult for a better understanding of organics reaction with temperature. In order to have a clear view about the reaction of macromolecular substances like carbohydrates, proteins and lipids with temperature and retention time a comprehensive study should be done to recognize these macromolecular matters and study their reaction with temperature separately. In order to enhance our understanding, the influence of heat and time on waste and suggest an inclusive solution the following further studies should be done.

- The AD experiment on SSO and TWAS was performed in a mesophilic condition. The effect of hydrothermal pretreatment should be also studied in thermophilic condition.

- A co-digestion of TWAS and SSO should be studied after the hydrothermal pretreatment in order to understand the reason behind TWAS low biomethane production that might cause by low $\mathrm{C} / \mathrm{N}$ ratio.

- A detailed analyse should be done on the influent, during the running experiment and effluent to recognize the compositions of waste, for example identify the specific carbohydrate or protein presented in the waste and also to understand the intermediate products.

- During the hydrothermal pretreatment up to a certain range carbohydrates and proteins are degraded to soluble part which reacts with each other with presence of heat and form refractory substances to AD. A two phases hydrothermal pretreatment (low range and high range temperature) should be studied in a combination of $\mathrm{AD}$ experiment. The first stage the feedstock should be hydrothermally pretreated in a low range temperature to increase the hydrolysis stage of easily solubilizing carbohydrate and protein. In second stage the supernatant part should be removed and the remaining part should go through the second stage of hydrothermal pretreatment with high temperature and study its effect in $\mathrm{AD}$. 


\section{Appendix}

A. Analytical Results for SSO

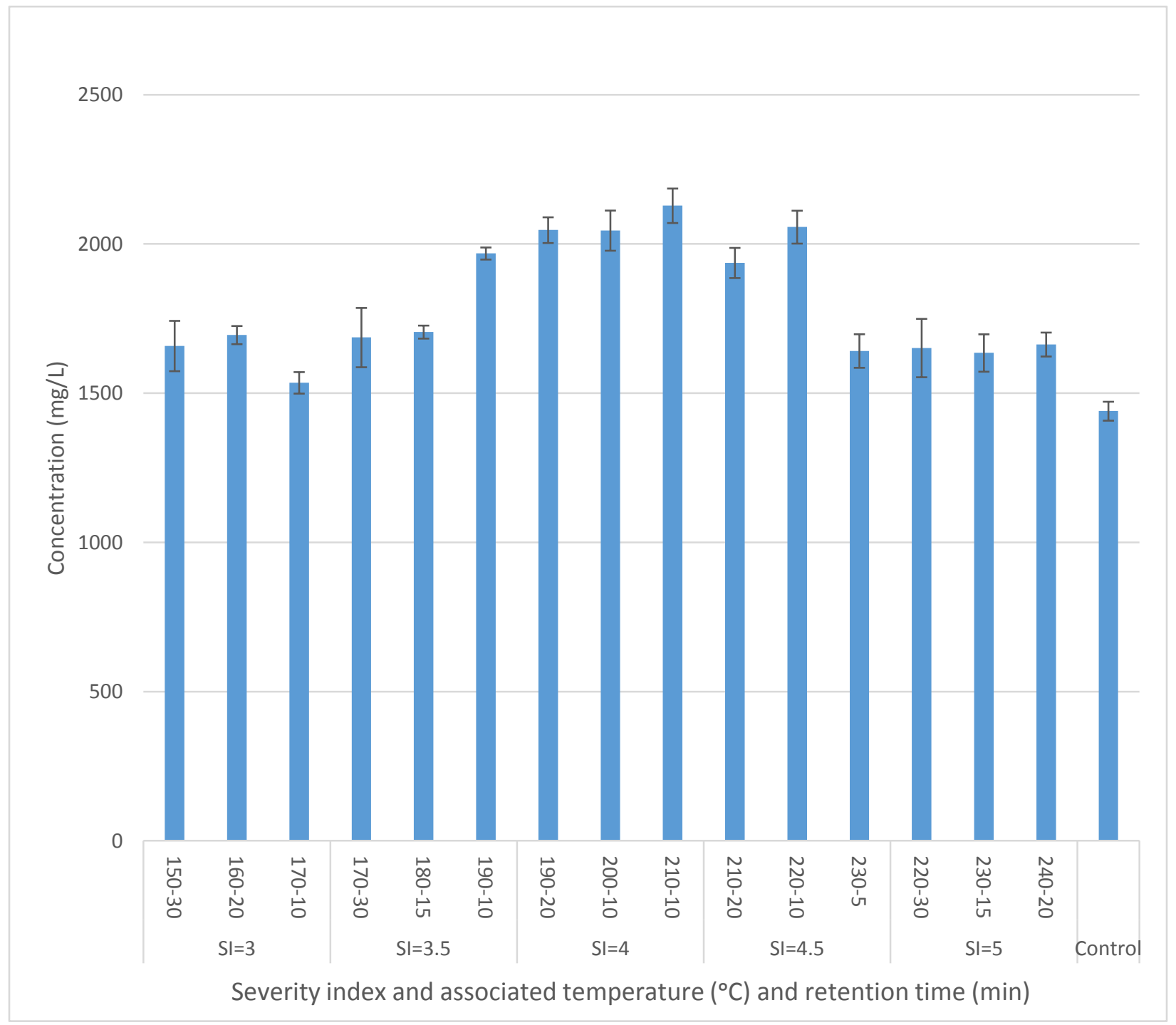

Figure A.1. The Effect of Hydrothermal Pretreatment on Concentration of Ammonia in SSO 


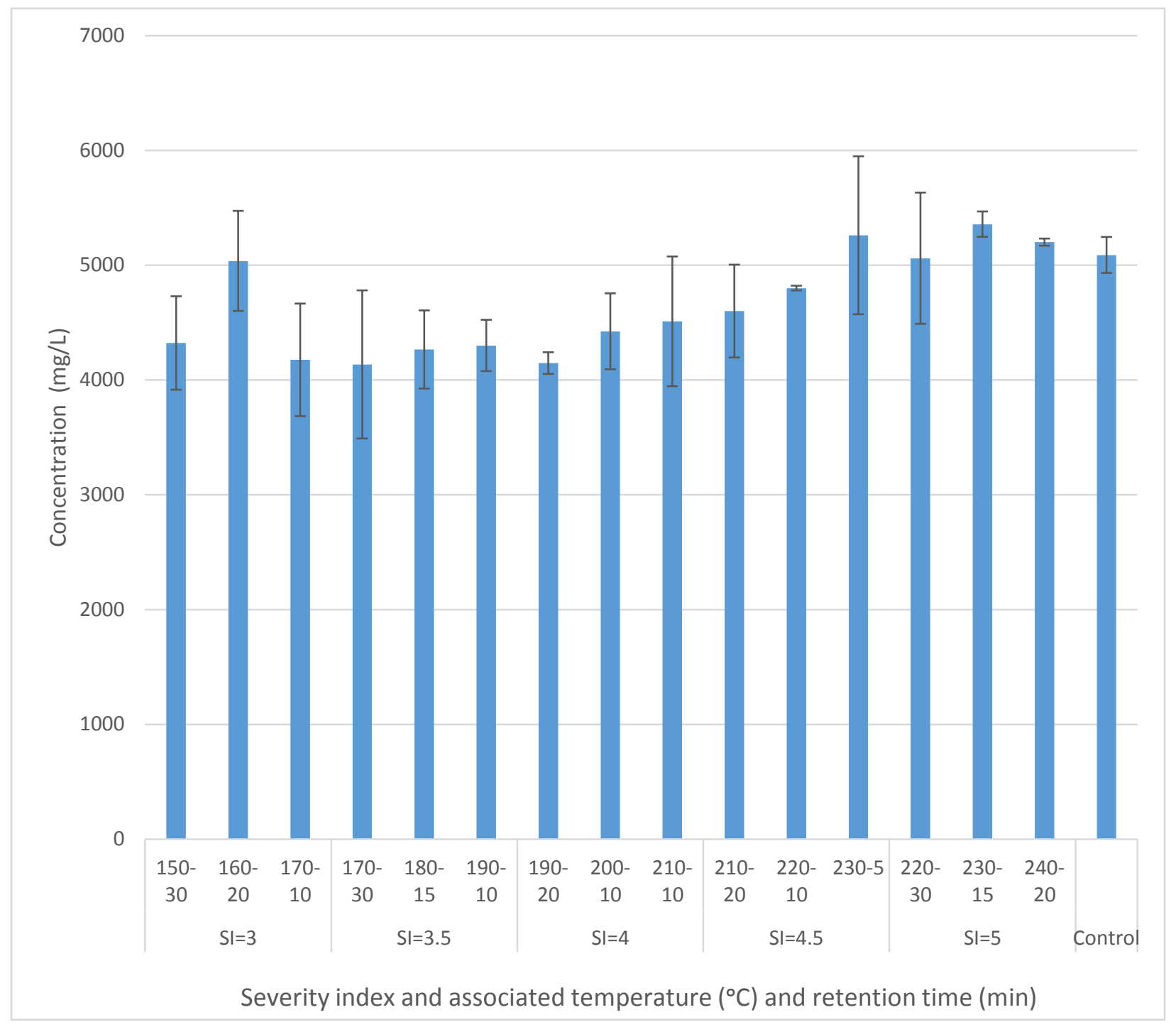

Figure A.2. The Effect of Hydrothermal Pretreatment on Concentration of Alkalinity in SSO 


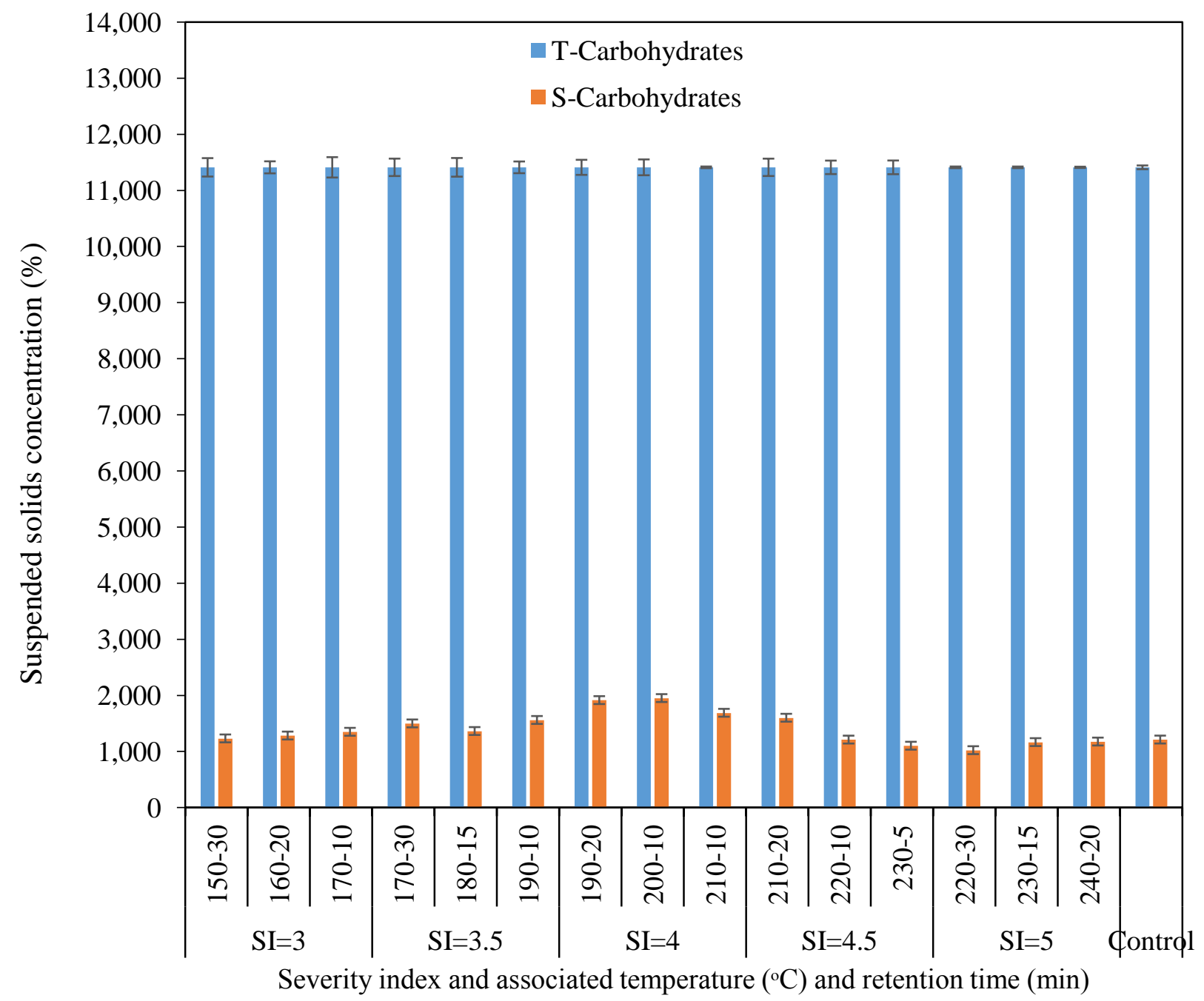

Figure A.3. The Effect of Hydrothermal Pretreatment on Concentration of Carbohydrates in $\mathrm{SSO}$ 


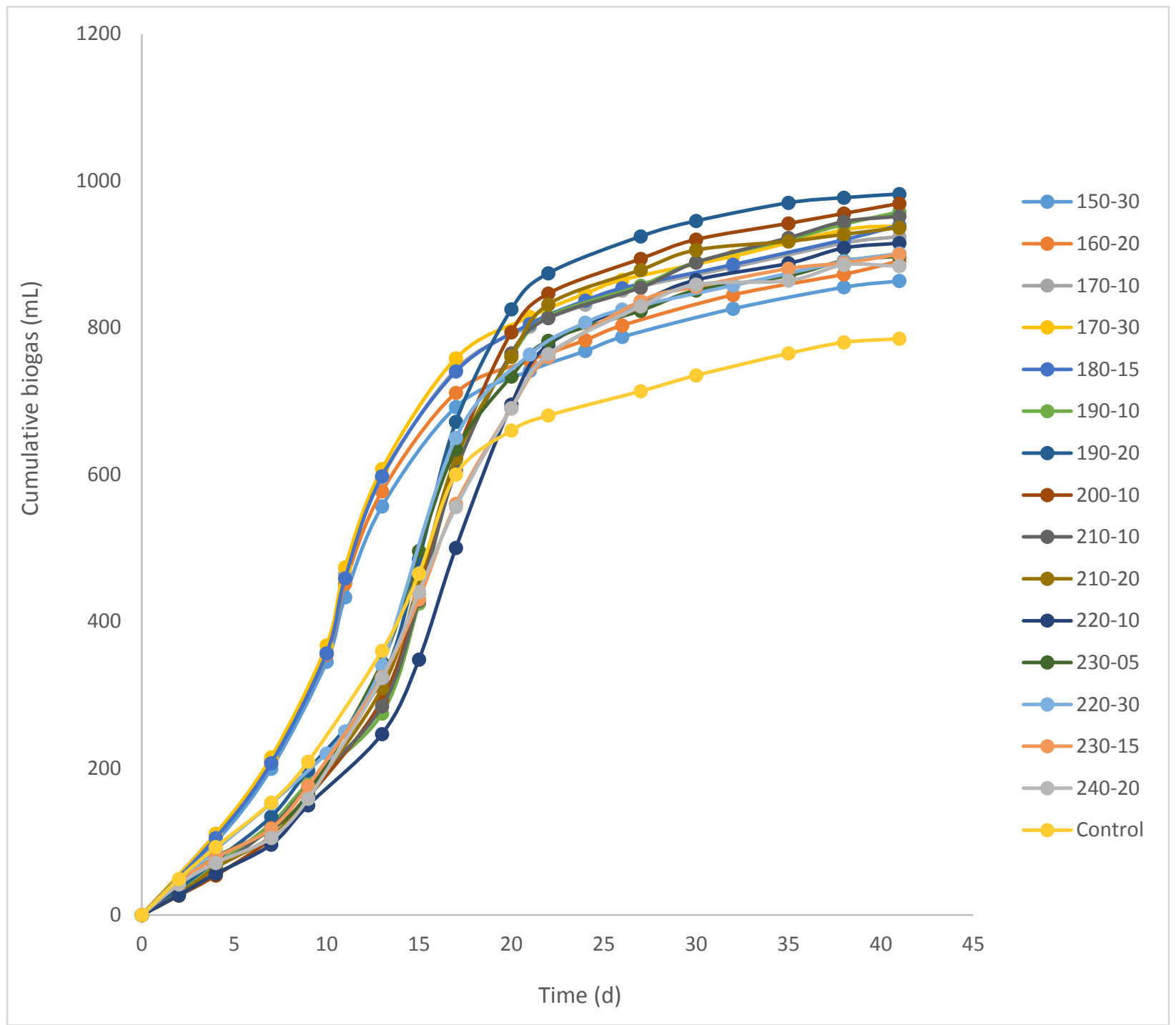

Figure A.4. The Effect of Hydrothermal Pretreatment on Biogas Production in SSO 


\section{B. Analytical Results of TWAS}

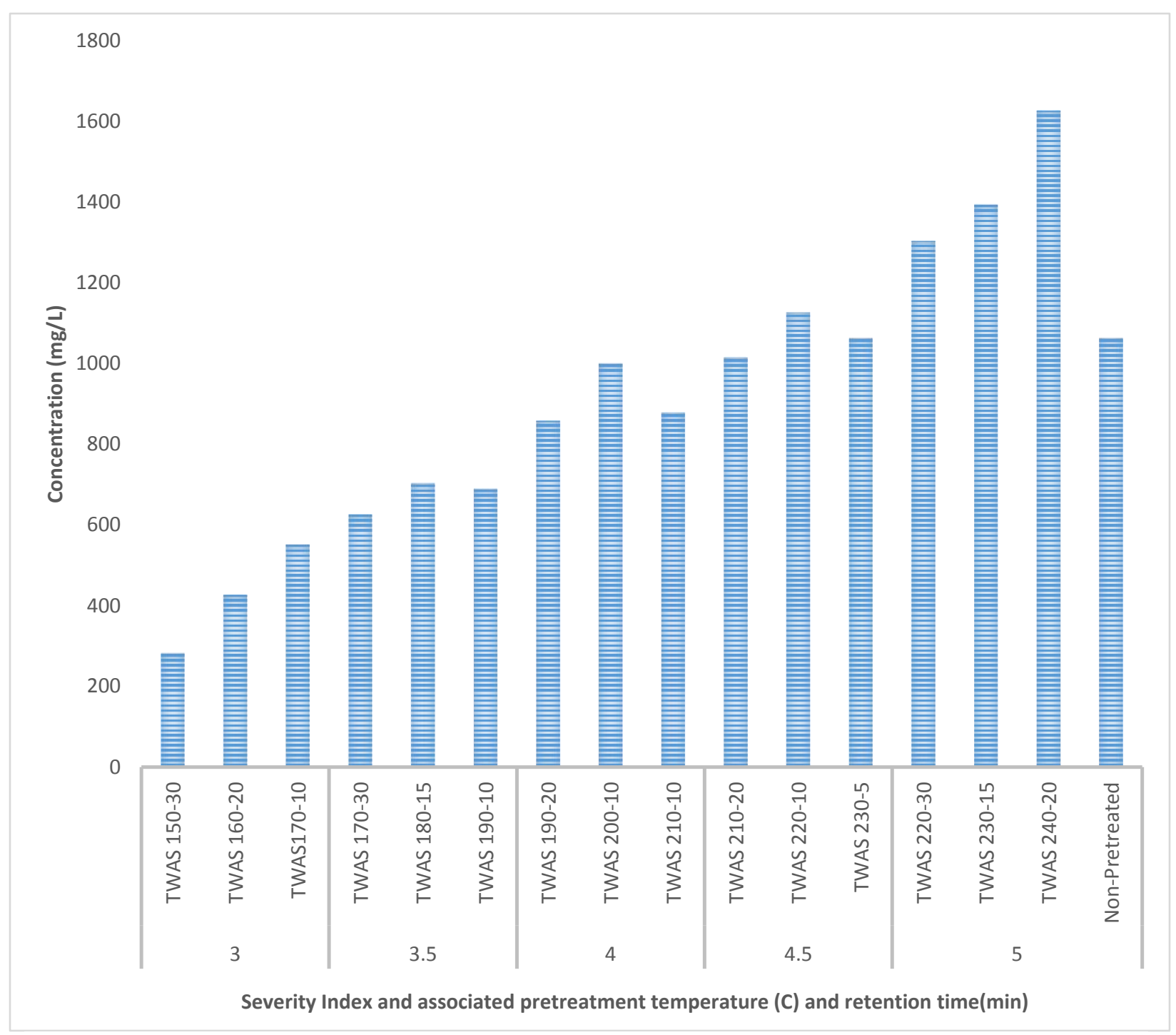

Figure B.1. The Effect of Hydrothermal Pretreatment on Concentration of Alkalinity in TWAS 


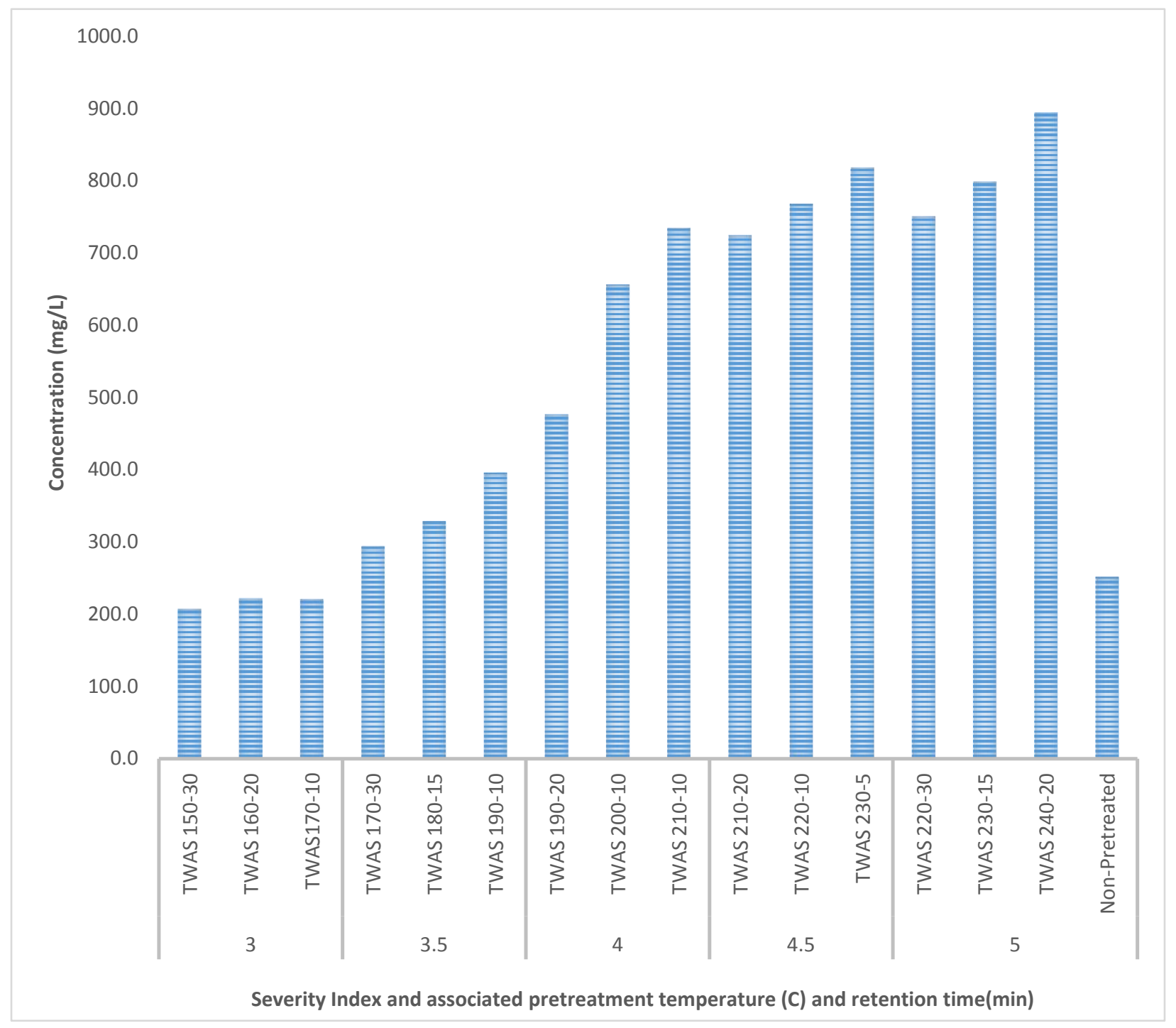

Figure B.2. The Effect of Hydrothermal Pretreatment on Concentration of Ammonia in TWAS 


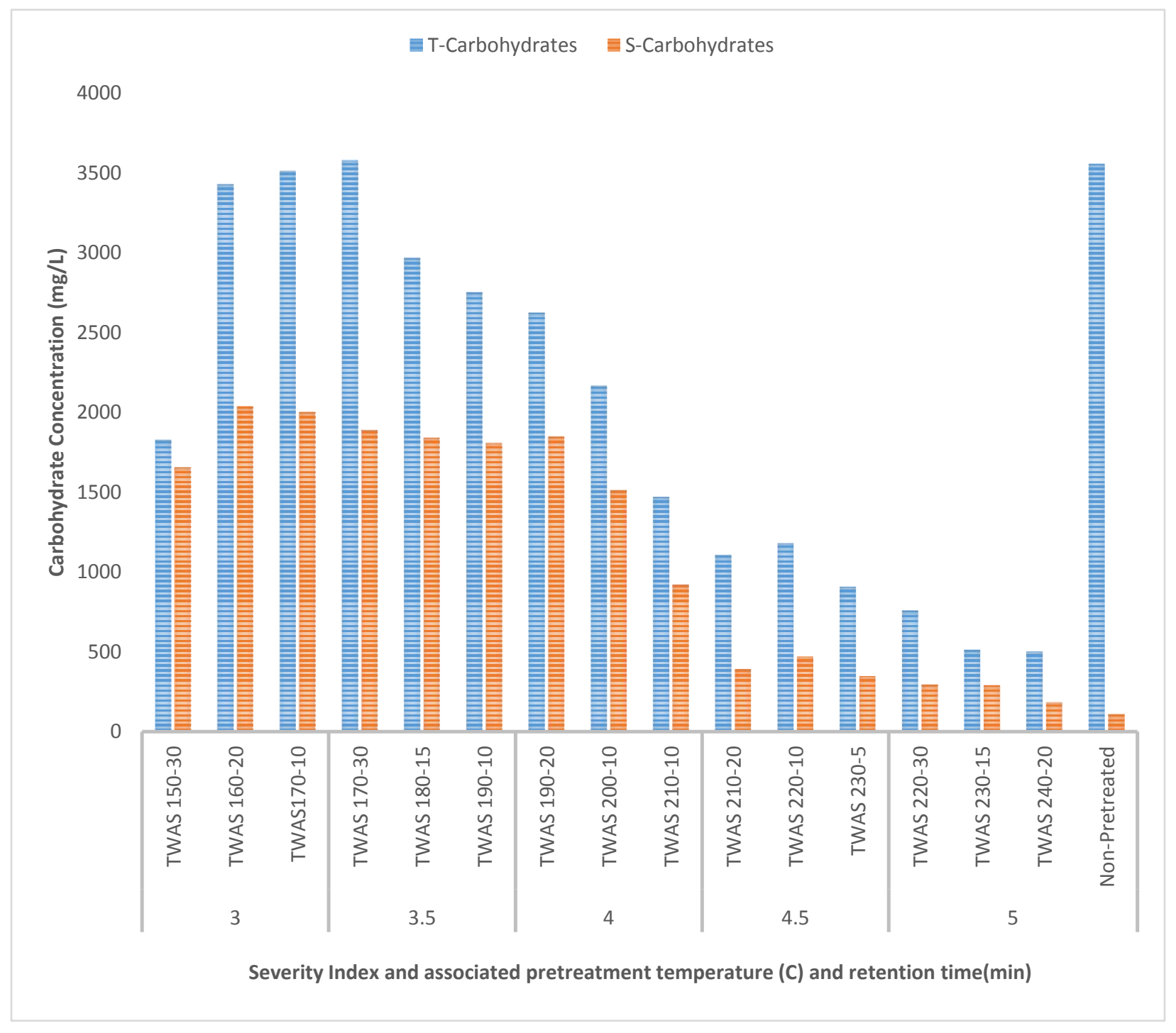

Figure B.3. The Effect of Hydrothermal Pretreatment on Concentration of Carbohydrates in TWAS 


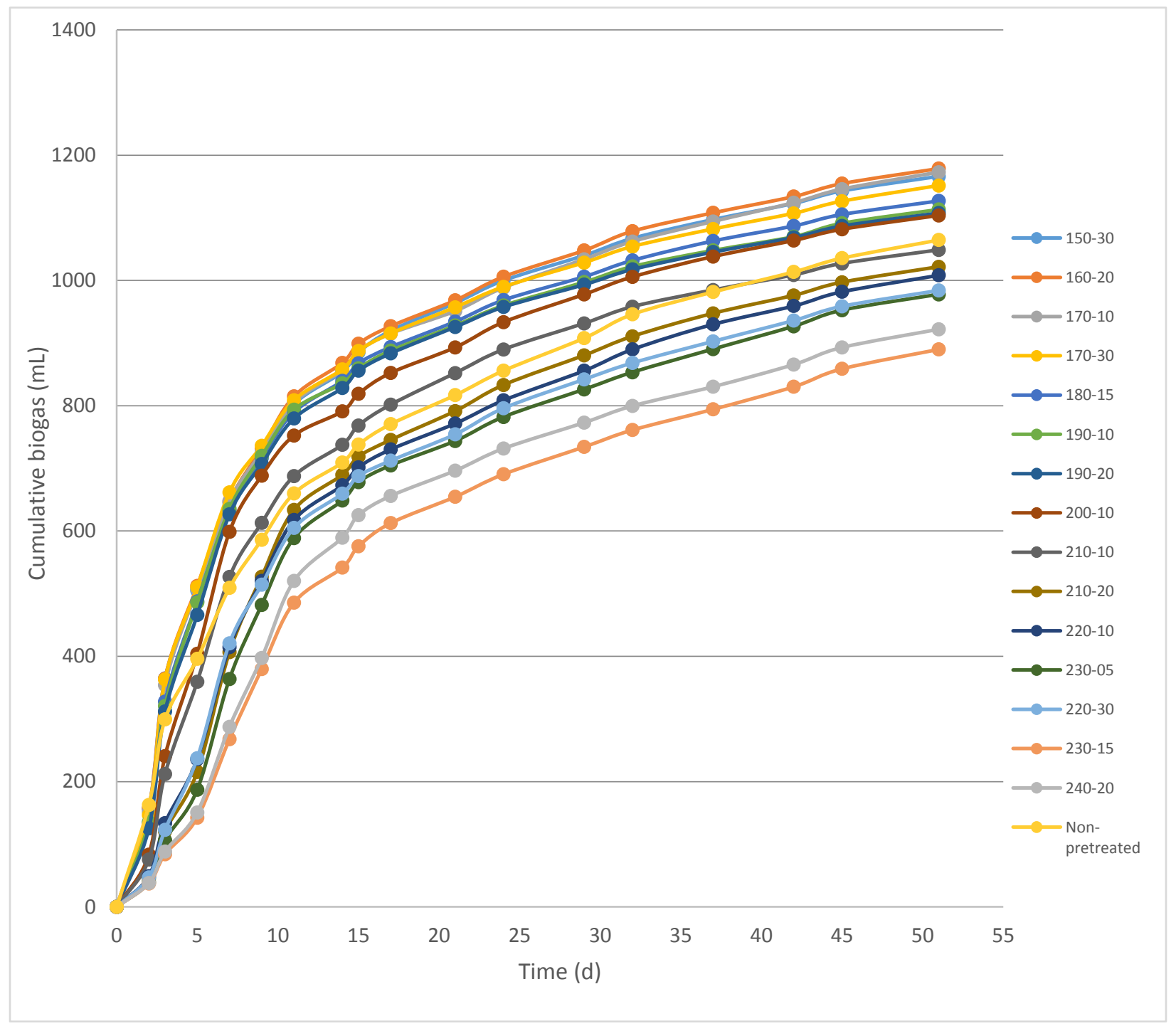

Figure B.4. The Effect of Hydrothermal Pretreatment on Biogas Production in TWAS 


\section{C.1. Mass balance of TWAS}

\begin{tabular}{|c|c|c|c|c|c|c|c|c|c|c|c|}
\hline \multicolumn{2}{|c|}{$\begin{array}{l}\text { Pretreatment } \\
\text { Scenarios }\end{array}$} & \multirow{2}{*}{$\begin{array}{c}\begin{array}{c}\text { TCOD } \\
\text { Substrate } \\
\mathrm{mg} / \mathrm{L}\end{array} \\
50367\end{array}$} & \multirow{2}{*}{$\begin{array}{c}\begin{array}{c}\text { Volume } \\
\text { Seed/m } \\
\text { L }\end{array} \\
203\end{array}$} & \multirow{2}{*}{$\begin{array}{c}\begin{array}{c}\text { Volume } \\
\text { substrate } \\
/ \mathrm{mL}\end{array} \\
47\end{array}$} & \multirow{2}{*}{$\begin{array}{l}\text { Initial } \\
\text { TCOD } \\
\mathrm{mg} / \mathrm{L} \\
24465\end{array}$} & \multirow{2}{*}{$\begin{array}{c}\begin{array}{c}\text { Final } \\
\text { TCOD } \\
\mathrm{mg} / \mathrm{L}\end{array} \\
15657 \\
\end{array}$} & \multirow{2}{*}{$\begin{array}{r}\begin{array}{l}\text { Cumulative } \\
\text { CH4 /mL }\end{array} \\
831\end{array}$} & \multirow{2}{*}{$\begin{array}{c}\begin{array}{c}\text { Mass of } \\
\text { COD } \\
\text { Added/gr }\end{array} \\
6.12\end{array}$} & \multirow{2}{*}{$\begin{array}{r}\begin{array}{c}\text { Mass of } \\
\text { COD }\end{array} \\
\text { removed/gr }\end{array}$} & \multirow{2}{*}{$\begin{array}{c}\begin{array}{c}\text { CH4 in } \\
\text { Theory/m } \\
\text { L }\end{array} \\
859\end{array}$} & \multirow{2}{*}{$\begin{array}{r}\begin{array}{r}\% \mathrm{CH} 4 \\
\text { produced }\end{array} \\
96.7\end{array}$} \\
\hline & $150-30$ & & & & & & & & & & \\
\hline SI & $160-20$ & 46633 & 200 & 50 & 24104 & 15107 & 841 & 6.03 & 2.25 & 877 & 95.8 \\
\hline 3.00 & $170-10$ & 49567 & 203 & 47 & 24392 & 15200 & 837 & 6.10 & 2.30 & 896 & 93.3 \\
\hline \multirow{3}{*}{$\begin{array}{c}\mathrm{SI} \\
3.50\end{array}$} & $170-30$ & 47467 & 201 & 49 & 24189 & 15193 & 822 & 6.05 & 2.25 & 877 & 93.7 \\
\hline & $180-15$ & 46333 & 200 & 50 & 24073 & 15600 & 802 & 6.02 & 2.12 & 826 & 97.0 \\
\hline & $190-10$ & 48300 & 202 & 48 & 24271 & 15760 & 792 & 6.07 & 2.13 & 830 & 95.4 \\
\hline \multirow{3}{*}{$\begin{array}{c}\text { SI } \\
4.00\end{array}$} & $190-20$ & 48500 & 197 & 53 & 24917 & 15407 & 791 & 6.23 & 2.38 & 927 & 85.3 \\
\hline & $200-10$ & 48500 & 204 & 46 & 24053 & 15987 & 785 & 6.01 & 2.02 & 786 & 99.8 \\
\hline & $210-10$ & 42033 & 196 & 54 & 23590 & 15867 & 748 & 5.90 & 1.93 & 753 & 99.3 \\
\hline \multirow{3}{*}{$\begin{array}{c}\text { SI } \\
4.50\end{array}$} & $210-20$ & 42500 & 196 & 54 & 23646 & 16213 & 728 & 5.91 & 1.86 & 725 & 100.5 \\
\hline & $220-10$ & 43300 & 197 & 53 & 23740 & 16687 & 719 & 5.94 & 1.76 & 688 & 104.5 \\
\hline & $230-05$ & 42467 & 196 & 54 & 23642 & 16627 & 696 & 5.91 & 1.75 & 684 & 101.7 \\
\hline \multirow{4}{*}{$\begin{array}{c}\text { SI } \\
5.00\end{array}$} & $220-30$ & 48500 & 207 & 43 & 23613 & 15473 & 701 & 5.90 & 2.03 & 794 & 88.4 \\
\hline & $230-15$ & 44367 & 198 & 52 & 23861 & 16473 & 640 & 5.97 & 1.85 & 720 & 88.8 \\
\hline & $240-20$ & 48500 & 208 & 42 & 23556 & 15860 & 663 & 5.89 & 1.92 & 750 & 88.3 \\
\hline & Raw 1 & 49600 & 203 & 47 & 24395 & 16480 & 762 & 6.10 & 1.98 & 772 & 98.7 \\
\hline
\end{tabular}




\section{References}

Alqaralleh, R. M. (2012). Effect of Alkaline Pretreatment on Anaerobic Digestion of Organic Fraction of Municipal Solid Waste Rania Mona Alqaralleh A thesis submitted under the supervision of In partial fulfillment of the requirements for the degree of Master of Applied Sciences $i$.

Appels, L., Baeyens, J., Degrève, J., \& Dewil, R. (2008). Principles and potential of the anaerobic digestion of waste-activated sludge. Progress in Energy and Combustion Science, 34(6), 755-781. https://doi.org/10.1016/j.pecs.2008.06.002

Arelli, V., Begum, S., Anupoju, G. R., Kuruti, K., \& Shailaja, S. (2018). Dry anaerobic codigestion of food waste and cattle manure: Impact of total solids, substrate ratio and thermal pre treatment on methane yield and quality of biomanure. Bioresource Technology, 253(November 2017), 273-280. https://doi.org/10.1016/j.biortech.2018.01.050

Ariunbaatar, J., Panico, A., Esposito, G., Pirozzi, F., \& Lens, P. N. L. (2014). Pretreatment methods to enhance anaerobic digestion of organic solid waste. Applied Energy, 123, 143156. https://doi.org/10.1016/j.apenergy.2014.02.035

Ariunbaatar, J., Panico, A., Frunzo, L., Esposito, G., Lens, P. N. L., \& Pirozzi, F. (2014). Enhanced anaerobic digestion of food waste by thermal and ozonation pretreatment methods, 146, 142-149. https://doi.org/10.1016/j.jenvman.2014.07.042

Barber, W. P. F. (2016). Thermal hydrolysis for sewage treatment: A critical review. Water Research, 104, 53-71. https://doi.org/10.1016/j.watres.2016.07.069

Bougrier, C., Battimelli, A., Delgenes, J. P., \& Carrere, H. (2007). Combined ozone pretreatment and anaerobic digestion for the reduction of biological sludge production in wastewater treatment. Ozone: Science and Engineering, 29(3), 201-206. https://doi.org/10.1080/01919510701296754

Bougrier, C., Delgenès, J. P., \& Carrère, H. (2008). Effects of thermal treatments on five different waste activated sludge samples solubilisation, physical properties and anaerobic digestion. Chemical Engineering Journal, 139(2), 236-244. https://doi.org/10.1016/j.cej.2007.07.099 
Canada Ministry of Environment. (2013). Municipal Solid Waste Organics Processing.

Carlsson, M., Lagerkvist, A., \& Morgan-Sagastume, F. (2012). The effects of substrate pretreatment on anaerobic digestion systems: A review. Waste Management, 32(9), 16341650. https://doi.org/10.1016/j.wasman.2012.04.016

Carrere, H., Antonopoulou, G., Affes, R., Passos, F., Battimelli, A., Lyberatos, G., \& Ferrer, I. (2016). Review of feedstock pretreatment strategies for improved anaerobic digestion: From lab-scale research to full-scale application. Bioresource Technology, 199, 386-397. https://doi.org/10.1016/j.biortech.2015.09.007

Carrère, H., Dumas, C., Battimelli, A., Batstone, D. J., Delgenès, J. P., Steyer, J. P., \& Ferrer, I. (2010). Pretreatment methods to improve sludge anaerobic degradability: A review. Journal of Hazardous Materials, 183(1-3), 1-15. https://doi.org/10.1016/j.jhazmat.2010.06.129

Carrère, H., Sialve, B., \& Bernet, N. (2009). Improving pig manure conversion into biogas by thermal and thermo-chemical pretreatments. Bioresource Technology, 100(15), 3690-3694. https://doi.org/10.1016/j.biortech.2009.01.015

Cesaro, A., \& Belgiorno, V. (2014). Pretreatment methods to improve anaerobic biodegradability of organic municipal solid waste fractions. Chemical Engineering Journal, 240, 24-37. https://doi.org/10.1016/j.cej.2013.11.055

Chen, T. H., Chynoweth, P., \& BIljetina, R. (1990). Anaerobic digestion of municipal solid waste in a nonmixed solids concentrating digestor. Applied Biochemistry and Biotechnology, 24-25(1), 533-544. https://doi.org/10.1007/BF02920276

Climent, M., Ferrer, I., Baeza, M. del M., Artola, A., Vázquez, F., \& Font, X. (2007). Effects of thermal and mechanical pretreatments of secondary sludge on biogas production under thermophilic conditions. Chemical Engineering Journal, 133(1-3), 335-342. https://doi.org/10.1016/j.cej.2007.02.020

Demirel, B., \& Yenigün, O. (2002). Two-phase anaerobic digestion processes: A review. Journal of Chemical Technology and Biotechnology, 77(7), 743-755. https://doi.org/10.1002/jctb.630

Demirer, G. N., \& Chen, S. (2005). Two-phase anaerobic digestion of unscreened dairy manure. 
Process Biochemistry, 40(11), 3542-3549. https://doi.org/10.1016/j.procbio.2005.03.062

Devlin, D. C., Esteves, S. R. R., Dinsdale, R. M., \& Guwy, A. J. (2011). The effect of acid pretreatment on the anaerobic digestion and dewatering of waste activated sludge. Bioresource Technology, 102(5), 4076-4082. https://doi.org/10.1016/j.biortech.2010.12.043

Dhar, B. R., Nakhla, G., \& Ray, M. B. (2012). Techno-economic evaluation of ultrasound and thermal pretreatments for enhanced anaerobic digestion of municipal waste activated sludge. Waste Management, 32(3), 542-549. https://doi.org/10.1016/j.wasman.2011.10.007

Ding, L., Cheng, J., Qiao, D., Yue, L., Li, Y. Y., Zhou, J., \& Cen, K. (2017). Investigating hydrothermal pretreatment of food waste for two-stage fermentative hydrogen and methane co-production. Bioresource Technology, 241, 491-499. https://doi.org/10.1016/j.biortech.2017.05.114

Donoso-Bravo, A., Pérez-Elvira, S., Aymerich, E., \& Fdz-Polanco, F. (2011). Assessment of the influence of thermal pre-treatment time on the macromolecular composition and anaerobic biodegradability of sewage sludge. Bioresource Technology, 102(2), 660-666. https://doi.org/10.1016/j.biortech.2010.08.035

Duan, L., Moreno-Andrade, I., Huang, C. lin, Xia, S., \& Hermanowicz, S. W. (2009). Effects of short solids retention time on microbial community in a membrane bioreactor. Bioresource Technology, 100(14), 3489-3496. https://doi.org/10.1016/j.biortech.2009.02.056

Dwyer, J., Starrenburg, D., Tait, S., Barr, K., Batstone, D. J., \& Lant, P. (2008). Decreasing activated sludge thermal hydrolysis temperature reduces product colour, without decreasing degradability. Water Research, 42(18), 4699-4709. https://doi.org/10.1016/j.watres.2008.08.019

Elbeshbishy, E., Dhar, B. R., Nakhla, G., \& Lee, H. S. (2017). A critical review on inhibition of dark biohydrogen fermentation. Renewable and Sustainable Energy Reviews, 79(May), 656-668. https://doi.org/10.1016/j.rser.2017.05.075

Elbeshbishy, E. E. (2011). Enhancement of Biohydrogen and Biomethane Production from Wastes Using Ultrasonication. PhD Thesis.

Elbeshbishy, E., Hafez, H., Dhar, B. R., \& Nakhla, G. (2011). Single and combined effect of 
various pretreatment methods for biohydrogen production from food waste. International Journal of Hydrogen Energy (Vol. 36, pp. 11379-11387). Elsevier Ltd. https://doi.org/10.1016/j.ijhydene.2011.02.067

Eskicioglu, C., Kennedy, K. J., \& Droste, R. L. (2006). Characterization of soluble organic matter of waste activated sludge before and after thermal pretreatment. Water Research, 40(20), 3725-3736. https://doi.org/10.1016/j.watres.2006.08.017

Fdz-Polanco, F., Velazquez, R., Perez-Elvira, S. I., Casas, C., del Barrio, D., Cantero, F. J., ... Rouge, P. (2008). Continuous thermal hydrolysis and energy integration in sludge anaerobic digestion plants. Water Science and Technology, 57(8), 1221-1226. https://doi.org/10.2166/wst.2008.072

Gavala, H. N., Yenal, U., Skiadas, I. V., Westermann, P., \& Ahring, B. K. (2003). Mesophilic and thermophilic anaerobic digestion of primary and secondary sludge. Effect of pretreatment at elevated temperature. Water Research, 37(19), 4561-4572. https://doi.org/10.1016/S0043-1354(03)00401-9

Ge, H., Jensen, P. D., \& Batstone, D. J. (2010). Pre-treatment mechanisms during thermophilicmesophilic temperature phased anaerobic digestion of primary sludge. Water Research, 44(1), 123-130. https://doi.org/10.1016/j.watres.2009.09.005

Gerrard, J. (2005). The Maillard Reaction: Chemistry, Biochemistry and Implications by Harry Nursten. Australian Journal of Chemistry, 58(10), 756. https://doi.org/10.1071/ch0505_br

Gossett, J. M. (1989). Abstract: introduction, 114(8), 877-887.

Guilford, N. G. H. (2017). The Anaerobic Digestion of Organic Solid Wastes of Variable Composition. Retrieved from https://tspace.library.utoronto.ca/handle/1807/80954

Habiba, L., Hassib, B., \& Moktar, H. (2009). Improvement of activated sludge stabilisation and filterability during anaerobic digestion by fruit and vegetable waste addition. Bioresource Technology, 100(4), 1555-1560. https://doi.org/10.1016/j.biortech.2008.09.019

Han, D., Lee, C. Y., Chang, S. W., \& Kim, D. J. (2017). Enhanced methane production and wastewater sludge stabilization of a continuous full scale thermal pretreatment and thermophilic anaerobic digestion. Bioresource Technology, 245(August), 1162-1167. 
https://doi.org/10.1016/j.biortech.2017.08.108

Han, H., \& Zhang, Z. (2017). The impact of the policy of municipal solid waste source-separated collection on waste reduction : a case study of China. Journal of Material Cycles and Waste Management, 19(1), 382-393. https://doi.org/10.1007/s10163-015-0434-3

Hartmann, H., \& Ahring, B. K. (2006). Strategies for the anaerobic digestion of the organic fraction of municipal solid waste: An overview. Water Science and Technology, 53(8), 7 22. https://doi.org/10.2166/wst.2006.231

Holm-Nielsen, J. B., Al Seadi, T., \& Oleskowicz-Popiel, P. (2009). The future of anaerobic digestion and biogas utilization. Bioresource Technology, 100(22), 5478-5484. https://doi.org/10.1016/j.biortech.2008.12.046

Hosseini Koupaie, E., \& Eskicioglu, C. (2016). Conventional heating vs. microwave sludge pretreatment comparison under identical heating/cooling profiles for thermophilic advanced anaerobic digestion. Waste Management, 53, 182-195. https://doi.org/10.1016/j.wasman.2016.04.014

I. J., D., C.H., I., T., N., N.I., S., \& Yusuf, M. B. S. (2013). Effect of Carbon To Nitrogen Ratio on Biogas Production. International Research Journal of Natural Sciences, 1 (3)(3), 1-10.

Izumi, K., Okishio, Y. ki, Nagao, N., Niwa, C., Yamamoto, S., \& Toda, T. (2010). Effects of particle size on anaerobic digestion of food waste. International Biodeterioration and Biodegradation, 64(7), 601-608. https://doi.org/10.1016/j.ibiod.2010.06.013

Jain, S., Jain, S., Tim, I., Lee, J., \& Wah, Y. (2015). A comprehensive review on operating parameters and different pretreatment methodologies for anaerobic digestion of municipal solid waste, 52, 142-154. https://doi.org/10.1016/j.rser.2015.07.091

Jin, Y., Li, Y., \& Li, J. (2016). In fl uence of thermal pretreatment on physical and chemical properties of kitchen waste and the ef fi ciency of anaerobic digestion. Journal of Environmental Management, 180, 291-300. https://doi.org/10.1016/j.jenvman.2016.05.047

Karim, K., Hoffmann, R., Klasson, K. T., \& Al-Dahhan, M. H. (2005). Anaerobic digestion of animal waste: Effect of mode of mixing. Water Research, 39(15), 3597-3606. https://doi.org/10.1016/j.watres.2005.06.019 
Khalid, A., Arshad, M., Anjum, M., Mahmood, T., \& Dawson, L. (2011). The anaerobic digestion of solid organic waste. Waste Management, 31(8), 1737-1744. https://doi.org/10.1016/j.wasman.2011.03.021

Kim, D., Lee, K., \& Park, K. Y. (2015a). Enhancement of biogas production from anaerobic digestion of waste activated sludge by hydrothermal pre-treatment. International Biodeterioration and Biodegradation, 101, 42-46. https://doi.org/10.1016/j.ibiod.2015.03.025

Kim, D., Lee, K., \& Park, K. Y. (2015b). International Biodeterioration \& Biodegradation Enhancement of biogas production from anaerobic digestion of waste activated sludge by hydrothermal pre-treatment. International Biodeterioration \& Biodegradation, 101, 42-46. https://doi.org/10.1016/j.ibiod.2015.03.025

Koupaie, E. H., Johnson, T., \& Eskicioglu, C. (2018). Comparison of different electricity-based thermal pretreatment methods for enhanced bioenergy production from municipal sludge. Molecules, 23(8). https://doi.org/10.3390/molecules23082006

Li, L., Diederick, R., Flora, J. R. V., \& Berge, N. D. (2013a). Hydrothermal carbonization of food waste and associated packaging materials for energy source generation. Waste Management, 33(11), 2478-2492. https://doi.org/10.1016/j.wasman.2013.05.025

Li, L., Diederick, R., Flora, J. R. V, \& Berge, N. D. (2013b). Hydrothermal carbonization of food waste and associated packaging materials for energy source generation. Waste Management, 33(11), 2478-2492. https://doi.org/10.1016/j.wasman.2013.05.025

Li, N., Chen, S., Liu, H., Xue, Y., Dai, X., \& Dichtl, N. (2014). Effects of thermal hydrolysis on organic matter solubilization and anaerobic digestion of high solid sludge. Chemical Engineering Journal, 264, 174-180. https://doi.org/10.1016/j.cej.2014.11.005

Li, Y., Jin, Y., Borrion, A., Li, H., \& Li, J. (2017). Effects of organic composition on mesophilic anaerobic digestion of food waste. Bioresource Technology, 244, 213-224. https://doi.org/10.1016/j.biortech.2017.07.006

Li, Y., Jin, Y., Li, J., Li, H., \& Yu, Z. (2016). Effects of thermal pretreatment on the biomethane yield and hydrolysis rate of kitchen waste. Applied Energy, 172(1020), 47-58. 
https://doi.org/10.1016/j.apenergy.2016.03.080

Liao, B. Q., Kraemer, J. T., \& Bagley, D. M. (2006). Anaerobic membrane bioreactors: Applications and research directions. Critical Reviews in Environmental Science and Technology (Vol. 36). https://doi.org/10.1080/10643380600678146

Lin, L., Xu, F., Ge, X., \& Li, Y. (2018). Improving the sustainability of organic waste management practices in the food-energy-water nexus: A comparative review of anaerobic digestion and composting. Renewable and Sustainable Energy Reviews, 89(February), 151167. https://doi.org/10.1016/j.rser.2018.03.025

Liu, X., Wang, W., Gao, X., Zhou, Y., \& Shen, R. (2012b). Effect of thermal pretreatment on the physical and chemical properties of municipal biomass waste. Waste Management, 32(2), 249-255. https://doi.org/10.1016/j.wasman.2011.09.027

Liu, X., Wang, W., Gao, X., Zhou, Y., \& Shen, R. (2012a). Effect of thermal pretreatment on the physical and chemical properties of municipal biomass waste. Waste Management, 32(2), 249-255. https://doi.org/10.1016/j.wasman.2011.09.027

Ma, J., Hang, T., Smits, M., Verstraete, W., \& Carballa, M. (2011). Bioresource Technology Enhanced biomethanation of kitchen waste by different pre-treatments. Bioresource Technology, 102(2), 592-599. https://doi.org/10.1016/j.biortech.2010.07.122

Mahmoodi, P., Karimi, K., \& Taherzadeh, M. J. (2018). Hydrothermal processing as pretreatment for efficient production of ethanol and biogas from municipal solid waste. Bioresource Technology, 261(February), 166-175. https://doi.org/10.1016/j.biortech.2018.03.115

Miron, Y., Zeeman, G., Van Lier, J. B., \& Lettinga, G. (2000). The role of sludge retention time in the hydrolysis and acidification of lipids, carbohydrates and proteins during digestion of primary sludge in CSTR systems. Water Research, 34(5), 1705-1713. https://doi.org/10.1016/S0043-1354(99)00280-8

Molino, A., Nanna, F., Ding, Y., Bikson, B., \& Braccio, G. (2013). Biomethane production by anaerobic digestion of organic waste. Fuel, 103, 1003-1009. https://doi.org/10.1016/j.fuel.2012.07.070 
Nandiyanto, A. B. D., Ragadhita, R., Maulana, A. C., \& Abdullah, A. G. (2018). Feasibility Study on the Production of Biogas in Dairy Farming. IOP Conference Series: Materials Science and Engineering, 288(1). https://doi.org/10.1088/1757-899X/288/1/012024

Naroznova, I., Møller, J., Larsen, B., \& Scheutz, C. (2016). Evaluation of a new pulping technology for pre-treating source-separated organic household waste prior to anaerobic digestion. Waste Management, 50, 65-74. https://doi.org/10.1016/j.wasman.2016.01.042

Nazari, L., Yuan, Z., Santoro, D., Sarathy, S., Ho, D., Batstone, D., .. Ray, M. B. (2017). Lowtemperature thermal pre-treatment of municipal wastewater sludge: Process optimization and effects on solubilization and anaerobic degradation. Water Research, 113, 111-123. https://doi.org/10.1016/j.watres.2016.11.055

Neumann, P., Pesante, S., Venegas, M., \& Vidal, G. (2016). Developments in pre-treatment methods to improve anaerobic digestion of sewage sludge. Reviews in Environmental Science and Biotechnology, 15(2), 173-211. https://doi.org/10.1007/s11157-016-9396-8

Neyens, E., \& Baeyens, J. (2003). A review of thermal sludge pre-treatment processes to improve dewaterability. Journal of Hazardous Materials, 98(1-3), 51-67. https://doi.org/10.1016/S0304-3894(02)00320-5

Parthiba, O., Trably, E., Mehariya, S., Bernet, N., Wong, J. W. C., \& Carrere, H. (2017). Bioresource Technology Pretreatment of food waste for methane and hydrogen recovery : A review, (September). https://doi.org/10.1016/j.biortech.2017.09.105

Pérez-Elvira, S. I., Abelleira-Pereira, J. M., Nebot, E., Sánchez-Oneto, J., de la Cruz, R., \& Portela, J. R. (2014). Enhancement of methane production in mesophilic anaerobic digestion of secondary sewage sludge by advanced thermal hydrolysis pretreatment. Water Research, 71, 330-340. https://doi.org/10.1016/j.watres.2014.12.027

Pilli, S., Yan, S., Tyagi, R. D., \& Surampalli, R. Y. (2015). Thermal pretreatment of sewage sludge to enhance anaerobic digestion: A review. Critical Reviews in Environmental Science and Technology, 45(6), 669-702. https://doi.org/10.1080/10643389.2013.876527

R. D. Raman, W. Wu-Haan, L. B. Moody, D. Grewell, \& R. T. Burns. (2013). Evaluation of Ultrasonic Pretreatment on Anaerobic Digestion of Different Animal Manures. 
Transactions of the ASABE, 53(2), 577-583. https://doi.org/10.13031/2013.29572

Razavi, A. S., Hosseini Koupaie, E., Azizi, A., Hafez, H., \& Elbeshbishy, E. (2019).

Hydrothermal pretreatment of source separated organics for enhanced solubilization and biomethane recovery. Bioresource Technology, 274(October 2018), 502-511. https://doi.org/10.1016/j.biortech.2018.12.024

Sapkaite, I., Barrado, E., Fdz-Polanco, F., \& Pérez-Elvira, S. I. (2017). Optimization of a thermal hydrolysis process for sludge pre-treatment. Journal of Environmental Management, 192, 25-30. https://doi.org/10.1016/j.jenvman.2017.01.043

Shahriari, H. (2011). Enhancement of Anaerobic Digestion of Organic Fraction of Municipal Solid Waste by Microwave Pretreatment. Retrieved from http://search.proquest.com/pqdt/docview/1366366940/abstract/F85F3FFD6AEC4F63PQ/48 ?accountid=27835\%5Cnhttp $: /$ media.proquest.com $/$ media/pq $/ \mathrm{classic} / \mathrm{doc} / 2992128391 / \mathrm{fmt} / \mathrm{p}$ rv/rep/NPDF?_a=ChgyMDE1MDEwNzA2NTc1NTc5OTozMjgzNDMSBTg1ODM1GgpP TkVfUOVBUkNIIgwxMzMuNS4xNDAu

Shahriari, H., Warith, M., Hamoda, M., \& Kennedy, K. J. (2012). Anaerobic digestion of organic fraction of municipal solid waste combining two pretreatment modalities, high temperature microwave and hydrogen peroxide. Waste Management, 32(1), 41-52. https://doi.org/10.1016/j.wasman.2011.08.012

Shao, L., Wang, T., Li, T., Lü, F., \& He, P. (2013). Comparison of sludge digestion under aerobic and anaerobic conditions with a focus on the degradation of proteins at mesophilic temperature. Bioresource Technology, 140, 131-137. https://doi.org/10.1016/j.biortech.2013.04.081

Sikkema, R., Junginger, H. M., Pichler, W., Hayes, S., \& Faaij, A. P. C. (2010). The international logistics of wood pellets for heating and power production in Europe. Biofuels, Bioproducts and Biorefining, (4), 132-153. https://doi.org/10.1002/bbb

Steffen, R., Szolar, O., \& Braun, R. (1998). Feedstocks for anaerobic digestion. Institute for Agrobiotechnology Tulin, University of Agricultural Sciences, Vienna, 1-29.

Stuckey, D. C., \& McCarty, P. L. (1984). The effect of thermal pretreatment on the anaerobic 
biodegradability and toxicity of waste activated sludge. Water Research, 18(11), 13431353. https://doi.org/10.1016/0043-1354(84)90002-2

Tarique, A., Kafeel, A., \& Mehtab, A. (2017). Sludge quantification at water treatment plant and its management scenario. Environmental Monitoring and Assessment, 189(9). https://doi.org/10.1007/s10661-017-6166-1

Valo, A., Carrère, H., \& Delgenès, J. P. (2004). Thermal, chemical and thermo-chemical pretreatment of waste activated sludge for anaerobic digestion. Journal of Chemical Technology and Biotechnology, 79(11), 1197-1203. https://doi.org/10.1002/jctb.1106

Vlyssides, A. G., \& Karlis, P. K. (2004). Thermal-alkaline solubilization of waste activated sludge as a pre-treatment stage for anaerobic digestion, 91, 201-206. https://doi.org/10.1016/S0960-8524(03)00176-7

Wang, D., Shen, F., Yang, G., Zhang, Y., Deng, S., \& Zhang, J. (2018). Bioresource Technology Can hydrothermal pretreatment improve anaerobic digestion for biogas from lignocellulosic biomass? Bioresource Technology, 249(August 2017), 117-124. https://doi.org/10.1016/j.biortech.2017.09.197

Wang, J. Y., Liu, X. Y., Kao, J. C. M., \& Stabnikova, O. (2006). Digestion of pre-treated food waste in a hybrid anaerobic solid-liquid (HASL) system. Journal of Chemical Technology and Biotechnology, 81(3), 345-351. https://doi.org/10.1002/jctb.1401

Weiland, P. (2010). Biogas production: Current state and perspectives. Applied Microbiology and Biotechnology, 85(4), 849-860. https://doi.org/10.1007/s00253-009-2246-7

Wijffels, R. H., \& Barten, H. (n.d.). Bio_methane_and_Bio_hydrogen_2003.pdf.

Wilson, C. A., \& Novak, J. T. (2009). Hydrolysis of macromolecular components of primary and secondary wastewater sludge by thermal hydrolytic pretreatment. Water Research, 43(18), 4489-4498. https://doi.org/10.1016/j.watres.2009.07.022

Xu, J., Yuan, H., Lin, J., \& Yuan, wenxiang. (2014). Evaluation of thermal, thermal-alkaline, alkaline and electrochemical pretreatments on sludge to enhance anaerobic biogas production. Journal of the Taiwan Institute of Chemical Engineers, 45(5), 2531-2536. https://doi.org/10.1016/j.jtice.2014.05.029 
Xue, Y., Liu, H., Chen, S., Dichtl, N., Dai, X., \& Li, N. (2015). Effects of thermal hydrolysis on organic matter solubilization and anaerobic digestion of high solid sludge. Chemical Engineering Journal, 264, 174-180. https://doi.org/10.1016/j.cej.2014.11.005

Zábranská, J., Štěpová, J., Wachtl, R., Jenlček, P., \& Dohányos, M. (2000). The activity of anaerobic biomass in thermophilic and mesophilic digesters at different loading rates. Water Science and Technology, 42(9), 49-56.

Zhang, C., Su, H., Baeyens, J., \& Tan, T. (2014). Reviewing the anaerobic digestion of food waste for biogas production. Renewable and Sustainable Energy Reviews, 38, 383-392. https://doi.org/10.1016/j.rser.2014.05.038

Zhang, J., \& Slater, G. W. (n.d.). u Ottawa High Temperature Microwave Pretreatment for Enchancement of Anaerobic Sludge Digestion.

Zhang, Y., \& Banks, C. J. (2013). Impact of different particle size distributions on anaerobic digestion of the organic fraction of municipal solid waste. Waste Management, 33(2), 297307. https://doi.org/10.1016/j.wasman.2012.09.024 